\title{
Untersuchungen zu synaptischen Proteinen in einem Tiermodell für die Alzheimer-Krankheit
}

\author{
INAUGURAL-DiSSERTATION \\ zur Erlangung des Doktorgrades \\ der Medizinischen Fakultät der \\ Georg-August-Universität zu Göttingen
}

vorgelegt von

\section{Sarah Luise Wente}

aus

Stadthagen 
Dekan:

I. Berichterstatter:

II. Berichterstatter/in:

III. Berichterstatter/in:

Tag der mündlichen Prüfung: $\quad$ 11.07.2011
Prof. Dr. med. C. Frömmel

Prof. Dr. rer. nat. T. A. Bayer

Prof. Dr. med. T. Dresbach

Prof. Dr. rer. nat. P. Virsik-Köpp 


\section{INHALTSVERZEICHNIS}

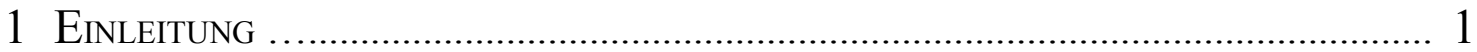

1.1 Epidemiologie der Demenzerkrankungen .................................. 1

$1.2 \quad$ Klinische Aspekte der Alzheimer-Demenz …................................... 2

1.2.1 Symptomatik und klinischer Verlauf ............................................ 2

1.2.2 Mild Cognitive Impairment (MCI) …........................................ 3

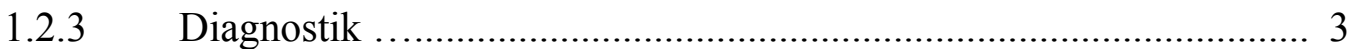

1.2.4 Therapeutische Ansätze ........................................................... 4

1.3 Neuropathologie der Alzheimer-Demenz ..................................... 6

1.3.1 Makroskopische Veränderungen ...................................................6 6

1.3.2 Mikroskopische Veränderungen ................................................ 6

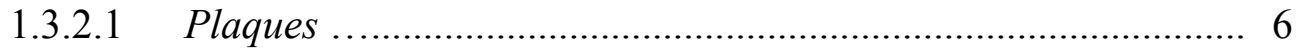

1.3.2.2 Neurofibrilläre Tangles ........................................................ 8

1.3.2.3 Neuronenverlust ........................................................... 8

1.3.2.4 Amyloidangiopathie ............................................................ 9

1.3.2.5 Axonale und synaptische Degeneration ................................... 9

1.4 Pathogenese der Alzheimer-Demenz …........................................... 10

1.4.1 APP-Prozessierung …............................................................ 10

1.4.2 Amyloidhypothese .................................................................. 11

1.5 Genetik der Alzheimer-Demenz ….............................................. 12

1.5.1 APP- und Präsenilin-Mutationen der familiären AD ..................... 12

1.5.2 Apolipoprotein E4 als Risikofaktor der sporadischen AD ............. 14

1.6 Mausmodelle der Alzheimer-Demenz .............................................. 14

1.6.1 FAD-Mutationen in Mausmodellen ............................................... 14

1.6.2 Das APP ${ }^{\mathrm{SL}}$ PS1KI-Mausmodell ................................................. 15

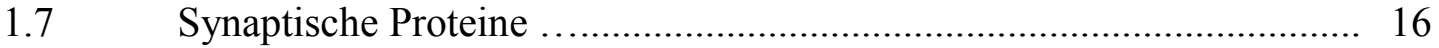

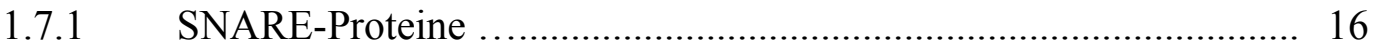

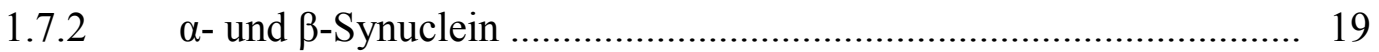

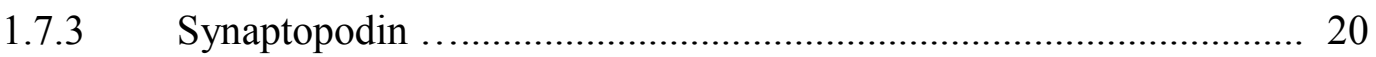

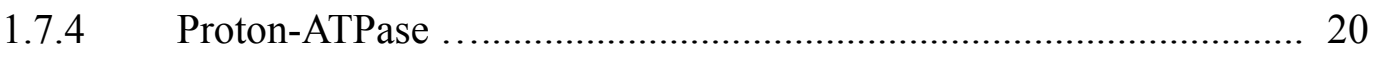

1.8 Zielsetzung und Fragestellung .................................................... 20 


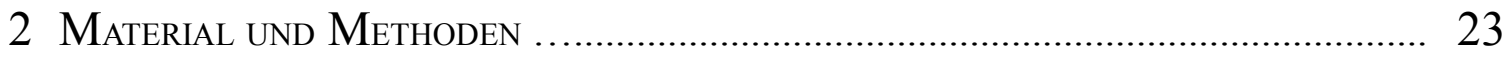

2.1 Generierung der APPSLPS1KI-Mauslinie ...................................... 23

2.2 Herstellung der mikroskopischen Präparate ....................................... 23

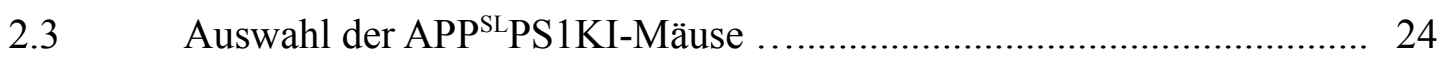

$2.4 \quad$ Humane Präparate .................................................................... 24

2.5 Immunhistochemische Färbungen .................................................... 25

2.5.1 Indirekte Immunhistochemie _................................................... 25

2.5.2 Immunhistochemische Färbung von Paraffinschnitten ................. 26

2.5.3 Testung der Primärantikörper ...................................................... 27

2.5.4 Sekundärantikörper ............................................................. 30

2.6 Mikroskopie und Fotografie ....................................................... 31

2.7 Quantifizierung dystropher Neuriten ............................................. 31

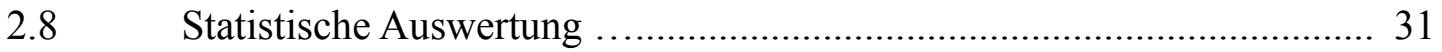

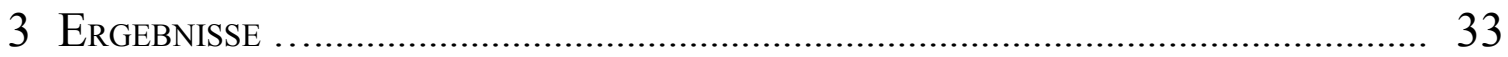

3.1 DAB-Immunfärbung synaptischer Proteine und APP ........................ 33

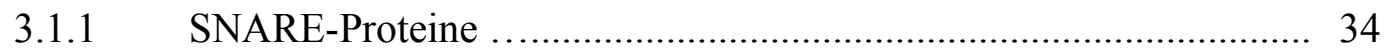

3.1.1.1 Syntaxin 7 und Syntaxin 13 .............................................. 34

3.1.1.2 Synaptobrevin ............................................................... 38

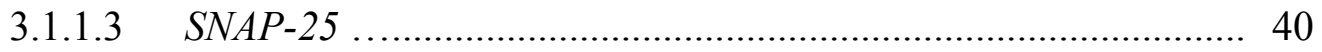

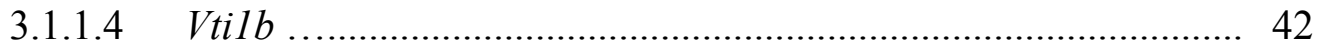

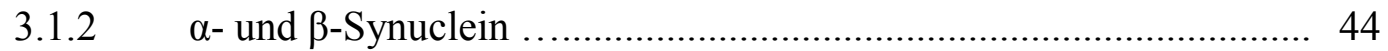

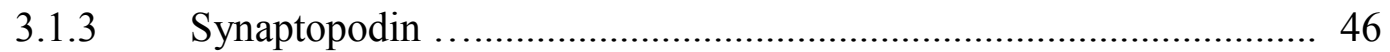

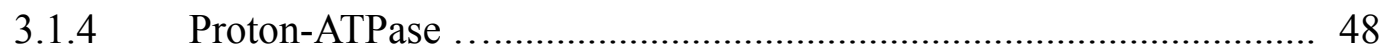

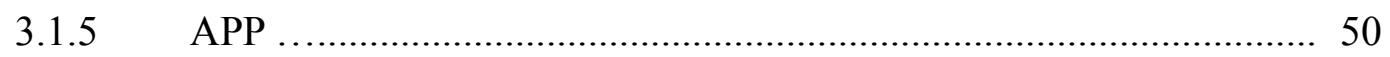

3.2 Immunfluoreszenzfärbung von A $\beta$, APP und Vtilb ......................... 52

3.3 Quantifizierung dystropher Neuriten ............................................ 57 


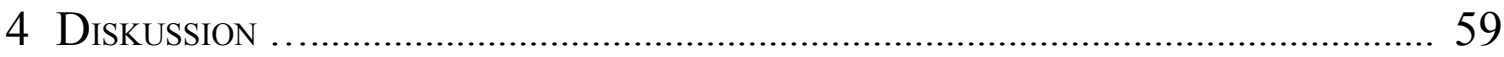

4.1 Akkumulation synaptischer Proteine in dystrophen Zellfortsätzen der APPSLPS1KI-Maus

4.2 Akkumulation synaptischer Proteine in dystrophen Zellfortsätzen humaner Alzheimer-Gehirne ........................................................ 61

4.3 Regionale Unterschiede im Ausprägungsgrad der neuritischen

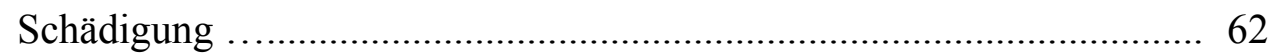

4.4 Phänotypische Auffälligkeiten der 6 Monate alten APPSLPS1KIMaus in Bezug zur neuritischen Schädigung . 64

4.5 Neuritische Dystrophie als Folgeerscheinung und möglicher Auslöser pathologischer Prozesse der AD 65

5 ZUSAMMENFASSUNG

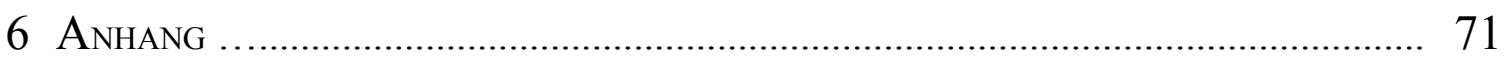

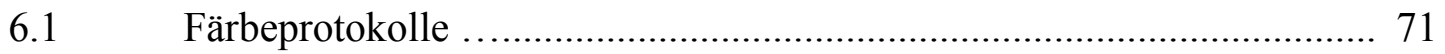

6.1.1 DAB-Immunfärbung Paraffin-fixierter Hirnschnitte ..................... 71

6.1.2 Fluoreszenz-Immunfärbung Paraffin-fixierter Hirnschnitte ............ 72

6.2 Einzelwerte der Quantifizierung dystropher Neuriten ....................... 74

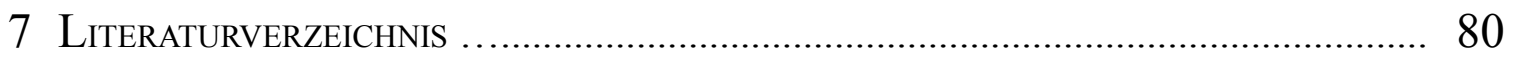




\section{Abbildungsverzeichnis}

Abbildung 1: $\quad$ Überlebenskurve von Patienten mit MCI ................................................. 3

Abbildung 2: Hirnatrophie bei AD ............................................................................ 6

Abbildung 3: A $\beta$-Färbung einer diffusen und einer neuritischen Plaque . .......................... 6

Abbildung 4: APP-positive dystrophe Neuriten ….................................................... 7

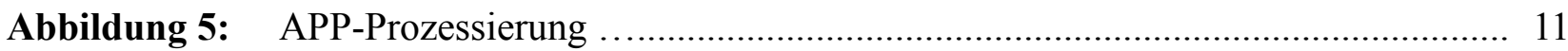

Abbildung 6: Klassische und modifizierte Amyloidhypothese ........................................ 12

Abbildung 7: Funktion und Verteilung synaptischer Proteine ......................................... 17

Abbildung 8: $\quad$ SNARE-vermittelter Membranfusionsprozess …..................................... 18

Abbildung 9: $\quad \alpha$-Synuclein-Immunfärbung einer neuritischen Plaque ............................... 19

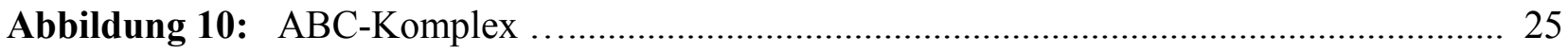

Abbildung 11: Quantifizierung dystropher Neuriten am Beispiel Vti1b ............................. 32

Abbildung 12: DAB-Färbung von Syntaxin 13 und Syntaxin 7 in der APP ${ }^{\text {SL } P S 1 K I-M a u s ~ . . . . . ~} 36$

Abbildung 13: DAB-Färbung von Syntaxin 13 und Syntaxin 7 im humanen AD-Gehirn ...... 37

Abbildung 14: DAB-Färbung von Synaptobrevin in der APP ${ }^{\mathrm{SL}} \mathrm{PS} 1 \mathrm{KI}-\mathrm{Maus}$........................ 39

Abbildung 15: DAB-Färbung von SNAP-25 in der APP ${ }^{S L}$ PS1KI-Maus .............................. 41

Abbildung 16: DAB-Färbung von SNAP-25 im humanen AD-Gehirn ................................ 41

Abbildung 17: DAB-Färbung von Vti1b in der APP ${ }^{S L}$ PS1KI-Maus ................................... 43

Abbildung 18: DAB-Färbung von Vtilb im humanen AD-Gehirn ..................................... 43

Abbildung 19: DAB-Färbung von Synuclein $\alpha$ und $\beta$ in der APP ${ }^{\mathrm{SL}} \mathrm{PS} 1 \mathrm{KI}-\mathrm{Maus} . . . \ldots \ldots \ldots \ldots \ldots . . . . . .45$

Abbildung 20: DAB-Färbung von Synuclein $\alpha$ und $\beta$ im humanen AD-Gehirn ................... 45

Abbildung 21: DAB-Färbung von Synaptopodin in der APP ${ }^{\mathrm{SL}} \mathrm{PS} 1 \mathrm{KI}-\mathrm{Maus}$........................... 47

Abbildung 22: DAB-Färbung von Synaptopodin im humanen AD-Gehirn .......................... 47

Abbildung 23: DAB-Färbung von Proton-ATPase in der APP ${ }^{\mathrm{SL}} \mathrm{PS} 1 \mathrm{KI}-\mathrm{Maus}$......................... 49

Abbildung 24: DAB-Färbung von Proton-ATPase im humanen AD-Gehirn ......................... 49

Abbildung 25: DAB-Färbung von APP in der APP ${ }^{S L}$ PS1KI-Maus ..................................... 51

Abbildung 26: DAB-Färbung von APP im humanen AD-Gehirn ........................................ 51

Abbildung 27: Immunfluoreszenzdoppelfärbung von A $\beta$ und APP …............................... 54

Abbildung 28: Immunfluoreszenzdoppelfärbung von APP und Vti1b ….......................... 55

Abbildung 29: Immunfluoreszenzdoppelfärbung von $A \beta$ und Vtilb .................................. 56

Abbildung 30: Quantifizierung dystropher Neuriten .................................................... 58

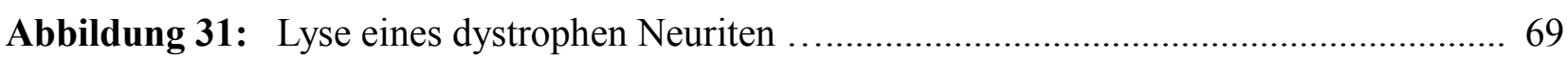




\section{TABELLENVERZEICHNIS}

Tabelle 1: Prävalenz von Demenzen in Abhängigkeit vom Alter ................................... 1

Tabelle 2: Liquormarker bei Alzheimer-Demenz .......................................................... 4

Tabelle 3: Stadieneinteilung nach Braak ............................................................... 8

Tabelle 4: Informationen zu den untersuchten Fällen humaner AD ................................. 24

Tabelle 5: Getestete Primärantikörper (1) ................................................................. 28

Tabelle 6: Getestete Primärantikörper (2) ................................................................... 29

Tabelle 7: Primärantikörper der Immunfluoreszenzfärbungen ....................................... 30

Tabelle 8: Sekundärantikörper der DAB- und Immunfluoreszenzfärbungen ...................... 30

\section{Abkürzungsverzeichnis}

$\begin{array}{ll}\text { A } \beta & \beta \text {-Amyloid } \\ \text { A } \beta_{40 / 42} & \beta \text {-Amyloid-Isoform, die an Aminosäureposition } 40 \text { bzw. } 42 \text { endet } \\ \text { ABC-Komplex } & \text { Avidin-Biotin-Enzym-Komplex } \\ \text { AD } & \text { Alzheimer's Disease / Alzheimer-Demenz } \\ \text { ApoE } & \text { Apolipoprotein E } \\ \text { APP } & \text { amyloid precursor protein / Amyloidvorläuferprotein } \\ \text { CA } & \text { Cornu ammonis (Ammonshorn) } \\ \text { DAB } & 3,3 \text {-Diaminobenzidin } \\ \text { DAPI } & 4 \text { ',6-Diamidin-2-phenylindol } \\ \text { FAD } & \text { Familial Alzheimer's Disease / Familiäre Form der Alzheimer-Demenz } \\ \text { FCS } & \text { fetal calf serum / fetales Kälberserum } \\ \text { KI } & \text { knock in } \\ \text { MCI } & \text { Mild Cognitive Impairment } \\ \text { MMST } & \text { Mini-Mental-Status-Test } \\ \text { NMDA } & \text { N-Methyl-D-Aspartat } \\ \text { PBS } & \text { phosphate buffered saline / Phosphat-gepufferte Kochsalzlösung } \\ \text { PHF } & \text { paired helical filaments / gepaarte helikale Filamente } \\ \text { PS1/2 } & \text { Präsenilin 1/2 } \\ \text { sAPP } & \text { sezerniertes APP } \\ \text { SNAP } & \text { soluble NSF attachment protein } \\ \text { SNARE } & \end{array}$




\section{Einleitung}

\subsection{Epidemiologie der Demenzerkrankungen}

In Deutschland sind gegenwärtig etwa 1,2 Millionen Menschen von einer Demenzerkrankung betroffen. Mit einem Anteil von 60 bis 80\% stellt die Alzheimer-Demenz die häufigste Ursache der Demenzerkrankungen dar. Die vaskuläre Demenz macht mit etwa $17 \%$ die zweithäufigste Demenzform aus, während übrige Demenzformen sich auf einen Anteil von ca. 13\% belaufen (Bickel 2010, Alzheimer's Association Report 2009).

Alzheimer's Association gibt an, dass die Alzheimer-Erkrankung in den USA im Jahr 2007 die fünfthäufigste Todesursache bei Menschen über 65 Jahren darstellte und damit in der Häufigkeit nur von kardialen Erkrankungen, Brustkrebs, Prostatakrebs und Schlaganfällen übertroffen wurde.

Als Folge der kontinuierlichen Bevölkerungsalterung wird die Prävalenz der Demenzerkrankungen weiter zunehmen: Die mittlere Prävalenzrate steigt steil mit dem Alter an, sodass sich ab einem Alter von 65 Jahren alle fünf Jahre eine Verdopplung der Krankheitszahlen voraussagen lässt. Während die Prävalenzrate in der Altersgruppe der 65 - bis 69 -Jährigen noch 1,2\% beträgt, erreicht sie bei den über 90-Jährigen einen Anteil

\begin{tabular}{|c|c|c|}
\hline Altersgruppe & $\begin{array}{c}\text { Mittlere } \\
\text { Prävalenzrate (\%) }\end{array}$ & $\begin{array}{c}\text { Geschätzte } \\
\text { KRANKENZahl NaCh } \\
\text { ALtersstruKTUR } \\
\text { (Ende 2008) }\end{array}$ \\
\hline $65-69$ & 1,2 & 62.000 \\
\hline $70-74$ & 2,8 & 127.000 \\
\hline $75-79$ & 6,0 & 180.000 \\
\hline $80-84$ & 13,3 & 300.000 \\
\hline $85-89$ & 23,9 & 310.000 \\
\hline 90 und älter & 34,6 & 175.000 \\
\hline 65 und älter & 6,9 & 1.154 .000 \\
\hline
\end{tabular}

Tabelle 1: Prävalenz von Demenzen in Abhängigkeit vom Alter (Bickel 2010, S. 1). von mehr als 30\%. Für die Bundesrepublik Deutschland bedeutet diese Prognose eine Zunahme der geschätzten Krankenzahl von 1,2 Millionen im Jahr 2010 auf ca. 2,6 Millionen im Jahr 2050 (Bickel 2010).

Alzheimer's Disease International schätzt die gegenwärtige Zahl von Alzheimer-Patienten weltweit auf mindestens 24 Millionen. Männer und Frauen gleichen Alters erkranken mit ähnlich hoher Wahrscheinlichkeit an einer Demenz. Insgesamt entfallen jedoch ca. 70\% der Demenzerkrankungen auf Frauen. Wichtigster Grund dafür ist die insgesamt höhere Lebenserwartung von Frauen, die damit in den höchsten Altersgruppen, in denen das Erkrankungsrisiko ansteigt, zahlreicher vertreten sind (Bickel 2001, Bickel 2010). 


\subsection{Klinische Aspekte der Alzheimer-Demenz}

\subsubsection{Symptomatik und klinischer Verlauf}

Unterschieden werden zwei Verlaufsformen der Alzheimer-Erkrankung: Die sporadische Form (Senile Demenz vom Alzheimer-Typ) mit einem Beginn der Erkrankung nach dem 65. Lebensjahr und insgesamt langsamer Progredienz macht einen Anteil von über 90\% aller Alzheimer-Erkrankungen aus. Sie ist damit die am weitesten verbreitete Ursache einer Demenz überhaupt.

Die seltenere familiäre Form (Präsenile Demenz vom Alzheimer-Typ, Familiäre Alzheimer-Demenz (FAD)) ist durch einen Beginn vor dem 65. Lebensjahr und vergleichsweise rasche Verschlechterung gekennzeichnet. Ungefähr 5 bis 10\% aller Alzheimer-Erkrankungen weisen eine familiäre Häufung auf. Ihre Prävalenz liegt bei weniger als 0,1\% (Blennow et al. 2006).

Die senile Form der Alzheimer-Erkrankung zeigt meist einen langsam fortschreitenden Verlauf mit einem schleichenden Beginn der Symptomatik, die sich v.a. in einem Verlust kognitiver Funktionen offenbart. Im Vordergrund stehen Merkleistungs- und Orientierungsstörungen. Während das Langzeitgedächtnis zu Beginn der Erkrankung noch intakt sein kann, manifestiert sich die Störung des Kurzzeit- und Immediatgedächtnisses bereits zu einem frühen Zeitpunkt des Krankheitsgeschehens. Ebenso charakteristisch ist eine Beeinträchtigung des Denkvermögens, die sich in einer eingeschränkten Urteilsfähigkeit und der Unfähigkeit, abstrakte Gedanken zu fassen, äußert. Im Bereich der Sprache zeigen sich ausgeprägte Wortfindungsstörungen, Perseveration, Echolalie und der Gebrauch von Neologismen; in späten Krankheitsstadien kann das Kommunikationsvermögen auf den Einsatz weniger verbaler und gestischer Stereotypien reduziert sein (Bandelow et al. 2008, Masuhr und Neumann 2007).

Neben dem Abbau kognitiver Leistungen, der das Frühstadium der Krankheit beherrscht, treten im weiteren Krankheitsverlauf nicht-kognitive Störungen hinzu. Mit zunehmendem Krankheitsbewusstsein steigt das Risiko für eine begleitende Depression stark an. Antriebsstörungen können in ihrer Ausprägung von psychomotorischer Unruhe mit Agitiertheit und aggressivem Verhalten bis hin zu Motivationsverlust und apathischen Zuständen reichen. Störungen des Affekts mit einem Verlust emotionaler Kontrolle sind ebenso typisch für ein fortgeschrittenes Stadium der Erkrankung wie ein beeinträchtigtes Sozialverhalten; wahnhafte Ideen und Halluzinationen können hinzukommen. Die neurologische Symptomatik der Alzheimer-Erkrankung ist gekennzeichnet durch den für eine Demenz typischen Verlust erworbener Fähigkeiten und kann zahlreiche neuropsychologische Symptome wie Aphasie, Apraxie und Agnosie umfassen. Zudem können Reflexdifferenzen und ein diskreter Parkinsonismus auftreten. 
Ein an Alzheimer-Demenz erkrankter Patient verstirbt im Schnitt nach fünf bis acht Jahren. Häufigste Todesursache sind Infekte (z.B. Pneumonien), die als Komplikationen der Bettlägerigkeit auftreten (Masuhr und Neumann 2007).

\subsubsection{Mild Cognitive Impairment (MCI)}

Da die Diagnosestellung einer demenziellen Erkrankung in frühen Stadien häufig schwierig ist, hat sich der Begriff Mild Cognitive Impairment $(M C I)$ etabliert, der ein Übergangsstadium zwischen kognitiven Veränderungen des normalen Alterungsprozesses und AD darstellt. Die amnestische Form des MCI liegt vor, wenn Gedächtnisstörungen vom Patienten sowie fremdanamnestisch berichtet

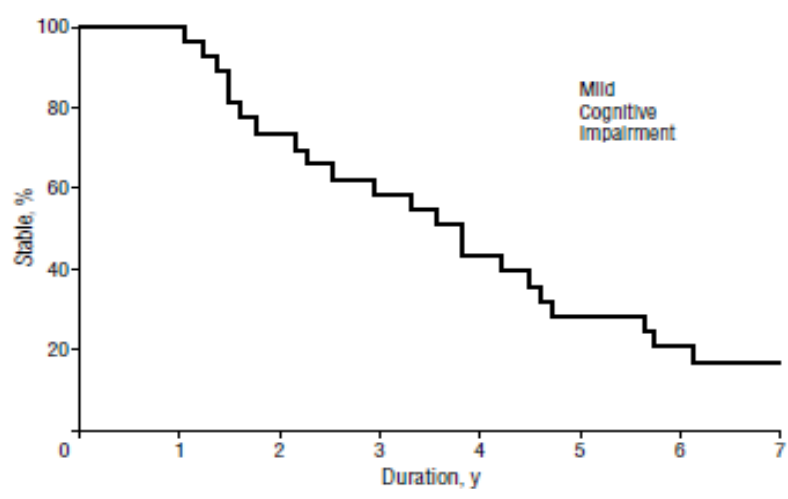

Abbildung 1: Überlebenskurve von Patienten mit MCI. 80\% der Patienten entwickelten innerhalb von 6 Jahren eine Demenz (Petersen et al. 2001, S. 1986). werden und der Gedächtnisverlust dabei objektiv größer ist als aufgrund des Alters und Bildungsgrades zu erwarten wäre. Gleichzeitig sind andere kognitive Funktionen und die Bewältigung von Alltagsaktivitäten unbeeinträchtigt.

In einer Longitudinalstudie entwickelten 80\% der Patienten mit MCI im Verlauf von sechs Jahren eine Alzheimer-Demenz (s. Abbildung 1), jedoch sind auch vollständige Remissionen möglich. Das Stadium des MCI vor Progression zu klinisch manifester AD gilt als vielversprechend für eine frühe therapeutische Intervention (Petersen et al. 2001, Petersen et al. 1999).

\subsubsection{Diagnostik}

Bis zum heutigen Zeitpunkt ist die Diagnosestellung der Alzheimer-Demenz mit definitiver Sicherheit nur autoptisch möglich. Es handelt sich um eine klinische Diagnose, die durch Erhebung und Evaluation neuropsychologischer und apparativer Befunde gestützt wird. Die Erhebung der Fremdanamnese ist wie für andere psychiatrische Erkrankungen auch von hoher diagnostischer Relevanz, da Krankheitseinsicht und Kooperativität der Patienten häufig stark eingeschränkt sind.

Die neurologische und psychiatrische Untersuchung des Patienten, laboranalytische Messungen und bildgebende Verfahren dienen der Überprüfung der klinischen Verdachtsdiagnose bzw. dem Ausschluss anderer zu Grunde liegender Erkrankungen. 
Zur Erfassung neuropsychologischer Defizite in der klinischen Untersuchung stehen verschiedene Screeningverfahren zur Verfügung. Der Mini-Mental-Status-Test (MMST) nach Folstein ist das am häufigsten für kognitive Störungen verwandte Screeningverfahren. So kann die Durchführung eines MMST innerhalb von 30 Minuten wichtige Hinweise auf demenzielle Symptome liefern. Der Untersucher überprüft mit einfachen Fragen z.B. räumliche und zeitliche Orientierung, Gedächtnisfunktion, Aufmerksamkeit, Rechnen, Sprachverständnis und -produktion (Folstein et al. 1975).

Die laborchemische Untersuchung von Blut und Liquor dient der Erkennung potenziell reversibler Ursachen der Demenz (z.B. Vitamin-B ${ }_{12}$-Mangel, Schilddrüsenfunktionsstörung) sowie der Bestimmung charakteristischer Biomarker für die Alzheimer-Erkrankung (Blennow et al. 2006).

Die Liquoranalytik hat sich zu einem wichtigen Bestandteil in der Diagnose der Alzheimer-Demenz entwickelt. Als zuverlässige Biomarker gelten das Tau-Protein, das phosphorylierte Tau-Protein und $\mathrm{A} \beta_{1-42}$ (Blennow und Hampel 2003,

\begin{tabular}{|c|c|c|c|}
\hline LIQUORMARKER & VERÄNDERUNG & SPEZIFITÄT & SEnSitivität \\
\hline Tau & $\uparrow$ (ca. 300-fach) & $90 \%$ & $55-81 \%$ \\
\hline Phospho-Tau & $\uparrow$ & $92 \%$ & $80 \%$ \\
\hline$A \beta_{1-42}$ & $\downarrow$ (auf 50\% der Werte bei Gesunden) & $90 \%$ & $86 \%$ \\
\hline
\end{tabular}
Blennow et al. 2006).

Tabelle 2: Veränderungen der Liquormarker Tau, Phospho-Tau und $A \beta_{1-42}$ bei Alzheimer-Demenz (nach Blennow und Hampel 2003).

Bildgebende Verfahren in der Routinediagnostik der Alzheimer-Demenz dienen in erster Linie dem Ausschluss anderer ätiologisch relevanter Ursachen. So können mittels Computertomographie (CT) oder Magnetresonanztomographie (MRT) potenziell reversible Ursachen des demenziellen Syndroms wie Hirntumor, subdurales Hämatom oder Normaldruckhydrozephalus erkannt werden. Die Standarduntersuchungen erlauben zudem eine Identifikation vaskulärer oder degenerativer Veränderungen des Gehirns (Jessen 2008).

\subsubsection{Therapeutische Ansätze}

Bei der Therapie der Alzheimer-Demenz kann im Wesentlichen zwischen Antidementiva mit symptomatischem Effekt, neuen Wirkstoffkandidaten mit krankheitsmodifizierendem Potenzial und Wirkstoffkandidaten, denen auf Basis epidemiologischer Studien eine protektive Wirkung zugeschrieben wurde, unterschieden werden.

Gestörte Neurotransmittersysteme im Gehirn von Alzheimer-Patienten stellen einen wichtigen Angriffspunkt für Medikamente mit symptomatischen Effekten dar. $\mathrm{Zu}$ diesen Antidementiva gehören die Acetylcholinesterase-Inhibitoren Donepezil, Rivastigmin und Galantamin. Störungen in den präsynaptischen cholinergen Nervenendigungen im Hippokampus und Neokortex infolge der Degeneration der Neurone des basalen Vorderhirnnukleus werden als Ursache der Merkleistungsstörung und anderer kognitiver Symptome der AD angesehen (Terry AV und Buccafusco 2003). Die 
Acetylcholinesterase-Inhibitoren sind für die Behandlung der leichten bis mittelschweren AD zugelassen und versprechen eine bis zu zwei Jahre andauernde Verbesserung der Symptomatik, ohne auf den natürlichen Verlauf der Erkrankung einzuwirken (Bullock et al. 2005).

Die Konzentration des exzitatorischen Neurotransmitters Glutamat ist bei der AD erhöht und bewirkt eine kontinuierliche Aktivierung des NMDA-Rezeptors. Eine Signalweiterleitung wird durch die anhaltend hohen Spiegel des Neurotransmitters unterbunden. Störungen von Lern- und Gedächtnisprozessen werden als Folgen der Unteraktivierung des NMDA-Rezeptors angesehen. Memantin ist ein nicht-kompetitiver NMDA-Rezeptor-Antagonist und soll Neurone vor glutamatinduzierter Zelltoxizität schützen, ohne die für die Aufrechterhaltung kognitiver Funktionen notwendige physiologische NMDA-Aktivierung zu stören (Wilcock 2003).

Das bessere Verständnis der pathogenetischen Prozesse der AD (s. Kapitel 1.4) führte zur Entwicklung von Therapiestrategien mit krankheitsmodifizierendem Potenzial, die der Entstehung extrazellulärer Plaques oder intrazellulärer Neurofibrillen (s. Kapitel 1.3.2) entgegenwirken wollen. Als Substanzgruppe seien hier die Sekretasemodulatoren genannt, die im Tiermodell bereits über eine Blockade der $\beta$ - und $\gamma$-Sekretase oder eine Stimulation der $\alpha$-Sekretase die Konzentration von A $\beta$ senken konnten (Chang et al. 2004, Wolfe 2008b, Etcheberrigaray et al. 2004).

Epidemiologisch erhobene Daten liefern die theoretische Basis für Therapieversuche mit Wirkstoffen, die möglicherweise eine protektive Wirkung besitzen. Die Wirksamkeitsprüfung im Rahmen randomisierter klinischer Studien konnte jedoch für keine der Wirkstoffgruppen eindeutig positive Ergebnisse aufweisen. Zu dieser heterogenen Substanzgruppe gehören u.a. Östrogene und nichtsteroidale Antiphlogistika (Bayer und Wirths 2008b).

Immuntherapeutischen Ansätzen zur Behandlung der Alzheimer-Demenz wurde in den vergangenen Jahren viel Beachtung geschenkt. Nach ersten erfolgreichen Therapieversuchen im Mausmodell Ende der neunziger Jahre wurde eine klinische Pilotstudie mit einer aktiven Immunisierung gegen $\mathrm{A} \beta_{1-42}$ initiiert, die aufgrund schwerwiegender Nebenwirkungen (6\% der Probanden entwickelten eine Meningoenzephalitis) abgebrochen werden musste. An der Entwicklung sicherer aktiver Immunisierungsverfahren und der passiven Immunisierung durch Antikörper gegen A $\beta$ wird derzeit gearbeitet (Brody und Holtzman 2008). 


\subsection{Neuropathologie der Alzheimer-Demenz}

\subsubsection{Makroskopische Veränderungen}

Makroskopisch imponiert die AD durch eine Atrophie der Hirnrinde, die frontotemporal und parietal am auffälligsten ist. Die Verschmälerung des Kortex geht einher mit einer Erweiterung der Sulci und einer Vergrößerung der Seitenventrikel, die durch die Schrumpfung von Amygdala und Hippokampus im temporalen Horn ihre größte Ausprägung zeigt. Der Hippokampus kann auf die Hälfte seiner normalen Größe verkleinert sein.

Die Leptomeningen über der Konvexität des

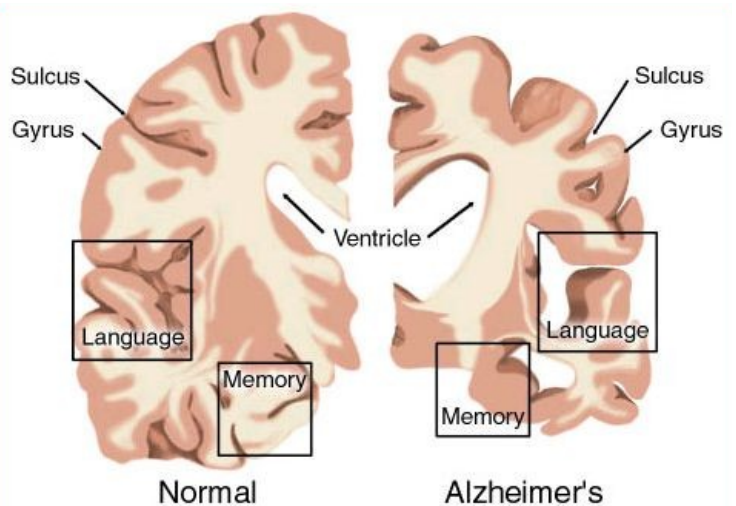

Abbildung 2: Hirnatrophie bei $A D$. Frontalschnitt eines normalen Gehirns (links) und eines $A D$-Gehirns (rechts) mit Größenzunahme der Ventrikel und Schrumpfung von Hippokampus und Kortex (http://www.ahaf.org/alzheimers/about/understanding/ brain-with-alzheimers.html).

Großhirns erscheinen häufig v.a. im Bereich der Mittellinie verdickt. Die Hirnnerven sind bis auf eine beobachtete Atrophie des Bulbus olfactorius keinen pathologischen Veränderungen unterlegen (Terry RD et al. 1999).

\subsubsection{Mikroskopische Veränderungen}

Die wichtigsten neuropathologischen Kennzeichen der Alzheimer-Demenz sind extrazelluläre Plaques, intrazelluläre Neurofibrillen, Nervenzellverlust sowie axonale und synaptische Degeneration. Im Folgenden soll eine Übersicht über Zusammensetzung, Lokalisation und pathogenetische Bedeutung der einzelnen Komponenten gegeben werden.

\subsubsection{Plaques}

Es existieren zwei Formen von Plaques, die aufgrund ihrer Zusammensetzung in neuritische und diffuse Plaques unterteilt werden (Alafuzoff et al. 2008). Alois Alzheimer beschrieb neuritische Plaques bereits zu Beginn des 20. Jahrhunderts als eine der charakteristischen Läsionen der später nach ihm benannten Demenzkrankheit. Es handelt sich um mikroskopisch sichtbare extrazelluläre Ablagerungen von $\beta$ -

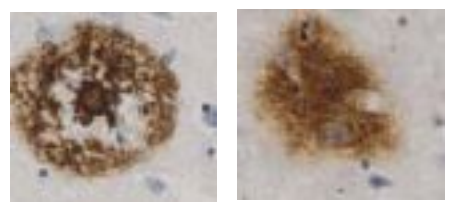

Abbildung 3: Aß-Färbung einer neuritischen (links) und einer diffusen Plaque (rechts) (Alafuzoff et al. 2008, S. 536). Amyloid-Peptiden (Glenner und Wong 1984), die von aufgetriebenen dystrophen Neuriten umgeben sind. Die abnorm veränderten Neuriten sind in der Mehrzahl präsynaptisch (Gonatas et al. 1967). 
Hauptbestandteil der Plaques ist $\mathrm{A} \beta_{1-42}$, das zwar in weitaus geringerer Menge produziert wird, jedoch eine sehr viel stärkere Aggregationstendenz aufweist als seine um zwei Aminosäuren kürzere Variante $A \beta_{1-40}$ (Jarrett et al. 1993). Das $A \beta$ in neuritischen Plaques ordnet sich überwiegend in Form von Fibrillen an und bildet einen kompakten Kern im Zentrum der Plaque.

Zwei Typen dystropher Neuriten werden im Allgemeinen unterschieden: Fusiforme Neuriten enthalten hauptsächlich gepaarte helikale Filamente (paired helical filaments, PHF; s.u.) und sind charakteristisch für AD. Der zweite Typ dystropher Neuriten zeigt dagegen eine aufgetriebene, bulböse Struktur und weist eine Akkumulation von Neurofilamenten, synaptischen Vesikeln und Zellorganellen ohne PHF auf. Diese Form abnormer Neuriten kommt sowohl in AD-Plaques als auch in Plaques nicht-dementer älterer Menschen vor. In den Auftreibungen neuritischer Fortsätze wurden unterschiedliche Zellbestandteile wie das Amyloidvorläuferprotein (APP) (Ishii et al. 1989, Cole et al. 1991, Cras et al. 1991, Joachim et al. 1991), Tau (Joachim et al. 1987), Ubiquitin (Perry et al. 1987), Synaptophysin (Masliah und Terry 1983, Masliah et al. 1991, Brion et al. 1991) und verschiedene Neurotransmitter (Armstrong und Terry 1985, Armstrong et al. 1986, Armstrong et al. 1989) gefunden. Ihr Nachweis in Plaques spricht mit hoher Wahrscheinlichkeit für deren Akkumulation infolge unterbrochener zellulärer Transportmechanismen.

Neuritische Plaques sind umgeben von aktivierten Mikrogliazellen, die sich v.a. in der Nähe des Amyloidkerns befinden, und reaktiven Astrozyten, die außerhalb der Plaque liegen und mit ihren Aussprossungen in das Plaqueinnere reichen. Die Größe dieser Plaques zeigt eine große Variationsbreite mit Durchmessern von 10 bis über $120 \mu \mathrm{m}$. Diffuse Plaques dagegen sind weniger dicht kompaktierte, amorphe $A \beta$-Aggregationen, die nicht von neuritischer Dystrophie begleitet werden. Sie enthalten kaum bzw. kein $\mathrm{A} \beta_{1-40}$.

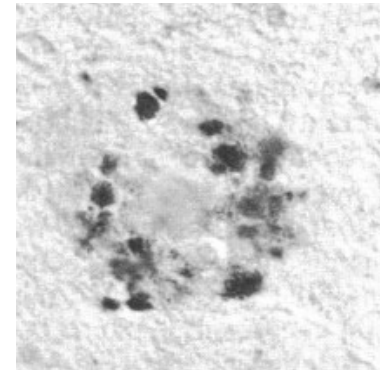

Abbildung 4: APP-positive dystrophe Neuriten in der Umgebung einer neuritischen Plaque (Cras et al. 1991, S. 7553).

Neuritische Plaques sind in großer Anzahl v.a. im limbischen und Assoziationskortex zu finden. Diffuse Plaques hingegen kommen parallel zu neuritischen Plaques und anderen pathologischen Merkmalen in den o.g. kortikalen Arealen vor. Sie liegen jedoch auch als einzige neuropathologische Veränderung in Hirngebieten vor, in denen andere Alzheimer-Korrelate fehlen und die auch symptomatisch keine Mitbeteiligung an der AD zeigen. Sie konnten außerdem im Gehirn gesunder älterer Menschen nachgewiesen werden und werden heute als mögliche Vorläuferläsionen neuritischer Plaques angesehen (Selkoe 2001). 


\subsubsection{Neurofibrilläre Tangles}

Neurofibrilläre Tangles sind intrazelluläre Bündel aus abnormal hyperphosphoryliertem TauProtein, das in seiner physiologischen Form als axonales Protein für die Anordnung und Stabilität von Mikrotubuli verantwortlich ist. Im gesunden Zustand besteht eine Balance zwischen der Aktivität verschiedener Kinasen und Phosphatasen, die die Phosphorylierung des Proteins regulieren. Die Hyperphosphorylierung von Tau führt zur Dissoziation des Proteins von seinen mikrotubulären Bindungsstellen und zur Auflösung der Mikrotubuli sowie zur Polymerisation des Proteins zu unlöslichen Fibrillen und größeren Aggregaten in neurofibrillären Tangles. Die Auflösung der Mikrotubuli hat eine Störung axonaler Transportprozesse zur Folge und ist mitverantwortlich für axonale und synaptische Dysfunktion und Transmitterdefizite.

Tangles sind nicht pathognomonisch für die AD und wurden auch für andere neurodegenerative Erkrankungen (z.B. subakut sklerosierende Panenzephalitis, supranukleäre Blickparese) beschrieben. Obwohl noch nicht abschließend geklärt werden konnte, ob die Formation von Tangles als Ursache oder Konsequenz der AD angesehen werden muss, mehren sich die Hinweise darauf, dass Tangles als Antwort auf A $\beta$-Akkumulation und Plaquebildung zu werten sind (Blennow et al. 2006, Selkoe 2001).

Das Auftreten neurofibrillärer Tangles scheint besser mit kognitiven Defiziten zu korrelieren als das Vorhandensein von A $\beta$-Plaques und wird zur Stadieneinteilung der AD genutzt (Braak H und Braak E 1991, Braak H et al. 2006).

\begin{tabular}{|l|l|}
\hline \multicolumn{2}{|l|}{ StadieneINTEILUNG NaCH BraAK } \\
\hline Stadium I/II: & Transentorhinale Stadien: Veränderungen betreffen entorhinalen und transentorhinalen Kortex \\
\hline Stadium III/IV: & $\begin{array}{l}\text { Limbische Stadien: Veränderungen beziehen weitere Teile des limbischen Systems wie den } \\
\text { Hippokampus (Ammonshorn) ein }\end{array}$ \\
\hline Stadium V/VI: & $\begin{array}{l}\text { Neokortikale Stadien: Neurofibrillenpathologie dehnt sich bei weiterer Zunahme pathologischer } \\
\text { Veränderungen in den zunächst betroffenen Arealen auf den Neokortex aus }\end{array}$ \\
\hline
\end{tabular}

Tabelle 3: Stadieneinteilung der AD nach Braak anhand neurofibrillärer Veränderungen (nach Braak H und Braak E 1991).

\subsubsection{Neuronenverlust}

Der Verlust von Neuronen bei der AD kann in fast allen Hirnregionen nachgewiesen werden. Besonders ausgeprägt ist der Nervenzelluntergang im Neokortex, im Hippokampus, im entorhinalen Kortex, im basalen Vorderhirnnukleus (Nucleus basalis Meynert), im Locus coeruleus und im dorsalen Raphekern. Über den genauen Ablauf des Zelltods bei der Alzheimer-Erkrankung besteht bis heute keine Klarheit. Als wahrscheinlichster Mechanismus gilt die Apoptose, die aus dem Einwirken unterschiedlicher zellschädigender Einflüsse resultiert (Terry RD et al. 1999). 


\subsubsection{Amyloidangiopathie}

Bei der Amyloidangiopathie handelt es sich um eine Infiltration kleiner bis mittelgroßer Gefäße der Leptomeningen und des kortikalen Parenchyms, die ihre größte Ausprägung in okzipitalen und zerebellären Regionen zeigt. Die weiße Substanz ist nicht von dieser Pathologie betroffen. Ein Drittel der gesunden älteren Menschen zeigt eine milde bis moderate Amyloidangiopathie, die vorwiegend leptomeningeal lokalisiert ist. Obwohl manche Plaques in räumlicher Nähe zu kleinen Blutgefäßen stehen oder sogar in ihrem Zentrum eine Kapillare aufweisen, konnte keine Beziehung zur Intensität der Amyloidangiopathie und Plaque- und Tanglelast hergestellt werden (Terry RD et al. 1999).

\subsubsection{Axonale und synaptische Degeneration}

Die Kennzeichen axonaler Pathologie der AD sind neben dystrophen Neuriten, die die Peripherie neuritischer Plaques säumen, axonale Auftreibungen oder Sphäroide, die ultrastrukturell eine Akkumulation von axonal transportierten Proteinen wie Zytoskelettbausteinen oder Zellorganellen und Lipiden aufweisen und Defekte axonaler Transportvorgänge anzeigen. Der Störung axonaler Transportprozesse wird eine entscheidende pathogenetische Bedeutung im Krankheitsprozess der AD beigemessen (Stokin et al. 2005, Wirths et al. 2007). Elektronenmikroskopisch weisen die dilatierten Axone eine verdünnte oder partiell fehlende Myelinscheide auf (Wirths et al. 2007).

Der Verlust von Synapsen wird als Hauptkorrelat der kognitiven Beeinträchtigung an AlzheimerDemenz erkrankter Patienten beurteilt (Terry RD et al. 1991). Immunhistochemische Untersuchungen mit dem präsynaptischen Marker Synaptophysin im Neokortex von AD-Gehirnen zeigten eine Abnahme der Dichte präsynaptischer Endigungen von durchschnittlich 45\% (Davies et al. 1987, Brion et al. 1991, Honer et al. 1992). Auch im Hippokampus nimmt die SynaptophysinImmunreaktivität ab (Samuel et al. 1994, Scheff und Price 1996). Der Einsatz des Synapsenmarkers EP10 zeigte, dass auch im gesunden Gehirn eine altersabhängige Abnahme der Synapsendichte stattfindet, die jedoch nicht neokortikale und hippokampale Hirnregionen betrifft wie bei der AD. Diese Tatsache spricht für einen selektiven, regionalen Synapsenverlust (Honer et al. 1992). Der synaptische Verlust ist am größten in reifen neuritischen Plaques (Terry RD et al. 1964); die synaptische Degeneration in diffusen Plaques ist hingegen nicht stärker ausgeprägt als im umgebenden Neuropil (Masliah et al. 1990).

Neuere Studien an transgenen Tiermodellen zeigen, dass eine vorübergehende Hochregulation der Zahl präsynaptischer Endigungen in der Prä-Plaque-Phase, die sich in einem Anstieg der Synaptophysin-Immunreaktivität widerspiegelt, dem synaptischen Verlust der Plaque-Phase vorausgeht. Darüber hinaus zeigt sich im zeitlichen Verlauf des Synapsenuntergangs, dass eine 
Neurotransmitter-spezifische Vulnerabilität der Synapsen vorzuliegen scheint. Am anfälligsten und daher am frühesten betroffen ist das cholinerge Transmittersystem, gefolgt vom glutamatergen und zuletzt GABAergen System (Bell und Cuello 2006).

\subsection{Pathogenese der Alzheimer-Demenz}

\subsubsection{APP-Prozessierung}

Mitte der achtziger Jahre gelang es Masters et al. erstmals, A $\beta$ als Hauptbestandteil der Plaques zu identifizieren (Masters et al. 1985). A $\beta$, das innerhalb des normalen Zellzyklus konstitutiv produziert wird (Haass et al. 1992), entsteht durch Prozessierung aus seinem Vorläuferprotein APP. APP gehört zur Gruppe der Typ-I-Membranproteine und weist einen großen N-terminalen extrazellulären und einen kurzen zytoplasmatischen Anteil auf. Die A $\beta$-Domäne liegt zum Teil innerhalb der Plasmamembran. Durch alternatives Spleißen entstehen verschiedene Isoformen von APP, die sich in der Anzahl ihrer Aminosäuren unterscheiden (677 bis 770 Aminosäuren), wobei die Isoform APP695 die häufigste Variante darstellt. Die Prozessierung von APP kann auf zwei Wegen erfolgen. Unterschieden werden die amyloidogene und die nicht-amyloidogene Prozessierung.

Im nicht-amyloidogenen Abbau von APP spaltet die $\alpha$-Sekretase das Protein innerhalb der A $\beta$ Domäne und verhindert so die Entstehung von A $\beta$-Peptiden. Produkte der proteolytischen Spaltung sind ein sezerniertes $\alpha$-Fragment der Ektodomäne ( $\operatorname{sAPP} \alpha$ ) und ein kurzer C-terminaler membrangebundener Anteil mit einer Länge von 83 Aminosäuren (C83). In einem zweiten Schritt katalysiert die $\gamma$-Sekretase die Aufspaltung des C83-Fragments in ein p3-Peptid und in die intrazelluläre APPDomäne (AICD), die im Zytoplasma metabolisiert wird. $\alpha$-Sekretasen sind als Mitglieder der ADAM (= a disintegrin and metalloprotease)-Proteinfamilie identifiziert worden (Buxbaum et al. 1998, Lammich et al. 1999).

Pathologisch relevant ist die amyloidogene Prozessierung von APP, bei der durch enzymatische Degradation des Vorläuferproteins das schädliche $\mathrm{A} \beta$ entsteht. Durch $\beta$-Sekretase-Aktivität, die hauptsächlich durch das Enzym BACE1 (= beta-site APP-cleaving enzyme 1) aus der Familie der Aspartylproteasen generiert wird (Vassar et al. 1999), wird ebenfalls ein großer Anteil der APPEktodomäne sezerniert (sAPP $\beta$ ). Im Unterschied zum Abbau durch die $\alpha$-Sekretase liegt die Spaltstelle der $\beta$-Sekretase vor der A $\beta$-Domäne. Das verbleibende 99 Aminosäuren lange Fragment (C99) wird von der $\gamma$-Sekretase gespalten, was zur Freisetzung des A $\beta$-Peptids von 40 oder 42 Aminosäuren Länge führt $\left(A \beta_{1-40}, A \beta_{1-42}\right) . \gamma$-Sekretase ist ein intramembranös gelegener Proteasekomplex, der sich aus den Komponenten Präsenilin, Nicastrin, PEN-2 (= presenilin enhancer 2) 
und APH-1 (= anterior pharynx defective 1) zusammensetzt (Wolfe 2008a). Unter normalen Bedingungen wird die Konzentration von $\mathrm{A} \beta$ im Gehirn durch proteolytische Enzymwirkung und verschiedene Transportmechanismen reguliert (Tanzi et al. 2004). Da es keinen Anhalt für Störungen innerhalb dieser Regelkreise gibt, wurden alternative pathogenetische Konzepte für die Entstehung der AD entwickelt (Blennow et al. 2006, Bayer und Wirths 2008b).

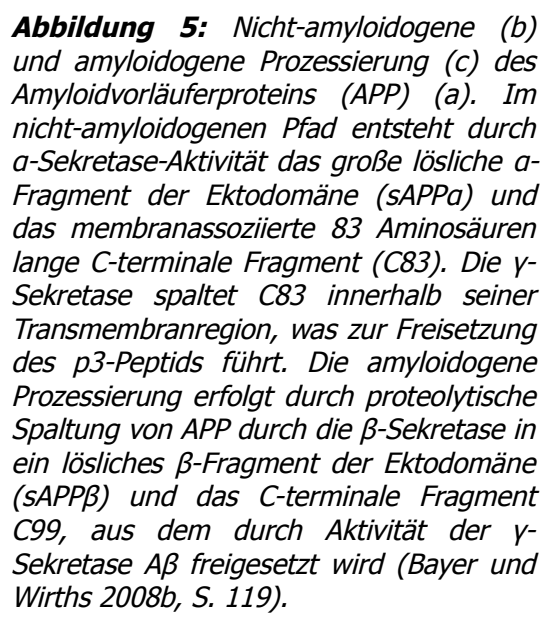

Abbildung 5: Nicht-amyloidogene (b) und amyloidogene Prozessierung (c) des nicht-amyloidogenten a-Sekretase-Aktivität das große lösliche $a$ Fragment der Ektodomäne (SAPPa) und das membranassoziierte 83 Aminosäuren lange C-terminale Fragment (C83). Die $y^{-}$ Sekretase spaltet C83 innerhalb seiner Transmembranregion, was zur Freisetzung des p3-Peptids führt. Die amyloidogene Prozessierung erfolgt durch proteolytische Spaltung von APP durch die $\beta$-Sekretase in ein lösliches $\beta$-Fragment der Ektodomäne (sAPP $\beta)$ und das C-terminale Fragment Sekretase $A \beta$ freigesetzt wird (Bayer und Wirths 2008b, S. 119).

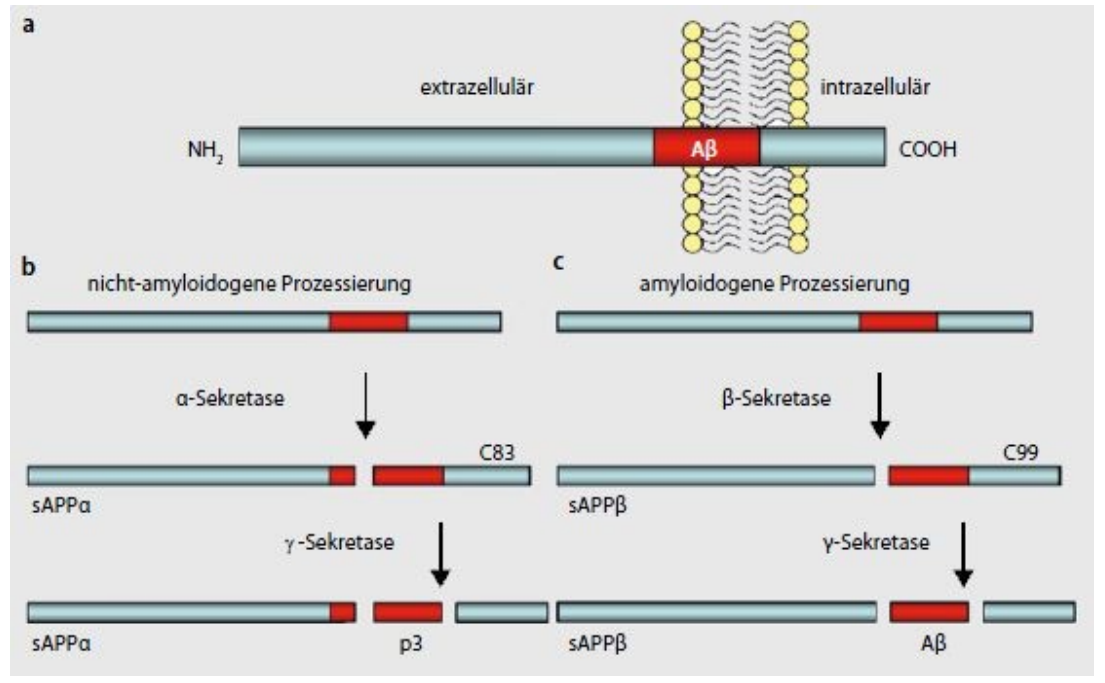

\subsubsection{Amyloidhypothese}

Bereits 1991 formulierten Hardy und Allsop ihre Hypothese zur zentralen Bedeutung des A $\beta$ Peptids in der Ätiologie der Alzheimer-Erkrankung. Ihr Amyloid-Kaskade-Modell geht davon aus, dass der erhöhten extrazellulären Konzentration von $\mathrm{A} \beta$ dessen Aggregation in extrazellulär gelegenen Plaques folge. Der Plaqueablagerung schließen sich weitere pathologische Veränderungen wie die Bildung von Neurofibrillen an. Der folgende Verlust von Neuronen und die Unterbrechung synaptischer Übertragung treten als Ergebnis des gestörten APP-Metabolismus auf (Hardy und Allsop 1991).

Neuere Erkenntnisse legen eine Modifikation der Amyloidhypothese nahe, die der intrazellulären A $\beta$-Akkumulation und nicht der extrazellulären Plaqueablagerung eine entscheidende Rolle in der Pathogenese beimisst. So zeigten Fernandez-Vizarra et al., dass intrazelluläre A $\beta$-Ablagerungen eine der frühesten neurodegenerativen Veränderungen im Alzheimer-Gehirn sind (FernandezVizarra et al. 2004). Die Auswertung verschiedener Mausmodelle der AD ergab, dass der extrazellulären Plaquebildung eine massive intrazelluläre Akkumulation von A $\beta$-Peptiden vorausgeht. Für das in der vorliegenden Arbeit untersuchte APPSLPS1KI-Mausmodell konnte eine mit zunehmender Plaqueformation sinkende Konzentration intrazellulären A $\beta$-Proteins 
nachgewiesen werden. Der in diesem Modell auftretende altersabhängige Nervenzellverlust in der CA1-Region des Hippokampus (s. Kapitel 1.6.2) ist zudem nicht durch die Menge extrazellulärer Plaques zu erklären (Casas et al. 2004). Diese Beobachtung legt nahe, dass andere Faktoren wie die intrazelluläre $A \beta$-Anreicherung ursächlich am Nervenzellverlust in dieser Region beteiligt sein müssen. Besonders die toxischere und schlechter sezernierbare $A \beta_{42}$-Isoform wird für die pathologischen Veränderungen verantwortlich gemacht. Die intrazelluläre $A \beta$-Akkumulation führt so vermutlich durch eine Beeinträchtigung intrazellulärer Transportvorgänge zu synaptischer und neuronaler Dysfunktion. Diese Ergebnisse stützen eine modifizierte Amyloidhypothese, in der die intrazelluläre $A \beta$-Akkumulation als zentraler Auslöser in der pathologischen Kaskade der $\mathrm{AD}$ beschrieben wird (s. Abbildung 6) (Wirths et al. 2004, Bayer und Wirths 2008b).
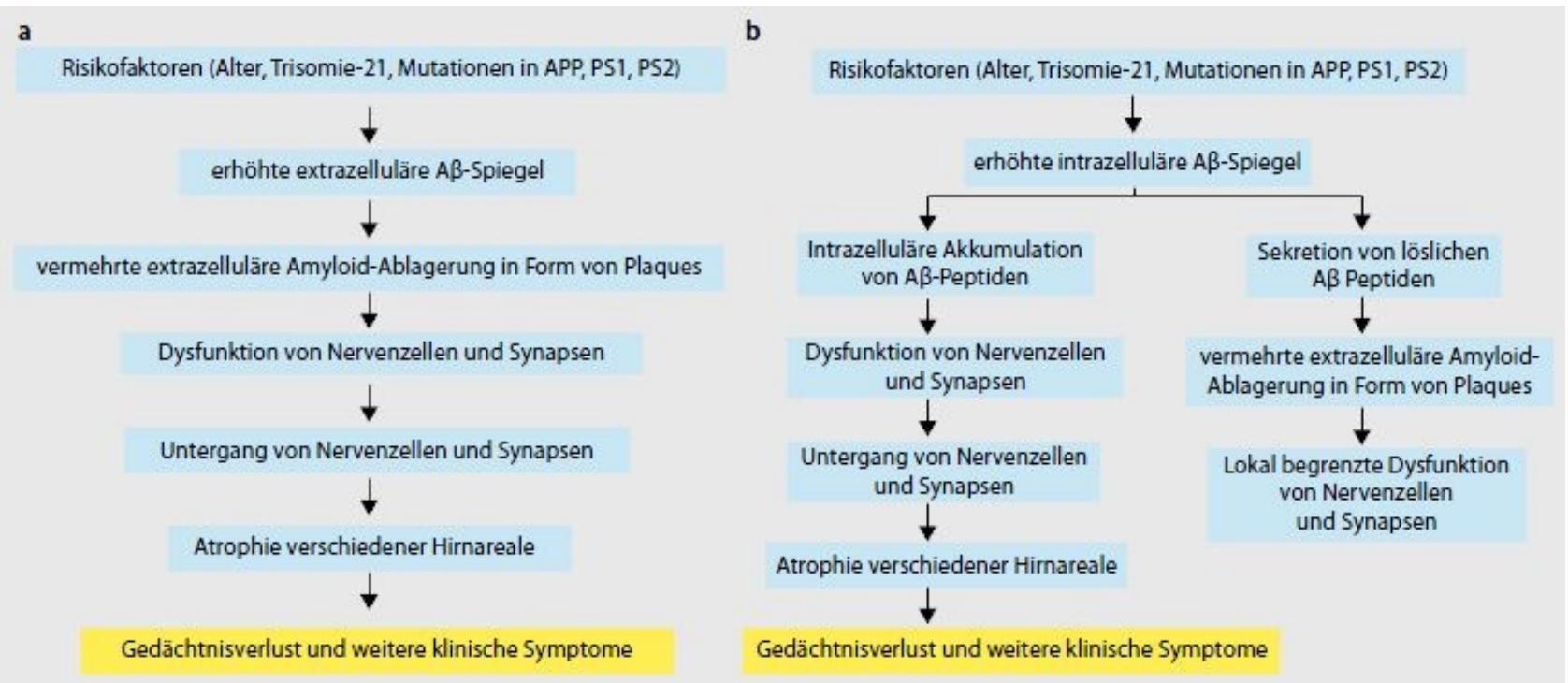

Abbildung 6: Schematische Darstellung der klassischen Amyloidhypothese nach Hardy und Allsop (a) und der auf neueren Erkenntnissen beruhenden modifizierten Amyloidhypothese (b), nach der v.a. intrazelluläre A $\beta$-Akkumulationen für neurodegenerative Prozesse der AD von zentraler Bedeutung sind (Bayer und Wirths 2008b, S. 120).

\subsection{Genetik der Alzheimer-Demenz}

\subsubsection{APP- und Präsenilin-Mutationen der familiären AD}

Die Alzheimer-Demenz ist eine ätiologisch heterogene Erkrankung, bei der familiäre und sporadische Formen existieren (s. Kapitel 1.2.1). Für die familiäre Form der AD mit einem Krankheitsbeginn vor dem 65. Lebensjahr konnte schon früh eine autosomal-dominant vererbliche Mutation im Gen für das Amyloidvorläuferprotein auf Chromosom 21 identifiziert werden (Goate et al. 1991). Mittlerweile sind neun APP-Missense-Mutationen bekannt, die allesamt in einer 
Erhöhung der A $\beta$-Produktion resultieren. Die Tatsache, dass diese Mutationen in der Nähe der Schnittstellen der Sekretasen liegen, deutet darauf hin, dass eine Beeinflussung der proteolytischen Spaltung von APP als Ursache erhöhter A $\beta$-Konzentrationen anzusehen ist (Selkoe 2001). Die Schwedische APP-Doppelmutation an Codon 670 und 671, die nahe der $\beta$-Sekretase-Schnittstelle $\mathrm{zu}$ einem Austausch von Lysin und Methionin zu Asparagin und Leucin (Lsy670Asn/Met671Leu) führt (Mullan et al. 1992), scheint sowohl die Konzentrationen von $A \beta_{40}$ als auch von $A \beta_{42 / 43} \mathrm{zu}$ erhöhen (Citron et al. 1994), während die APP-Prozessierung über den nicht-amyloidogenen $\alpha$ Sekretase-Pfad abnimmt. Die der $\gamma$-Sekretase-Schnittstelle benachbarte London-Mutation an Codon 717, bei der Valin durch Isoleucin, Phenylalanin oder Glycin ersetzt wird (Goate et al. 1991, Chartier-Harlin et al. 1991, Murrell et al. 1991), führt hingegen über einen selektiven Anstieg der $\mathrm{A} \beta_{42 / 43}$-Peptide zu einer Erhöhung der Gesamt-A $\beta$-Konzentration (Citron et al. 1992, Cai et al. 1993, Susuki et al. 1994, Haass et al. 1994). Patienten mit einer Mutation im APP-Gen erkranken vor dem 65. Lebensjahr, häufig bereits um das 50. Lebensjahr.

Eine Erhöhung der APP-Gendosis liegt bei Patienten mit Down-Syndrom (freie Trisomie 21 oder Translokationstrisomie 21) vor, die eine dreifache Kopie der APP-kodierenden Region auf Chromosom 21 aufweisen. Durch Überexpression von strukturell normalem APP und der konsekutiven Überproduktion von $A \beta$-Peptiden (v.a. $A \beta_{40}$ ) von Geburt an kommt es bereits im mittleren Erwachsenenalter zur Ausbildung der Alzheimer-Pathologie (Tokuda et al. 1997).

Der Erkenntnis, dass APP-Missense-Mutationen nur für einen Bruchteil der autosomal-dominant erblichen AD-Fälle verantwortlich sind, folgte die Untersuchung weiterer genetischer Loci außerhalb von Chromosom 21 auf eine mögliche Assoziation zu AD. So wurden auf Chromosom 14 Mutationen im Gen für Präsenilin 1 (PS1) beschrieben (Schellenberg et al. 1992, St George-Hyslop et al. 1992, Van Broeckhoven et al. 1992, Sherrington et al. 1995), später fand man ein dem PS1 homologes Gen - Präsenilin 2 (PS2) - auf Chromosom 1 (Rogaev et al. 1995, Levy-Lahad et al. 1995). Die Präsenilin-Mutationen bewirken über Beeinflussung der $\gamma$-Sekretase-Aktivität eine gesteigerte Produktion der besonders aggregationsfreudigen $A \beta_{42}$-Isoform. Wichtige Erkenntnisse lieferte die Kreuzung von Mäusen mit APP- und PS1-Missense-Mutationen, deren Nachkommenschaft eine stark beschleunigte Entwicklung AD-typischer Veränderungen zeigte (Holcomb et al. 1998). Insgesamt sind mehrere Hundert Familien weltweit von den Präsenilin-Mutationen betroffen. Dabei zeichnen sich die PS1-Missense-Mutationen durch einen besonders aggressiven Verlauf mit einem sehr frühen Krankheitsbeginn - häufig bereits in der vierten Lebensdekade - aus. 


\subsubsection{Apolipoprotein E4 als Risikofaktor der sporadischen AD}

Als einziger gesicherter genetischer Risikofaktor für die sporadische Form der Alzheimer-Demenz gilt das $\varepsilon 4-A 1 l e l$ des Apolipoproteins E (ApoE). Es existieren drei Varianten des menschlichen ApoEc-Allels, die sich lediglich durch den Austausch einer bzw. zweier Aminosäuren unterscheiden: 75\% der europäischen Bevölkerung sind Träger des ApoEع3-Allels, während die Varianten ApoEc4 und ApoEc2 Anteile von 15 bzw. 10\% ausmachen (St George-Hyslop 1999). Der Vergleich mit gesunden Kontrollpopulationen ergab, dass die Frequenz des ApoEc4-Allels bei Alzheimer-Patienten auf ca. 40\% erhöht ist (Saunders et al. 1993). Weiterhin liegt eine dosisabhängige Beziehung zwischen der Anzahl der vorhandenen Allelkopien und dem Erkrankungsbeginn bzw. -risiko vor (Corder et al. 1993). Heterozygoten ApoEع4-Allelträgern wird ein zwei- bis fünffach erhöhtes Erkrankungsrisiko zugeschrieben, für homozygote Allelträger liegt das Risiko noch höher. Im Gegensatz zu den autosomal-dominant vererbten APP- und PS-MissenseMutationen stellt Apoe4 jedoch lediglich einen prädisponierenden Faktor für die AD mit spätem Beginn dar und führt nicht zwangsläufig zur Manifestation der Erkrankung. Der Mechanismus, über den ApoEc4 zur Ausbildung der AD-Pathologie beiträgt, ist noch unklar. Eine gestörte zerebrale A $\beta$-Elimination scheint die Ursache für eine Erhöhung der A $\beta$-Level zu sein (Selkoe 2001).

\subsection{Mausmodelle der Alzheimer-Demenz}

\subsubsection{FAD-Mutationen in Mausmodellen}

Die Weiterentwicklung gentechnologischer Verfahren und die Identifizierung Alzheimer-assoziierter Gene zu Beginn der neunziger Jahre führte zur Entwicklung zahlreicher transgener Mausmodelle der Alzheimer-Krankheit. Obwohl die FAD nur einen Anteil von etwa 2 bis 5\% aller AlzheimerFälle ausmacht, erlaubt die Kenntnis ihrer zugrunde liegenden Mutationen die Nachahmung der humanen Pathologie in einem Modellorganismus.

Tiere mit APP-Mutationen zeigten erstmals signifikante pathologische Akkumulationen extrazellulärer Amyloidplaques, dystrophe Neuriten, eine Entzündungsreaktion in Form von Astround Mikrogliose, Synapsenverlust (Games et al. 1995), Verhaltens- und kognitive Defizite (Hsiao et al. 1996) und eine Neurodegeneration im Hippokampus (Sturchler-Pierrat et al. 1997).

In Mauslinien mit Mutationen im Präsenilin-1-Gen ließen sich trotz erhöhter extrazellulärer A $\beta_{42 / 43^{-}}$ Spiegel keine Plaques nachweisen (Duff et al. 1996), während in doppelt-transgenen Modellen mit mutantem humanen APP und PS1 schließlich eine generelle Zunahme und Beschleunigung der 
Plaquepathologie auftrat, die als Folge des durch Vorliegen der PS1-Mutation erhöhten A $\beta_{42 / 43^{-}}$ Levels gewertet wird (Holcomb et al. 1998).

Die Erkenntnisse aus jüngeren Studien an doppelt-transgenen Mausmodellen mit Mutationen für APP und PS1 zeigen, dass es bereits vor der Bildung extrazellulärer A $\beta$-Plaques zu einer Akkumulation intrazellulärer $\mathrm{A} \beta$-Peptide kommt, die mit zunehmendem Alter und sich verstärkender Plaqueformation wieder abnimmt (Wirths et al. 2001). Dieser Befund ist mit Beobachtungen an humanen AD-Fällen vereinbar. Schmitz et al. beschreiben einen weiteren interessanten Aspekt eines APP/PS1-doppelt-transgenen Mausmodells: Die APP ${ }^{\text {SL }}$ PS1M146LMaus, die zwei humane APP-Mutationen (Schwedische Doppelmutation K670N/M671L und London-Mutation V717I) und die humane M146L-Mutation für PS1 trägt, zeigt einen altersabhängigen Nervenzellverlust in der Pyramidenzellschicht des Hippokampus, der größer ist, als durch die Menge extrazellulärer Plaques zu erklären wäre, und zudem für Regionen beschrieben wird, die frei von extrazellulärer Plaquepathologie sind (Schmitz et al. 2004).

\subsubsection{Das APP ${ }^{\mathrm{SL}}$ PS1KI-Mausmodell}

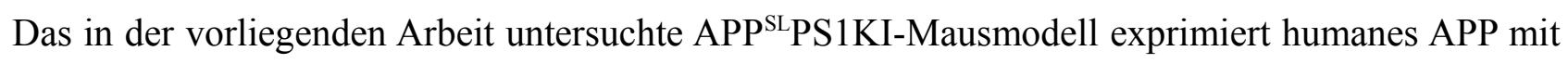
der Schwedischen und London-Mutation auf einem homozygoten mutanten murinen PS1-Knock-inHintergrund mit den Mutationen M233T und L235P im endogenen Präsenilin-Lokus. Die Generierung der Mauslinie wird in Kapitel 2.1 näher beschrieben.

Bereits im Alter von 2 Monaten sind erste extrazelluläre Akkumulationen N-modifizierter $A \beta_{x-42^{-}}$ Spezies detektierbar, die in ihrer Anzahl, Größe und Dichte in den folgenden Lebensmonaten weiter zunehmen. Insgesamt weist das Mausmodell eine große Vielfalt an N-terminal verkürzten $A \beta_{\mathrm{x}-42^{-}}$ Varianten auf und zeigt damit große Ähnlichkeit zur menschlichen AD-Pathologie. Mit 6 Monaten zeigen die Mäuse einen Neuronenverlust von 30\% in der CA1-Region des Hippokampus, der im Alter von 10 Monaten noch ausgeprägter ist (ca. 50\%). Interessanterweise fehlen Amyloidplaques in der CA1-Pyramidenzellschicht fast vollständig. Die Abwesenheit von Plaques in einem Gebiet mit massivem Neuronenverlust stützt daher die Hypothese, dass der Zelltod mit der früh auftretenden Ansammlung intraneuronalen A $\beta$-Peptids assoziiert werden muss. Dystrophe Neuriten, axonale Sphäroide, die axonalen Anschwellungen mit Akkumulationen von axonal transportierten Zellbestandteilen entsprechen, und myeline Ovoide aus phagozytierten Überresten degenerierter Nervenfasern sind histologische Funde, die für die pathogenetische Bedeutung gestörten axonalen Transports in der APPSLPS1KI-Maus sprechen (Casas et al. 2004, Wirths et al. 2007). Entzündliche Prozesse mit einer Aktivierung von Astrozyten und Mikroglia sollen zu axonaler Degeneration und 
Neuronenverlust beitragen (Wirths et al. 2010).

Wirths et al. beschreiben weiterhin das Vorhandensein kleiner Amyloidablagerungen in der weißen Substanz der Hintersäule der APP ${ }^{\text {SL }}$ PS1KI-Maus. Größere und zahlreichere Amyloidablagerungen finden sich üblicherweise in der grauen Substanz des Rückenmarks. Die phänotypischen Auffälligkeiten der APP ${ }^{\text {SL }}$ PS1KI-Maus korrelieren stark mit dem Fortschreiten axonaler Degeneration und mit hippokampalem Neuronenverlust. Der altersabhängige Untergang von Axonen resultiert in einer progressiven motorischen Dysfunktion, die sich beispielsweise in Gangstörungen, einem pathologischem Extensionsreflex, Wachstumsretardierung und der Entwicklung einer thorakolumbalen Kyphose manifestiert. Störungen des Arbeitsgedächtnisses beginnen im Alter von 6 Monaten und korrelieren mit dem in dieser Altersstufe einsetzenden Zellverlust in der CA1-Region des Hippokampus (Wirths et al. 2007).

\subsection{Synaptische Proteine}

Die synaptische Übertragung durch Neurotransmitterfreisetzung ist die Hauptkommunikationsform zwischen Zellen des zentralen Nervensystems. Gleichzeitig gilt die Degeneration von Axonen und Synapsen als wichtiger neuropathologischer Befund der Alzheimer-Erkrankung.

An der Regulation synaptischer Prozesse und dem strukturellen Aufbau des synaptischen Apparates sind eine Vielzahl bisher identifizierter Proteine beteiligt (s. Abbildung 7). Axonal transportierte Proteine, deren Bestimmungsort die Synapse ist, akkumulieren bei der AD in dystrophen Neuriten und Sphäroiden in der Peripherie von Plaques und sollen in der vorliegenden Arbeit mit Hilfe immunhistochemischer Methoden im Mausmodell untersucht werden. $\mathrm{Zu}$ diesen synaptischen Proteinen gehören SNARE-Proteine, die Proteine Synuclein $\alpha$ und $\beta$, Synaptopodin und das Enzym Proton-ATPase.

\subsubsection{SNARE-Proteine}

SNARE-Proteine sind wesentlich an intrazellulären Membranfusionsprozessen in eukaryotischen Zellen beteiligt. Membranfusionen spielen sowohl bei Transportprozessen zwischen intrazellulären Kompartimenten als auch an der Zelloberfläche eine wichtige Rolle. Bei der Exozytose von Neurotransmittern binden SNARE-Proteine der Vesikelmembran an SNARE-Proteine der präsynaptischen Zellmembran und vermitteln zusammen mit anderen regulatorisch beteiligten Proteinen eine gerichtete und spezifische Fusion der Membranen mit anschließender Transmitterfreisetzung in den synaptischen Spalt (Ungar und Hughson 2003). 
Als Bestandteile des intrazellulären Membranfusionsapparates wurden zuerst die Proteine NSF (= $\boldsymbol{N}$-ethylmaleimide-sensitive-factor) und seine Adapterprotein SNAP (= soluble NSF attachment protein) identifiziert, die an vielen intrazellulären Transportprozessen beteiligt sind (Block et al. 1988, Clary et al. 1990). SNARE (= soluble $\mathbf{N}$-ethylmaleimide-sensitive-factor attachment protein receptor)-Proteine wurden schließlich als Rezeptoren für SNAP isoliert (Söllner et al. 1993). SNARE-Proteine umfassen 60 bis 70 Aminosäuren lange SNARE-Motive, die sich zu größeren SNARE-Komplexen zusammenlagern: Vier $\alpha$-Helices in Coiled-Coil-Struktur ordnen sich dabei parallel zu Komplexen an, die in ihrem Inneren durch die Zusammenlagerung von 16 Schichten hydrophober Aminosäuren stabilisiert werden (Sutton et al. 1998, Antonin et al. 2002).

Funktionell unterschieden werden an der Vesikelmembran lokalisierte v-SNAREs (v = vesicle) von an der präsynaptischen Membran gelegenen t-SNAREs $(\mathrm{t}=$ target membrane). Eine zweite Klassifikation in R- und Q-SNAREs - nach den Aminosäuren Arginin (R) und Glutamin (Q), die im Inneren der SNARE-Komplexe eine polare Schicht bilden - beruht auf der Struktur der SNAREProteine. Die meisten intrazellulären Membranfusionsreaktionen erfordern die Beteiligung von vier SNAREs, davon meist ein R- und drei Q-SNAREs (Fasshauer et al. 1998).

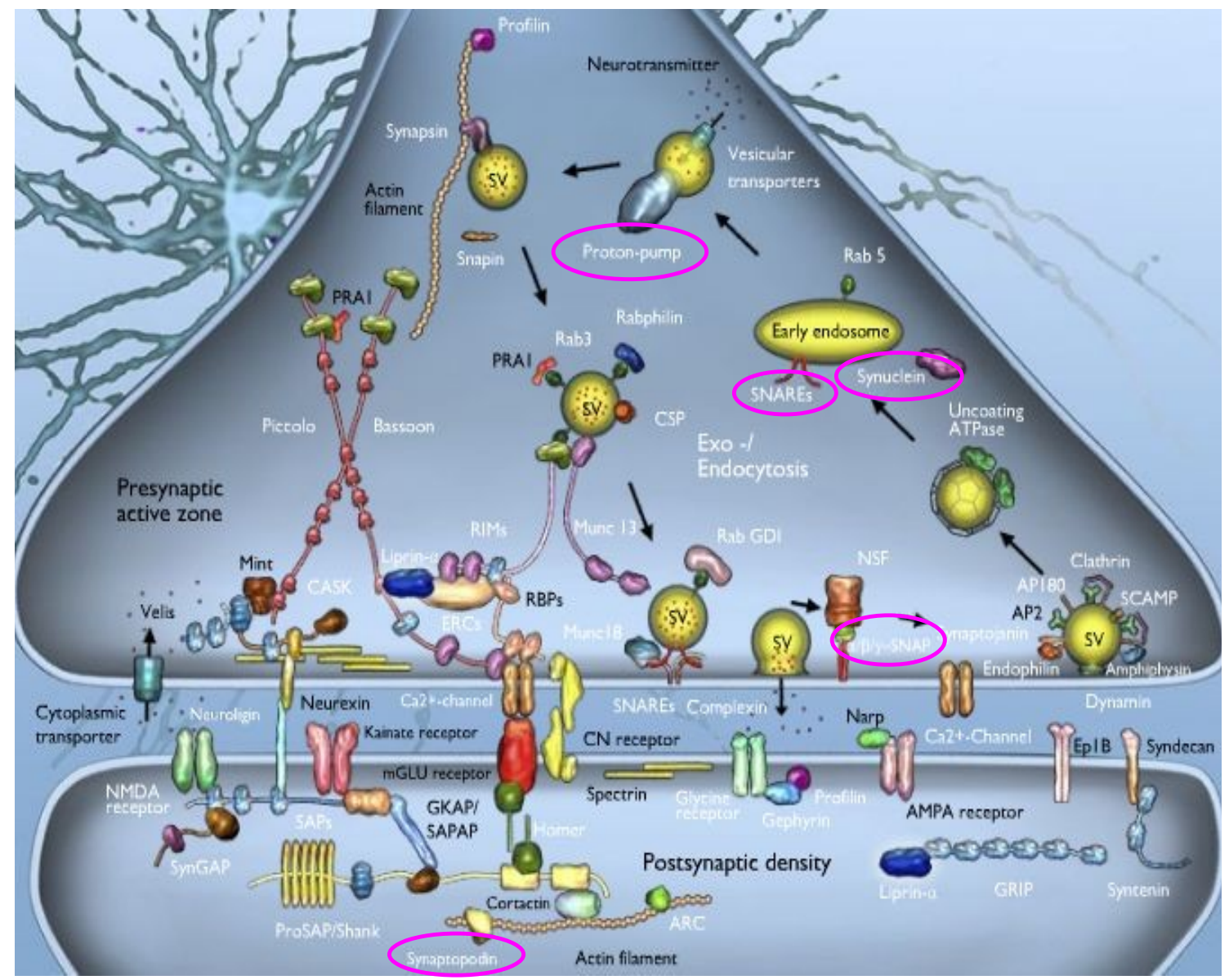

Abbildung 7: Funktion und Verteilung synaptischer Proteine. Proton-ATPase, SNARE-Proteine und Synucleine sind an der Präsynapse lokalisiert, während Synaptopodin ein Strukturprotein der postsynaptischen Verdichtungszone bildet. Zur Familie der SNARE-Proteine, die eine entscheidende Rolle in der Fusion zellulärer Membranen spielen, zählen u.a. Synaptobrevin 2 (VAMP 2), SNAP-25, Syntaxin 7, Syntaxin 13 und Vti1b (http://www.sysy.com/flash-synapse/ index2.html). 
Synaptobrevin (VAMP 2 = vesicle asso-ciated membrane proteine) und SNAP-25 (synaptosomeassociated protein of $25 \mathrm{kDa}$ ) sind für Membranfusionen essentielle SNARE-Proteine und liegen in Neuronen zusammen mit Syntaxin 1 vor. Synaptobrevin (VAMP 2) ist ein über eine carboxyterminale Transmembrandomäne in der Vesikelmembran verankertes v-SNARE, während es sich bei SNAP-25 und dem Partner Syntaxin 1 um t-SNAREs handelt, die an der präsynaptischen Membran lokalisiert sind. Abbildung 8 zeigt die SNARE-vermittelte Fusion von synaptischer und Vesikelmembran. Synaptobrevin ist zudem Zielstruktur des Tetanustoxins sowie der Botulinumtoxine B, D, F und G. Die clostridialen Neurotoxine bewirken über eine proteolytische Spaltung des Proteins eine Blockade der synaptischen Transmitterausschüttung (Schiavo et al. 1994).

$\mathrm{Zu}$ den neuronalen SNARE-Proteinen existieren homologe Proteine, die in unterschiedlichen Spezies an Exozytosevorgängen und intrazellulären Transportmechanismen beteiligt sind. Syntaxin 7 und Syntaxin 13 gehören wie ihr neuronales Homologon Syntaxin 1 der Syntaxin-Proteinfamilie aus Q-SNAREs an. Beide Proteine sind im Gegensatz zu ihren verwandten Syntaxinen 1 bis 4 an endosomalen Membranen unterschiedlicher Zellen lokalisiert. Syntaxin 7 ist an der Fusion später Endosomen und Lysosomen beteiligt und liegt dort im Komplex mit anderen SNARE-Proteinen vor, darunter auch Vti1b. Syntaxin 13 ist vorwiegend an frühen Endosomen $\mathrm{zu}$ finden und scheint die Verschmelzung endosomaler Membranen beim Recycling von Membranrezeptoren wie dem Transferrin-Rezeptor zu vermitteln (Prekeris et al. 1998, Prekeris et al. 1999).

Das im Komplex mit Syntaxin 7 und anderen SNAREs vorliegende Vtilb ist ebenfalls an endosomalen Membranen anzutreffen, wo es an Fusionsvorgängen beteiligt ist. Zudem wurde sein Vorkommen auf Vesikeln und Tubuli des trans-GolgiNetzwerks beschrieben (Kreykenbohm et al.

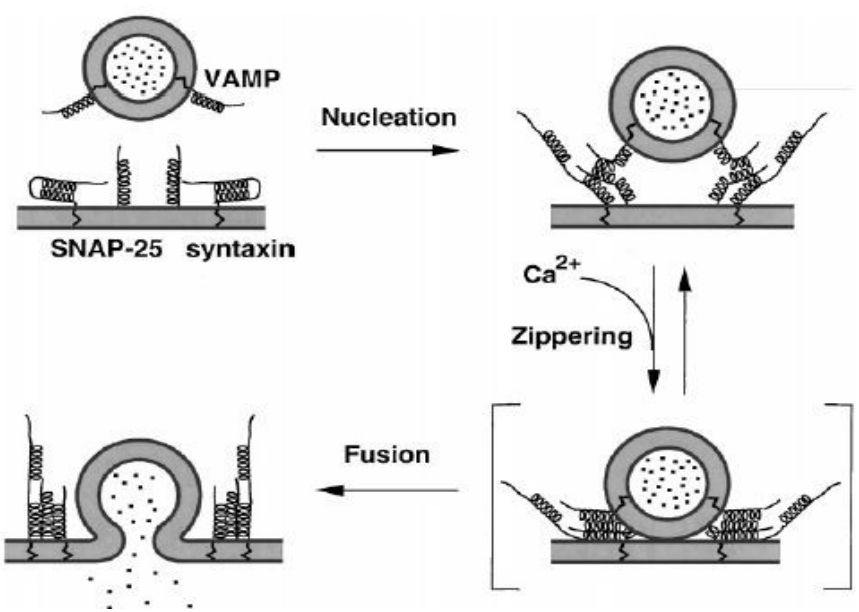

Abbildung 8: Modell der SNARE-vermittelten Fusion von Vesikeln mit der präsynaptischen Membran. Syntaxin liegt initial in einer geschlossenen Konformation vor und ist nicht mit SNAP-25 und Synaptobrevin verbunden. Die Bildung eines SNARE-Komplexes ("Nucleation") unter Konformationsänderung der beteiligten Proteine leitet den Fusionsprozess ein. Calciumeinstrom induziert den Kontakt beider Membranen ("Zippering"). Dieses instabile Zwischenstadium löst sich entweder schnell wieder auf oder geht in die Fusion der Membranen über (Lin und Scheller 2000, S. 28). 2002). 


\subsection{2 $\alpha$ - und $\beta$-Synuclein}

Synuclein-Proteine bilden eine Familie kleiner, löslicher Proteine aus $\alpha$-, $\beta$ - und $\gamma$-Synuclein, deren bekanntestes Mitglied $\alpha$-Synuclein ist. $\alpha$ - und $\beta$-Synuclein werden hauptsächlich im Gehirn exprimiert, während $\gamma$-Synuclein eine hohe Expression u.a. in verschiedenen Tumoren und im peripheren Nervensystem zeigt (George 2001).

$\alpha$-Synuclein ist ein präsynaptisch angereichertes Molekül des zentralen Nervensystems (Iwai et al. 1995a), dessen physiologische Funktion noch nicht hinreichend geklärt ist. Es liegen Hinweise auf eine Beteiligung an membranassoziierten Prozessen an der Präsynapse vor. So konnte u.a. gezeigt werden, dass $\alpha$-Synuclein an der Regulation der Größe des synaptischen Vesikelpools beteiligt ist (Murphy et al. 2000) und in der Modulation synaptischer Plastizität eine Rolle spielt (George et al. 1995).

$\alpha$-Synuclein ist Namensgeber einer Gruppe von Erkrankungen geworden, bei denen signifikante Aggregationen des Proteins ein wichtiges neuropathologisches Merkmal darstellen. $\mathrm{Zu}$ den sogenannten Synucleinopathien gehören u.a. die Parkinson-Krankheit, die Demenz mit Lewy-Körperchen und die Multisystematrophie. $\alpha$ Synuclein akkumuliert in für die Parkinson-Erkrankung charakteristischen Lewy-Körperchen und Lewy-Neuriten, die ubiquitinierte

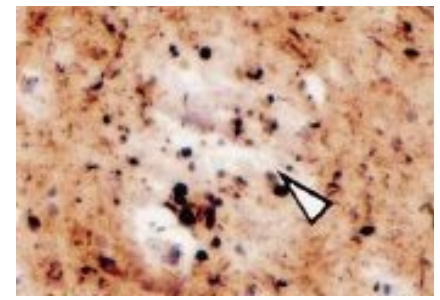

Abbildung 9: a-SynucleinImmunfärbung einer neuritischen Plaque im Gehirn eines Patienten mit der Lewy-Variante der $A D$ (Wirths et al. 2000, S. 3739). zytoplasmatische Einschlüsse des Proteins enthalten (Irizarry et al. 1998). Zudem finden sich Mutationen im Gen für $\alpha$-Synuclein in den seltenen familiären Fällen von Morbus Parkinson (Polymeropoulos 2000).

In Alzheimer-Plaques wurde ursprünglich ein 35 Aminosäuren langes Peptid (non-amyloid component, NAC) identifiziert, das aus einem $\mathrm{zu}$ humanem $\alpha$-Synuclein identischem Vorläuferprotein hervorgeht (non-amyloid component precursor, NACP) und amyloidogene Eigenschaften besitzt (Uéda et al. 1993, Iwai et al. 1995b).

Eine Überlappung klinischer und neuropathologischer Eigenschaften der Alzheimer- und der Parkinson-Erkrankung findet sich bei der Demenz mit Lewy-Körperchen und der LewyKörperchen-Variante der AD, die als pathologische Korrelate A $\beta$-Plaques, Lewy-Körperchen und Lewy-Neuriten sowie $\alpha$-Synuclein-Aggregationen in dystrophen Neuriten aufweisen (Hansen et al. 1990, Wirths et al. 2000). $\beta$-Synuclein kommt in Lewy-Körperchen nicht vor, scheint jedoch mit axonaler Pathologie des Hippokampus beim Morbus Parkinson und der Demenz mit LewyKörperchen assoziiert zu sein (Galvin et al. 1999). 


\subsubsection{Synaptopodin}

Synaptopodin ist ein zytoskelettales Protein, das an der Bildung des synaptischen Dornenapparates beteiligt ist. Es bindet an das Strukturprotein Aktin und ist reich an der Aminosäure Prolin. Synaptopodin kommt in renalen Podozyten sowie in dendritischen Dornen telenzephalischer Neurone vor, die Orte synaptischer Plastizität im Gehirn sind. Ihm wird eine Beteiligung in der Modulation der Aktin-abhängigen Form und Motililät dendritischer Dornen und podozytärer Fußfortsätze zugeschrieben (Mundel et al. 1997). Mäuse mit einer homozygoten Deletion des Synaptopodin-Gens fehlt der synaptische Dornenapparat und sie zeigen Defizite in der Entwicklung synaptischer Plastizität, was auf eine Mitbeteiligung von Synaptopodin an der Aktin-abhängigen Plastizität synaptischer Dornen hindeutet (Deller et al. 2000, Deller et al. 2003).

\subsubsection{Proton-ATPase}

Die Proton-ATPase oder vakuoläre Protonenpumpe ist ein komplexes, aus mehr als zehn Untereinheiten bestehendes Enzym, das in allen Geweben an der Ansäuerung vieler intrazellulärer Organellen beteiligt ist. Die wahrscheinlich sechs Transmembranregionen umfassende 116-kDaUntereinheit ist die größte Untereinheit der vakuolären Protonenpumpe in synaptischen Vesikeln und coated vesicles und erzeugt durch ihre Aktivität eine elektromotorische Kraft, die eine dem Konzentrationsgradienten entgegengesetzte Transmitteraufnahme bewirkt. Die Untereinheit ist für die Aktivität der Proton-ATPase essenziell (Perin et al. 1991, Jahn und Südhof 1994).

\subsection{Zielsetzung und Fragestellung}

Die Amyloidhypothese (s. Kapitel 1.4.2), die der Akkumulation von A $\beta$ die entscheidende Rolle in der Pathogenese der Alzheimer-Demenz zuschreibt, gilt nach wie vor als am weitesten akzeptierte Theorie zur Erklärung der klinischen Symptomatik der Erkrankung. Amyloidplaques sind dementsprechend die wohl am intensivsten erforschte pathologische Veränderung des AlzheimerGehirns. Interessanterweise konnte jedoch gezeigt werden, dass nicht die Amyloidmenge, sondern der Verlust synaptischer Konnektivität am engsten mit dem Schweregrad des kognitiven Defizits von Alzheimer-Patienten korreliert (Terry RD et al. 1991). Dieser Zusammenhang verdeutlicht die besondere Bedeutung, die der Untersuchung axonaler und synaptischer Prozesse beigemessen werden muss. Da eine funktionierende synaptische Übertragung die Integrität axonaler und dendritischer Fortsätze erfordert, liegt der Schluss nahe, dass das Vorliegen dystropher Neuriten 
sich störend auf die Zell-Zell-Kommunikation auswirkt. Dieser Zusammenhang wird durch die Korrelation zwischen der Zahl dystropher Neuriten und dem Ausprägungsgrad des demenziellen Abbaus gestützt (McKee et al. 1991).

Die Hypothese, dass eine axonale Schwellung möglicherweise die früheste Vorläuferläsion extrazellulärer Plaques darstellt, gewann in jüngerer Zeit durch Untersuchungen an transgenen Mausmodellen für die Alzheimer-Erkrankung an Aktualität. Wichtige Erkenntnisse lieferten Untersuchungen an den doppelt-transgenen Mausmodellen mit APP- und PS1-Mutationen: Im Gehirn junger APP/PS1-Mäuse konnte in somatodendritischen und axonalen Kompartimenten pyramidaler Neurone eine starke $A \beta$-Immunreaktivität in vesikulären Strukturen nachgewiesen werden, die mit zunehmendem Alter und höherer Plaquedichte abnahm (Wirths et al. 2002). Für das in der vorliegenden Arbeit untersuchte $\mathrm{APP}^{\mathrm{SL}} \mathrm{PS} 1 \mathrm{KI}-$ Mausmodell ist bekannt, dass intrazelluläre A $\beta$-Akkumulationen stark mit dem Neuronenverlust in der Pyramidenschicht der CA1-Region des Hippokampus korrelieren (s. Kapitel 1.6.2). Kein Zusammenhang besteht hingegen zwischen extrazellulärer Plaquemenge und Neuronenuntergang (Casas et al. 2004). Diese Beobachtung belegt die entscheidende Rolle von intrazellulärem zelltoxischem $\mathrm{A} \beta$ zu einem frühen Zeitpunkt der Pathogenese. Elektronenmikroskopische Untersuchungen konnten außerdem zeigen, dass intraneuronales $\mathrm{A} \beta$ im transgenen Mausmodell und in AD-Gehirnen bevorzugt in prä- und postsynaptischen Kompartimenten akkumuliert und mit einer veränderten synaptischen Morphologie assoziiert ist (Takahashi et al. 2002). Intrazelluläres A $\beta$ kann folglich als Auslöser axonaler Degeneration vermutet werden. Besonders das schlecht sezernierbare, toxische $A \beta_{1-42^{-}}$ Peptid scheint für die Beeinträchtigung intrazellulärer Transportvorgänge verantwortlich zu sein und - dem Konzept der modifizierten Amyloidhypothese entsprechend - synaptische und axonale Dysfunktion zu induzieren (Bayer und Wirths 2008a, Bayer und Wirths 2008b).

Die Ergebnisse am APP/PS1KI-Mausmodell deuten darauf hin, dass gestörter axonaler Transport ursächlich an der Entstehung extrazellulärer Plaques beteiligt ist und stützen die These, dass axonale Auftreibungen der Entstehung von Amyloidplaques vorausgehen (Wirths et al. 2007).

APP unterliegt einem schnellen, Kinesin-I-vermittelten axonalen Transport (Kamal et al. 2000) und ist ein häufig eingesetzter Marker zur Darstellung gestörter axonaler Transportprozesse, da es bei Unterbrechungen axonaler Fortsätze frühzeitig in axonalen Sphäroiden und Varikositäten akkumuliert (Coleman 2005). Neben APP steht heute eine Vielzahl unterschiedlicher Marker für axonales Mistrafficking zur Verfügung. In der vorliegenden Arbeit sind synaptische Proteine Zielstrukturen immunhistochemischer Färbungen. Enzym-markierte Primärantikörper werden zur Detektion synaptisch exprimierter Proteine am APPSLPS1KI-Mausmodell getestet. 
Der Einsatz synaptischer Marker für die Untersuchung der Alzheimer-Pathologie erscheint aus mehreren Gründen sinnvoll: Dystrophe Neuriten und Sphäroide sind Akkumulationsorte verschiedener in ihrem Transport gestörter Proteine. Die Immunfärbung synaptischer Proteine erfolgt unter der Zielsetzung, ihre pathologischen Akkumulationen in dystrophen Neuriten der Plaqueperipherie und in Sphäroiden ohne direkte Assoziation zu Plaques sichtbar zu machen. Das charakteristische Verteilungsmuster dieser Proteine im Gehirn der APPSLPS1KI-Maus soll beschrieben und interpretiert und ihre Tauglichkeit als Marker neuritischer Pathologie beurteilt werden.

Die Antikörper werden weiterhin an Hirnschnitten humaner Alzheimer-Fälle getestet. Es soll eine Aussage darüber getroffen werden, ob die Synapsenmarker auch im humanen Präparat der Markierung pathologischer Proteinakkumulationen dienen können und ob Unterschiede im Akkumulationsmuster der Proteine in humanen und murinen Präparaten auszumachen sind.

In einem weiteren Schritt soll versucht werden, dystrophe Neuriten im Kortex der APP ${ }^{\text {SLPS1KI- }}$ Maus zu quantifizieren, um den Ausprägungsgrad dieses pathologischen Merkmals für zwei verschiedene Altersstufen des Mausmodells zu beurteilen. 


\section{Material und Methoden}

\subsection{Generierung der APP ${ }^{\mathrm{SL}}$ PS1KI-Mauslinie}

Das doppelt-transgene APPSLPS1KI-Mausmodell entstand durch Kreuzung der zwei Mauslinien PS1KI und $\mathrm{APP}^{\mathrm{SL}}$. Die Generierung der PS1KI-Linie erfolgte in einem zielgerichteten Mutageneseverfahren. Der dabei verwendete Zielvektor enthielt in der codierenden Region des murinen PS1-Gens die Basenaustausche M233T und L235P, die durch ortsspezifische Mutagenese in Exon 7 des Wildtyp-Präsenilin-1-Gens eingeführt wurden. Die resultierenden chimären Mäuse wiesen das punktmutationstragende murine PS1-Allel in ihrer Keimbahn auf. Durch weitere Kreuzungen der Nachkommenschaft entstanden homozygote Tiere, die als PS1KI (knock in) bezeichnet werden. Homozygote PS1KI-Mäuse tragen kein Wildtyp-Präsenilin mehr, sondern exprimieren mutantes Präsenilin unter Kontrolle des mauseigenen Promotors.

Homozygote PS1KI-Mäuse mit einem gemischten genetischen 129SV-C57BL/6-Hintergrund wurden daraufhin mit $\mathrm{APP}^{\mathrm{SL}}$-Mäusen gekreuzt, die humanes APP751 mit der Schwedischen Doppelmutation (K670N/M671L) und der London-Mutation (V717I) unter der Kontrolle des murinen Thy1-Promoter überexprimieren. Der gemischte genetische Hintergrund der APP ${ }^{\mathrm{SL}}$-Mäuse ist C57BL/6-CBA.

Die resultierende APP ${ }^{\mathrm{SL}} \mathrm{PS} 1 \mathrm{KI}-\mathrm{Mauslinie}$ ist homozygot $(\mathrm{Ho})$ für das mutante murine PS1-Gen und heterozygot $(\mathrm{He})$ für das mutante humane APP-Transgen. Die Tiere haben statistisch den selben genetischen Hintergrund: C57BL/6 50\%, CBA 25\%, 129SV 25\% (Casas et al. 2004).

\subsection{Herstellung der mikroskopischen Präparate}

Für die immunhistochemischen Färbungen an Hirnschnitten der APP ${ }^{\text {SL }}$ PS1KI-Maus wurde in Paraffin eingebettetes Gewebe verwendet. Nach Entnahme der Gehirne erfolgte ohne vorherige Perfusion die Immersionsfixierung in 4\%igem Paraformaldehyd über Nacht. Während die transkardiale Perfusionsfixation den Vorteil besitzt, Blutzellen aus dem Gewebe zu entfernen und eine unerwünschte Hintergrundreaktion bei der immunhistochemischen Färbung zu minimieren, ahmt die Immersionsfixation mit direkter Überführung des Präparates in das Lösungsmittel die Situation im humanen Präparat am besten nach.

Das Gewebe wurde anschließend in $4 \%$ igem gepuffertem Formalin bei $4^{\circ} \mathrm{C}$ für mindestens einen 
Tag postfixiert, in einer aufsteigenden Ethanolreihe (50\%, 60\%, 70\%, 80\%, 90\%, 2 x 100\%) dehydriert und der Alkohol durch Xylolbehandlung entfernt. Die Paraffineinbettung erfolgte durch Einlegen der Gewebe in flüssiges Paraffin für zwei Stunden und anschließende Überführung der Gewebe in Paraffinblöcke.

Nach vollständiger Abkühlung und Erstarrung des Paraffins konnten am Mikrotom Sagittalschnitte der Gewebeblöcke von $4 \mu \mathrm{m}$ Dicke für die immunhistochemischen Färbungen hergestellt werden. Die Schnitte wurden vorsichtig in einen Behälter mit zweifach destilliertem Wasser auf Raumtemperatur überführt und auf Superfrost@Plus-Objektträger übertragen. Die Objektträger wurden anschließend schräg in ein 52 bis $56^{\circ} \mathrm{C}$ heißes Wasserbad getaucht, um das Gewebe glatt auf der Objektträgeroberfläche zu fixieren. Die Trocknung der Schnitte erfolgte für ca. 15 bis 20 Minuten auf einer erhitzten Platte gleicher Temperatur. Die Schnitte wurden über Nacht in einem $37^{\circ} \mathrm{C}$ warmen Schrank gelagert und vollständig getrocknet.

Die Zuschnitte humaner Alzheimer-Gehirne wurden in gleicher Weise fixiert, in Paraffin eingebettet und am Mikrotom in $4 \mu \mathrm{m}$ dicke Schnittpräparate überführt.

\subsection{Auswahl der APP ${ }^{\text {SL }}$ PS1KI-Mäuse}

Die immunhistochemischen Färbungen wurden an 6 Monate alten APPSLPS1KI-Mäusen durchgeführt, die in dieser Alterstufe bereits ausgeprägte pathologische Veränderungen aufweisen (s. Kapitel 1.6.2). Sämtliche in der vorliegenden Arbeit präsentierten Aufnahmen muriner Schnitte bilden deshalb die Situation im Gehirn der 6 Monate alten Maus ab.

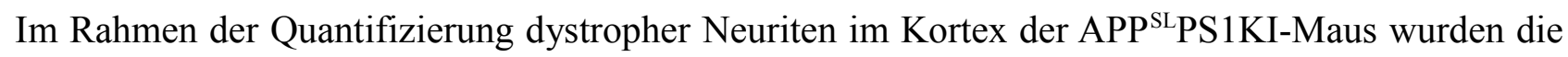
Ergebnisse für 6 und 10 Monate alte Mäuse miteinander verglichen.

\subsection{Humane Präparate}

Tabelle 4 fasst die verfügbaren Informationen zu den untersuchten humanen Präparaten zusammen:

\begin{tabular}{|l|l|l|l|}
\hline Fallnummer & Geschlecht & Alter & Diagnose und Krankheitsverlauf \\
\hline 1 (S00/145) & weiblich & 84 Jahre & Diagnose Alzheimer, Braak Stadium IV \\
\hline 2 (S99/271) & weiblich & 93 Jahre & Diagnose Alzheimer, Braak Stadium IV \\
\hline 3 (U5659) & weiblich & 72 Jahre & Diagnose Alzheimer, Krankheitsdauer 10 Jahre \\
\hline
\end{tabular}

Tabelle 4: Details zu den untersuchten Fällen humaner $A D$. 


\subsection{Immunhistochemische Färbungen}

\subsubsection{Indirekte Immunhistochemie}

Für die immunhistochemischen Färbungen wurden spezifisch gegen synaptisch exprimierte Proteine gerichtete Primärantikörper verwendet, die ihre Zielproteine in ihrer Epitopregion im Sinne einer Antigen-Antikörper-Region binden.

Die Färbungen basieren auf dem Prinzip der indirekten Immunhistochemie, bei der zunächst ein gegen das Zielantigen - in

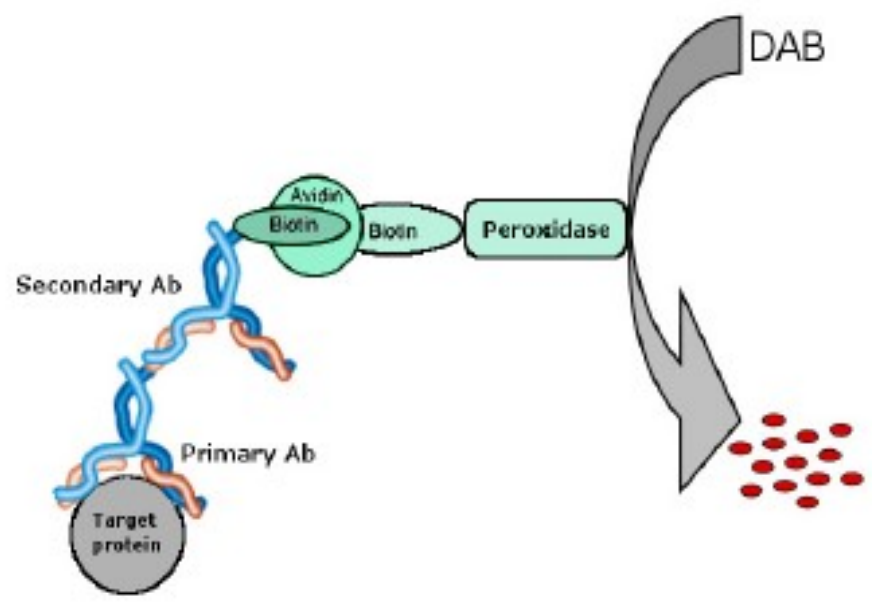
diesem Fall gegen ein synaptisches Protein - gerichteter unmarkierter Primärantikörper

Abbildung 10: Schematische Darstellung des Avidin-Biotin-EnzymKomplexes $(A B C)$. Der gegen das Zielprotein gerichtete Primärantikörper wird von einem biotinylierten Sekundärantikörper erkannt. Avidin-Biotinauf das Gewebe aufgetragen wird. Die Fc- Wechselwirkung vermittelt die ABC-Bindung an den Sekundärantikörper.

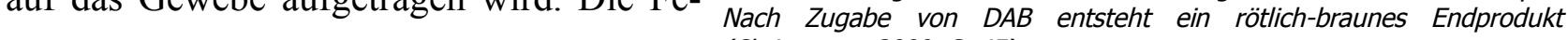
Region des Primärantikörpers wird dann (Christensen 2009, S. 45).

von einem Enzym- oder Fluoreszenzfarbstoff-markierten Sekundärantikörper erkannt, der gegen die Spezies gerichtet ist, aus der der eingesetzte Primärantikörper stammt. In der vorliegenden Arbeit werden unmarkierte Primärantikörper aus dem Kaninchen und der Maus verwendet.

Der für die Färbung mit 3,3'-Diaminobenzidin (DAB) eingesetzte Sekundärantikörper ist mit dem Enzym Biotin markiert. Die Biotinylierung des Antikörpers ermöglicht die Bindung des AvidinBiotin-Enzym-Komplexes. Die starke spezifische Wechselwirkung zwischen den Molekülen Avidin und Biotin erlaubt die Bindung des Komplexes an den biotinylierten Sekundärantikörper. Der ABCKomplex enthält zudem das an Biotin gebundene Enzym Meerrettichperoxidase, das über die Avidin-Biotin-Interaktionen an den Sekundärantikörper gebunden wird. Die Peroxidase verwendet $\mathrm{H}_{2} \mathrm{O}_{2}$ als Substrat; nach Zugabe der DAB-Färbelösung entsteht unter Freisetzung von Protonen ein rötlich-braunes Endprodukt aus dem zuvor farblosen Chromogen DAB und die Zielstrukturen werden sichtbar.

Die indirekte Immunfluoreszenzfärbung folgt dem gleichen Prinzip wie die DAB-Immunfärbung. Nach Inkubation des Gewebes mit dem unmarkierten Primärantikörper erfolgt die Auftragung eines Sekundärantikörpers, der in diesem Fall direkt mit einem Fluoreszenzfarbstoff gekoppelt ist. Die Fluorochrome werden unter dem Fluoreszenzmikroskop mit Licht einer bestimmten Wellenlänge 
angeregt und emittieren farbiges Fluoreszenzlicht. Alexa Flour®488-konjugiertes Anti-KaninchenImmunglobulin, dessen Anregungsmaximum bei einer Wellenlänge von $488 \mathrm{~nm}$ liegt, emittiert grünes Fluoreszenzlicht und markiert aus dem Kaninchen stammende Primärantikörper, während Alexa Flour ${ }^{\circledR 594-g e k o p p e l t e s ~ A n t i-M a u s-I m m u n g l o b u l i n ~ i m ~ B e r e i c h ~ s e i n e s ~ A n r e g u n g s m a x i m u m s ~}$ bei 594 nm in roter Farbe ausstrahlt und Primärantikörper mit Herkunft aus der Maus kennzeichnet.

\subsubsection{Immunhistochemische Färbung von Paraffinschnitten}

Nach Deparaffinierung der Präparate in Xylol (2 x 5 min) erfolgte die Rehydrierung des Gewebes in einer aufsteigenden Ethanolreihe (10 $\min 100 \%, 5 \min 95 \%, 1 \min 70 \%, 1 \operatorname{min~}_{2} 0$ ). Die DABFärbung verlangt die Blockade der endogenen Peroxidaseaktivität, die Ursache unspezifischer Hintergrundfärbungen sein kann, für 30 min in $0,3 \% \mathrm{H}_{2} \mathrm{O}_{2}$ in PBS. Die Demaskierung der Epitope des fixierten Gewebes wurde durch Erhitzen und kurzes Kochen der Schnitte in der Mikrowelle erreicht (10 min in 0,1-molarem Citratpuffer); danach erfolgte die Abkühlung für 15 min bei Raumtemperatur. Das Waschen der Objektträger in 0,1\% Triton X-100 enthaltender PBS für 3 x 5 min führte zur Permeabilisierung der Membranen. Die zusätzliche Vorbehandlung des Schnittes mit 88\%iger Ameisensäure für 3 min diente bei der Darstellung von $\beta$-Amyloid zur Erhöhung der Signalstärke.

Der Blockade unspezifischer Proteinbindungsstellen mit 10\% FCS und 4\% Milchpulver in PBS für 60 min folgte die Inkubation mit dem Primärantikörper (in 10\% FCS enthaltender PBS) in einer feuchten Kammer bei Raumtemperatur über Nacht (Verdünnungen s. Tabellen 5 und 7). Am Folgetag wurden die Schnitte zunächst in 0,1\% Triton X-100 enthaltender PBS gewaschen. Im Anschluss wurde der biotinylierte bzw. der mit einem Fluoreszenzfarbstoff markierte Sekundärantikörper aufgetragen.

Für die DAB-Färbung erfolgte die Inkubation mit dem biotinyliertem Sekundärantikörper für 60 min bei $37^{\circ} \mathrm{C}$ (Verdünnung 1:200 in $10 \%$ FCS enthaltender PBS). Nach dem Waschen der Objektträger ( 3 x 5 min in PBS) wurden die Schnitte bei $37^{\circ} \mathrm{C}$ für 90 min mit dem $\mathrm{ABC}$-Komplex (VECTASTAIN $®$ ABC Kit, Verdünnung 1:100 in 10\% FCS enthaltender PBS) inkubiert. Erneutem

Waschen ( 3 x $5 \mathrm{~min}$ in PBS) folgte die Auftragung der DAB-Färbelösung $(0,5 \mathrm{mg} / \mathrm{mL}$ in 0,05 M Tris- $\mathrm{HCl} \mathrm{pH} 7,5$ und Zugabe von $\mathrm{H}_{2} \mathrm{O}_{2}$ ) für 1 bis $5 \mathrm{~min}$. Die individuelle Färbedauer wurde für jeden Antikörper unter mikroskopischer Beobachtung des rötlich-braunen Farbumschlages ermittelt.

Einem weiteren Waschschritt (3 x 5 min in PBS) schloss sich die Gegenfärbung mit Hämatoxylin für $40 \mathrm{sec}$ an, gefolgt von einer kurzen Waschung in deionisiertem $\mathrm{H}_{2} \mathrm{O}$ und einer 5-minütigen Waschung unter fließendem Leitungswasser. Zellkerne erschienen nach Färbung mit Hämatoxylin 
blauviolett. Nach Behandlung der Schnitte in einer aufsteigenden Ethanolreihe (1 min 70\%, 5 min 95\%, 10 min 100\%) und Xylol (2 x 5 min) wurden die Präparate in Roti ${ }^{\circledR}$-Histokitt-Einschlussmittel eingebettet und mit einem Deckglas abgedeckt.

Die Inkubationszeit des fluoreszenzmarkierten Sekundarantikörpers (Verdünnung 1:200 in 10\% FCS enthaltender PBS) betrug $90 \mathrm{~min}$ bei $37^{\circ} \mathrm{C}$, wobei darauf zu achten war, die Antikörper jederzeit vor Lichtexposition zu schützen. Nach dem Waschen (3 x 5 min in PBS) erfolgte direkt die Gegenfärbung der Zellkerne mit DAPI (4',6-Diamidino-2-phenylindol) und die Einbettung in Vectashield ${ }^{\circledR}$ Mounting Medium.

Die Protokolle der DAB- und Fluoreszenzfärbung befinden sich im Anhang dieser Arbeit.

\subsubsection{Testung der Primärantikörper}

Die Primärantikörper wurden zunächst in der DAB-Färbung in vier verschiedenen Verdünnungen (1:2000, 1:1000, 1:500 und 1:250 in 10\% FCS enthaltender PBS) an der APP ${ }^{\text {SLPS1KI-Maus }}$ getestet. Entsprechende Kontrollfärbungen wurden an Wildtyp-Mäusen durchgeführt, die an beiden Genloci Wildtyp-Allele tragen und entsprechend als Negativkontrolle dienten. Die Immunfärbung mit dem zu testenden Antikörper galt als erfolgreich, wenn die Darstellung Alzheimer-typischer neuritischer Pathologie in der APP ${ }^{\mathrm{SL}} \mathrm{PS} 1 \mathrm{KI}-\mathrm{Maus}$ gelang. Die Verdünnung des Antikörpers, die bei nur schwacher Hintergrundfärbung die Zielstrukturen mit möglichst hohem Kontrast darstellte, wurde für alle weiteren DAB-Färbungen mit dem jeweiligen Primärantikörper im murinen Gewebe übernommen (s. Tabelle 5). Von den insgesamt 27 getesteten Antikörpern bildeten 17 keine pathomorphologischen Korrelate der AD ab: Die Darstellung dystropher Neuriten gelang mit diesen Antikörpern nicht (s. Tabelle 6).

Zusätzlich wurde ein Antikörper gegen APP für die Immunfärbungen verwendet, da sich APP als geeignetes Markerprotein axonaler Schädigung und dystropher Neuriten erwiesen hat und zum Vergleich mit den untersuchten synaptischen Markern herangezogen werden kann.

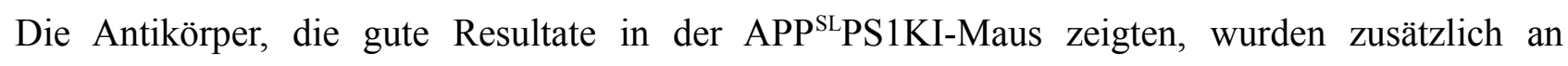
Hirnschnitten humaner Alzheimer-Fälle getestet. Die Konzentration des Primärantikörpers im humanen Hirngewebe lag dabei durchschnittlich um ein Zwei- bis Dreifaches höher als die Konzentration im Mausgehirn (s. Tabelle 5).

Für die Immunfluoreszenzfärbungen des murinen Gewebes wurden ebenfalls geringere Antikörperverdünnungen appliziert als für die DAB-Färbungen. Eine Übersicht über die in der Immunfluoreszenzfärbung eingesetzten Antikörper gibt Tabelle 6. 


\begin{tabular}{|c|c|c|c|c|c|}
\hline \multirow{2}{*}{$\begin{array}{l}\text { ZIELANTIGEN DES } \\
\text { ANTIKÖRPERS }\end{array}$} & \multirow[t]{2}{*}{ HERKUNFT } & \multicolumn{2}{|c|}{ VERDÜNNUNG } & \multirow{2}{*}{$\begin{array}{l}\text { ZuSÄTZLICHE } \\
\text { INFORMATIONEN }\end{array}$} & \multirow{2}{*}{$\begin{array}{l}\text { KatalOG- } \\
\text { NR. }\end{array}$} \\
\hline & & MuRIN & Human & & \\
\hline APP affi & Kaninchen & $1: 2000$ & $1: 1000-1: 500$ & $\begin{array}{l}\text { polyklonal, } \\
\text { affinitätsgereinigt }\end{array}$ & 127003 \\
\hline SNAP-25 (A) & Maus & $1: 2000$ & $1: 1000-1: 500$ & $\begin{array}{l}\text { monoklonal, } \\
\text { Aszites } \\
\text { Zellinie } 71.1\end{array}$ & 111001 \\
\hline SNAP-25 (IgG) & Maus & $1: 1000$ & $1: 500-1: 250$ & $\begin{array}{l}\text { monoklonal, } \\
\text { aufgereinigtes IgG, } \\
\text { Zelllinie } 71.2 \\
\end{array}$ & 111111 \\
\hline $\begin{array}{l}\text { Synaptobrevin } 2 \\
\text { (VAMP2) }\end{array}$ & Kaninchen & $1: 1500$ & $1: 800-1: 400$ & polyklonal & 104202 \\
\hline Syntaxin 7 & Kaninchen & $1: 250$ & $1: 500-1: 250$ & polyklonal & 110072 \\
\hline Syntaxin 13 & Kaninchen & $1: 500$ & $1: 500-1: 250$ & polyklonal & 110132 \\
\hline Vtilb & Kaninchen & $1: 500$ & $1: 200-1: 100$ & polyklonal & 164002 \\
\hline Synaptopodin & Kaninchen & $1: 250$ & $1: 200-1: 100$ & polyklonal & 163002 \\
\hline $\begin{array}{l}\text { Proton ATPase } \\
116 \text { kDa-Untereinheit }\end{array}$ & Kaninchen & $1: 100$ & $1: 100-1: 50$ & polyklonal & 109002 \\
\hline Synuclein $\alpha$ & Kaninchen & $1: 1000$ & $1: 400-1: 200$ & polyklonal & 128102 \\
\hline Synuclein $\alpha / \beta$ & Kaninchen & 1:2000 & 1:1000-1:500 & polyklonal & 128002 \\
\hline
\end{tabular}

Tabelle 5: Details zu den Primärantikörpern, mit denen in der DAB-Immunfärbung die Darstellung neuritischer Pathologie gelang. Hersteller dieser Primärantikörper ist Synaptic Systems GmbH, Göttingen. 


\begin{tabular}{|c|c|}
\hline ZiELANTIGEN DES ANTIKÖRPERS & BESCHREIBUNG DES ZiELPROTEINS \\
\hline \multicolumn{2}{|l|}{ SNARE-Proteine } \\
\hline Syntaxin 5 & SNARE-Protein, involviert in ER/Golgi-Transport \\
\hline Syntaxin 8 & SNARE-Protein, involviert in der Fusion später Endosomen \\
\hline Syntaxin 16 & Q-SNARE-Protein, ER-assoziiert \\
\hline \multicolumn{2}{|l|}{ SNARE-assoziierte Proteine } \\
\hline Munc 18 (rb-sec1, n-sec1) & peripheres Membranprotein, an Andocken und Fusion der Vesikel beteiligt \\
\hline \multicolumn{2}{|l|}{ Vesikel-assoziierte Proteine } \\
\hline AP 180 & $\begin{array}{l}\text { involviert in Clathrin-vermittelte Endozytose und endozytotischem Recycling } \\
\text { synaptischer Vesikel }\end{array}$ \\
\hline Clathrin light chain & kleine Untereinheit der Clathrin-Coats, involviert in Endozytose \\
\hline Endophilin 1 (SH3P4, SH3GL2) & Protein mit SH3-Domäne, involviert in Clathrin-vermittelte Endozytose \\
\hline Otoferlin & Transmembranprotein, involviert in Vesikelfusion \\
\hline Rab 5 & $\begin{array}{l}\text { Mitglied der Rab-Proteinfamilie und ras-Superfamilie kleiner monomerischer } \\
\text { GTPasen, beteiligt an der Fusion früher Endosomen }\end{array}$ \\
\hline \multicolumn{2}{|l|}{ Proteine der aktiven Zone } \\
\hline CASK & Protein der MAGUK-Proteinfamilie präsynaptischer aktiver Zonen \\
\hline CASKIN 1 & CASK-Interaktionspartner \\
\hline Liprin- $\alpha 3$ (Syd 2) & Protein involviert in Entwicklung präsynaptischer aktiver Zonen \\
\hline Munc 13 & $\begin{array}{l}\text { peripheres Membranprotein, in Synaptosomen angereichert, fehlt in } \\
\text { synaptischen Vesikeln, essentiell für synaptische Signalübertragung, }\end{array}$ \\
\hline Piccolo (Aczonin) & $\begin{array}{l}\text { großes Multidomänenprotein der präsynaptischen aktiven Zone, liegt meist } \\
\text { zusammen mit Bassoon vor }\end{array}$ \\
\hline Bassoon & $\begin{array}{l}\text { großes Multidomänenprotein der zytoskelettalen Matrix aktiver Zonen } \\
\text { (CAZ), liegt meist zusammen mit Piccolo vor }\end{array}$ \\
\hline \multicolumn{2}{|l|}{ Postsynaptische Proteine } \\
\hline Homer 1(VesL 1, Syn 47) & $\begin{array}{l}\text { Gerüstprotein der postsynaptischen Dichte (PSD), involviert im Targeting von } \\
\text { Glutamat-Rezeptoren }\end{array}$ \\
\hline PSD 93 (chapsin110, DLG 2) & Bestandteil der postsynaptischen Dichte (PSD) in zentralen Synapsen \\
\hline
\end{tabular}

Tabelle 6: Getestete Primärantikörper, die im murinen Gewebe keine neuritische Pathologie zur Darstellung brachten. Hersteller dieser Primärantikörper ist Synaptic Systems GmbH, Göttingen. 


\begin{tabular}{|c|c|c|c|c|}
\hline $\begin{array}{l}\text { ZIELANTIGEN DES } \\
\text { ANTIKÖRPERS }\end{array}$ & Herkunft & VERDÜNNUNG & $\begin{array}{l}\text { ZuSÄTZLICHE } \\
\text { INFORMATIONEN }\end{array}$ & Hersteller \\
\hline $\mathrm{A} \beta 17-24(4 \mathrm{G} 8)$ & Maus & $1: 1000$ & monoklonal & Covance, USA \\
\hline APP (22C11) & Maus & $1: 200$ & monoklonal & $\begin{array}{l}\text { Millipore, } \\
\text { Deutschland }\end{array}$ \\
\hline Vtilb & Kaninchen & $1: 100$ & polyklonal & $\begin{array}{l}\text { Synaptic Systems, } \\
\text { Deutschland }\end{array}$ \\
\hline APP affi & Kaninchen & $1: 200$ & polyklonal & $\begin{array}{l}\text { Synaptic Systems, } \\
\text { Deutschland }\end{array}$ \\
\hline
\end{tabular}

Tabelle 7: Details zu den Primärantikörpern der Immunfluoreszenzfärbungen.

\subsubsection{Sekundärantikörper}

Tabelle 8 fasst die Informationen $\mathrm{zu}$ den in der DAB- und Fluoreszenzfärbung verwendeten Sekundärantikörpern zusammen:

\begin{tabular}{|l|l|l|l|}
\hline AnTIKöRPER & HERKUNFT & KATALOG-NR. & HERSTELLER \\
\hline $\begin{array}{l}\text { Anti-Kaninchen-Immunglobulin, } \\
\text { biotinyliert }\end{array}$ & Schwein & E0353 & Dako, Dänemark \\
\hline $\begin{array}{l}\text { Anti-Maus-Immunglobulin, } \\
\text { biotinyliert }\end{array}$ & Kaninchen & E0354 & Dako, Dänemark \\
\hline $\begin{array}{l}\text { Alexa Fluor }{ }^{\circledR} \text { 594-konjugiertes Anti- } \\
\text { Maus-Immunglobulin }\end{array}$ & Huhn & A-21201 & $\begin{array}{l}\text { Invitrogen, } \\
\text { Deutschland }\end{array}$ \\
\hline $\begin{array}{l}\text { Alexa Fluor }{ }^{\circledR} \text { 488-konjugiertes Anti- } \\
\text { Kaninchen-Immunglobulin }\end{array}$ & Ziege & A-11008 & $\begin{array}{l}\text { Invitrogen, } \\
\text { Deutschland }\end{array}$ \\
\hline
\end{tabular}

Tabelle 8: Details zu Sekundärantikörpern der DAB- und Fluoreszenzfärbungen. Alle Antikörper sind polyklonal und wurden in einer Verdünnung von 1:200 in 10\% FCS enthaltender PBS verwendet. 


\subsection{Mikroskopie und Fotografie}

Auflicht- und fluoreszenzmikroskopische Untersuchungen wurden an einem Olympus-BX-51Mikroskop durchgeführt, welches mit einer Olympus-DP-50-Digitalkamera ausgestattet ist, die zur Fotografie der histologischen Schnitte verwendet wurde.

Die Bilder wurden mit dem Programm GIMP 2.6 (http://www.gimp.org) geringfügig in Kontrast und Helligkeit bearbeitet, ohne die Originalaufnahmen im Wesentlichen zu verändern.

\subsection{Quantifizierung dystropher Neuriten}

Die Quantifizierung der mit Antikörpern detektierbaren Akkumulationen synaptischer Proteine in dystrophen Neuriten der Plaqueperipherie wurde an jeweils vier 6 und 10 Monate alten

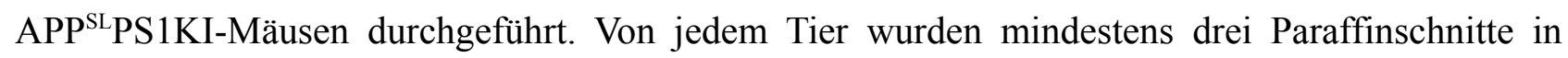
einer Entfernung von mindestens $25 \mu \mathrm{m}$ zueinander auf ihre Syntaxin-13-, Vti1b- und Synuclein- $\alpha$ Immunreaktivität hin mit DAB als Chromogen angefärbt. Mikrofotografien des Kortex wurden am Olympus-BX-51-Mikroskop mit einer Olympus-DP-50-Kamera aufgenommen.

Zur weiteren Auswertung wurde die ImageJ-Software (NIH, USA; http://rsbweb.nih.gov/ij/) verwendet. Nach Binarisierung der Aufnahmen zu 8-Bit-Schwarz-Weiß-Bildern erfolgte die Festlegung einer Intensitätsschwelle zur Erkennung der DAB-Färbung (s. Abbildung 11). Die Schwelle wurde für jede Aufnahme manuell angepasst, um die spezifische Detektion dystropher Neuriten zu optimieren. Gegebenenfalls wurde der $\mathrm{zu}$ analysierende Bereich mit dem Auswahlwerkzeug des Programms adjustiert, um in kortikalen Bereichen mit kleinstmöglicher Hintergrundreaktion zu messen. Abschließend wurden die von der DAB-Immunfärbung bedeckten Areale in prozentualen Anteilen der Gesamtfläche gemessen und die Mittelwerte für jedes Tier ermittelt.

\subsection{Statistische Auswertung}

Für jedes Tier wurden zunächst Mittelwerte aus der in Prozent der Gesamtfläche angegebenen DAB-markierten Fläche berechnet. Zum Vergleich der Mittelwerte für 6 und 10 Monate alte Mäuse wurde ein ungepaarter t-Test mit 95\%igem Konfidenzintervall $(\mathrm{p}<0,05)$ durchgeführt, um zu prüfen, ob signifikante Abweichungen der Mittelwerte beider Gruppen vorliegen.

Das Programm GraphPad Prism 5.03 für Windows (http://www.graphpad.com/prism/prism.htm) diente der Auswertung und der grafischen Darstellung der statistischen Analysen. 

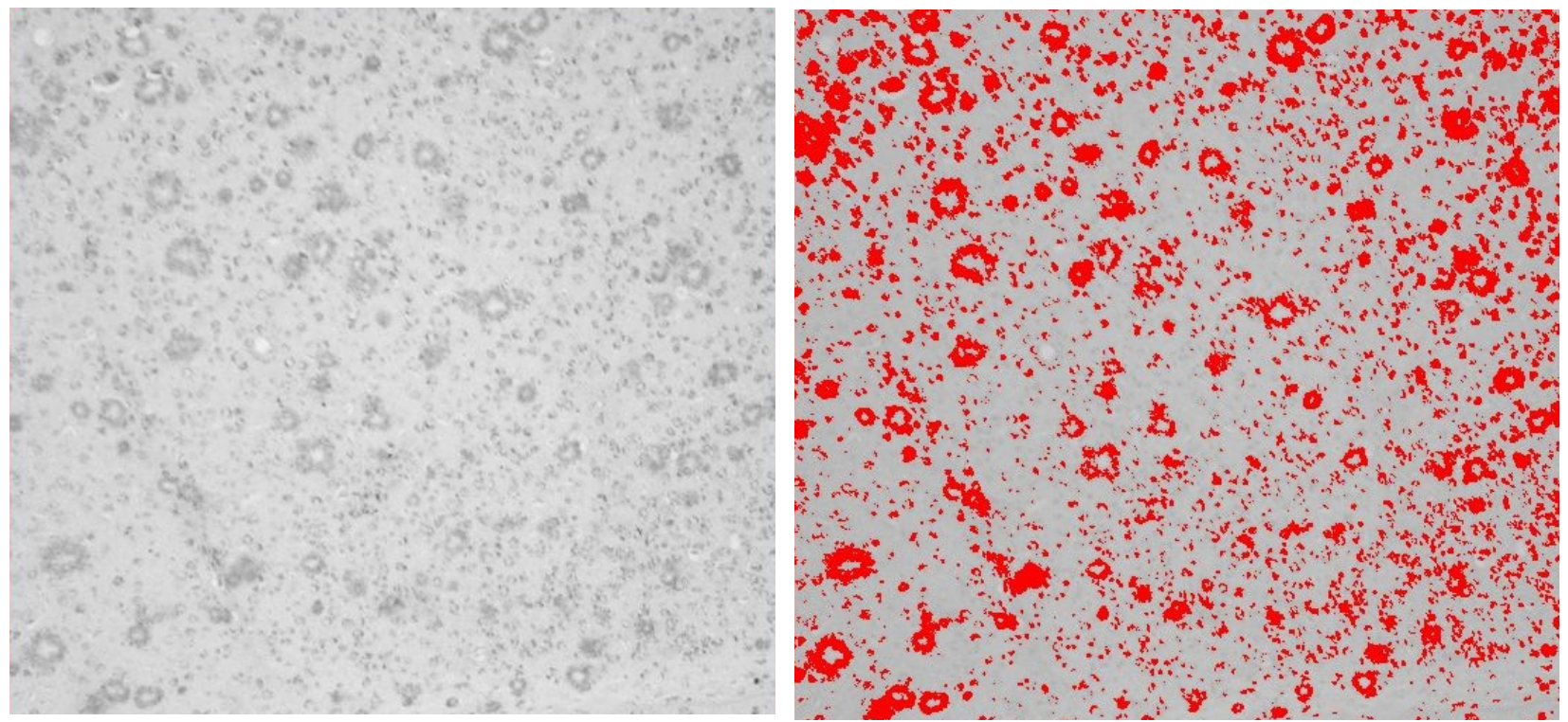

Abbildung 11: Vorgehensweise bei der Quantifizierung dystropher Neuriten am Beispiel Vti1b. Die Originalaufnahme wurde in ein 8-Bit-Schwarz-WeiB-Bild umgewandelt (links) und eine Intensitätsschwelle zur Erkennung der DAB-Färbung festgelegt (rechts). Das Programm erkennt die rot markierten Bereiche als DAB-Färbung. 


\section{ERgEbNisSE}

\subsection{DAB-Immunfärbung synaptischer Proteine und APP}

Insgesamt wurden 27 Primärantikörper gegen synaptische Proteine für die DAB-Immunfärbungen

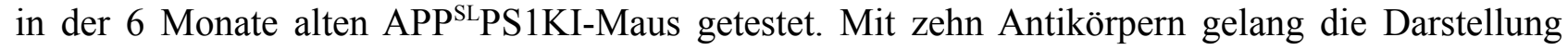
pathologischer Veränderungen im Mausgehirn (s. Tabelle 5). 17 weitere Antikörper zeigten keine

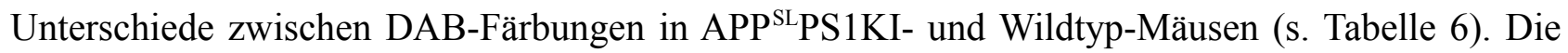
erfolgreich in der Maus getesteten Antikörper wurden ebenfalls für Färbungen humaner AlzheimerPräparate eingesetzt.

Bei der Präsentation der Ergebnisse wird in folgender Weise verfahren: Für jeden erfolgreich getesteten Antikörper werden Ergebnisse im Kortex, Hippokampus und Thalamus der APP ${ }^{\text {SLPS1KI- }}$ Maus gezeigt und beschrieben. Dabei repräsentieren die Großhirnrinde und der Hippokampus primär von der Alzheimer-Pathologie betroffene Gebiete, während der Thalamus erst in fortgeschrittenen Stadien der Erkrankung von pathologischen Veränderungen betroffen ist. Weitere Besonderheiten im Färbemuster der Antikörper werden ebenfalls an entsprechender Stelle vorgestellt. Ergebnisse aus der DAB-Immunfärbung humaner Alzheimer-Gehirnschnitte werden für jeden Antikörper im Anschluss an die Resultate aus murinem Gewebe präsentiert.

APP soll als etablierter Marker für axonales Mistrafficking dem Vergleich mit synaptischen Markern herangezogen werden. 


\subsubsection{SNARE-Proteine}

\subsubsection{Syntaxin 7 und Syntaxin 13}

Die Färbung mit Antikörpern gegen Syntaxin 7 und Syntaxin 13 zeigt im Kortex der 6 Monate alten

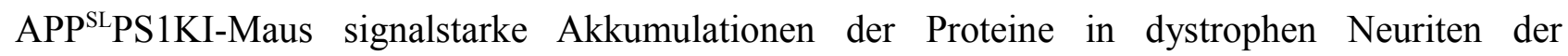
Plaqueperipherie. Die Plaques sind über den gesamten Kortex diffus verteilt (s. Abbildungen 12 a, g) und weisen eine markante zentrale Aufhellung auf, die frei von DAB-Immunfärbung ist. Die nicht gefärbte Aussparung im Inneren der Plaque entspricht dem reifen, dicht kompaktierten Amyloidkern neuritischer Plaques. Die äußeren Anteile der Plaque heben sich deutlich von schwach gefärbten neuropilären Hintergrundstrukturen und dem kompakten Amyloidkern ab. Das Färbemuster aus kräftig anfärbbarer Plaqueperipherie und ungefärbtem Plaquekern lässt die Plaques als im Anschnitt ringförmige, prominente Strukturen erscheinen.

100fache Vergrößerung zeigt die ultrastrukturellen Besonderheiten der Syntaxin-Immunfärbung (s. Abbildungen 12 c, i). Die Färbung mit dem Antikörper gegen Syntaxin 13 zeigt eine besonders signalstarke Plaqueperipherie, in der zahlreiche gut abgrenzbare, intensiver gefärbte rund-ovale Anteile erkennbar sind. Diese bulbösen Strukturen entsprechen den Aggregationen des Zielproteins in dystrophen Neuriten, in deren dilatierten Abschnitten präsynaptisches Syntaxin 13 akkumuliert und ein starkes Signal verursacht. Abbildung 12 c zeigt einen Zellfortsatz, der von außen die Plaqueperipherie erreicht und in seinem Verlauf eine Auftreibung aufweist. Unabhängig von Plaques sind Sphäroide mit dem Syntaxin-13-Antikörper darstellbar (s. Pfeile in Abbildung 12 b).

Der Übergang zum Plaquekern ist unscharf begrenzt; faserartige Strukturen scheinen aus der Peripherie sternförmig ins Innere der Plaque zu ziehen. Dieses Phänomen ist unter dem Mikroskop unter Veränderung der Scharfeinstellung jedoch besser $\mathrm{zu}$ erfassen als auf den gezeigten Abbildungen. Grundsätzlich entspricht die Größe des signalfreien Amyloidkerns etwa der Hälfte des Gesamtdurchmessers einer Plaque.

Dystrophe Neuriten in der Umgebung hippokampaler Plaques weisen ebenfalls starke Syntaxin-13Immunreaktivität auf. Sie zeigen in ihrer Größe eine deutliche Variationsbreite und verteilen sich über die gesamte Hippokampusformation (s. Abbildung $12 \mathrm{~d}$ ).

Auch in anderen als den primär von der AD betroffenen telenzephalen Hirngebieten lassen sich Plaques nachweisen. Die Syntaxin-13-Färbung zeigt im Thalamus der 6 Monate alten APP ${ }^{\text {SLPS1KI- }}$ Maus im Vergleich zum Kortex wenige Plaques, deren Äußeres sich nur unscharf von der Umgebung abgrenzen lässt, da Syntaxin 13 schwächer in der Peripherie thalamischer Plaques akkumuliert, was für eine insgesamt weniger ausgeprägte Schädigung der umgebenden Zellfortsätze spricht (s. Abbildung 12 e). Einzelne bulbös aufgetriebene Anteile dystropher Neuriten sind 
aufgrund ihrer geringeren Anzahl gut sichtbar, da sie in der Plaqueperipherie weniger dicht gepackt liegen als im Kortex (s. Abbildung 12 e).

Bemerkenswert ist außerdem die starke intrazelluläre Färbung der Purkinje-Zellen des Kleinhirns durch Anti-Syntaxin-13 (s. Abbildung 12 f).

Syntaxin-7-Färbung zeigt eine insgesamt homogenere Anfärbbarkeit der Plaqueperipherie kortikaler Plaques (s. Abbildungen 12 g-i). Pathologische Dilatationen einzelner Neuriten der Plaqueumgebung mit hoher Syntaxin-7-Immunreaktivität sind weniger gut detektierbar als in der Syntaxin-13-Färbung, was für eine gleichmäßigere Akkumulation des Proteins in den defekten Zellfortsätzen spricht. Die Relation von hellem Plaquezentrum zu gefärbtem Plaquesaum entspricht in etwa dem Größenverhältnis der Syntaxin-13-Färbung.

Syntaxin 7 zeigt wie Syntaxin 13 eine Anreicherung in Plaques des Hippokampus (s. Abbildung 12 j) und akkumuliert schwach in der Umgebung thalamischer Plaques (s. Abbildung $12 \mathrm{k}$ ). Auch in der Syntaxin-7-Färbung erscheint die Anzahl der Plaques im Thalamus bei geringer Signalintensität der Plaqueumgebung deutlich kleiner.

Während Anti-Syntaxin-7 die zerebellären Purkinje-Zellen - im Gegensatz zu Syntaxin 13 - nicht anfärbt, fällt die insgesamt stärkere Zellfärbung kortikaler Neurone durch den Anti-Syntaxin-7Antikörper auf (s. Abbildungen 12 h, 1).

Syntaxin 7 und Syntaxin 13 akkumulieren auch in humanen Alzheimer-Plaques. Das Färbemuster unterscheidet sich deutlich von dem im murinen Gewebe, wo der kreisrunde Randsaum aus dystrophen Neuriten als geschlossene Struktur erscheint und ein gut abgrenzbares Plaquezentrum aufweist. Die Abbildungen 13 b und c zeigen in 40facher Vergrößerung mit Anti-Syntaxin-7- und Anti-Syntaxin-13-Antikörpern gefärbte Plaques im Kortex. Die Plaques im humanen Gewebe imponieren als signalverdichtete Bereiche, in denen einzelne, in losem Verband zusammenliegende dystrophe Neuriten auszumachen sind. 

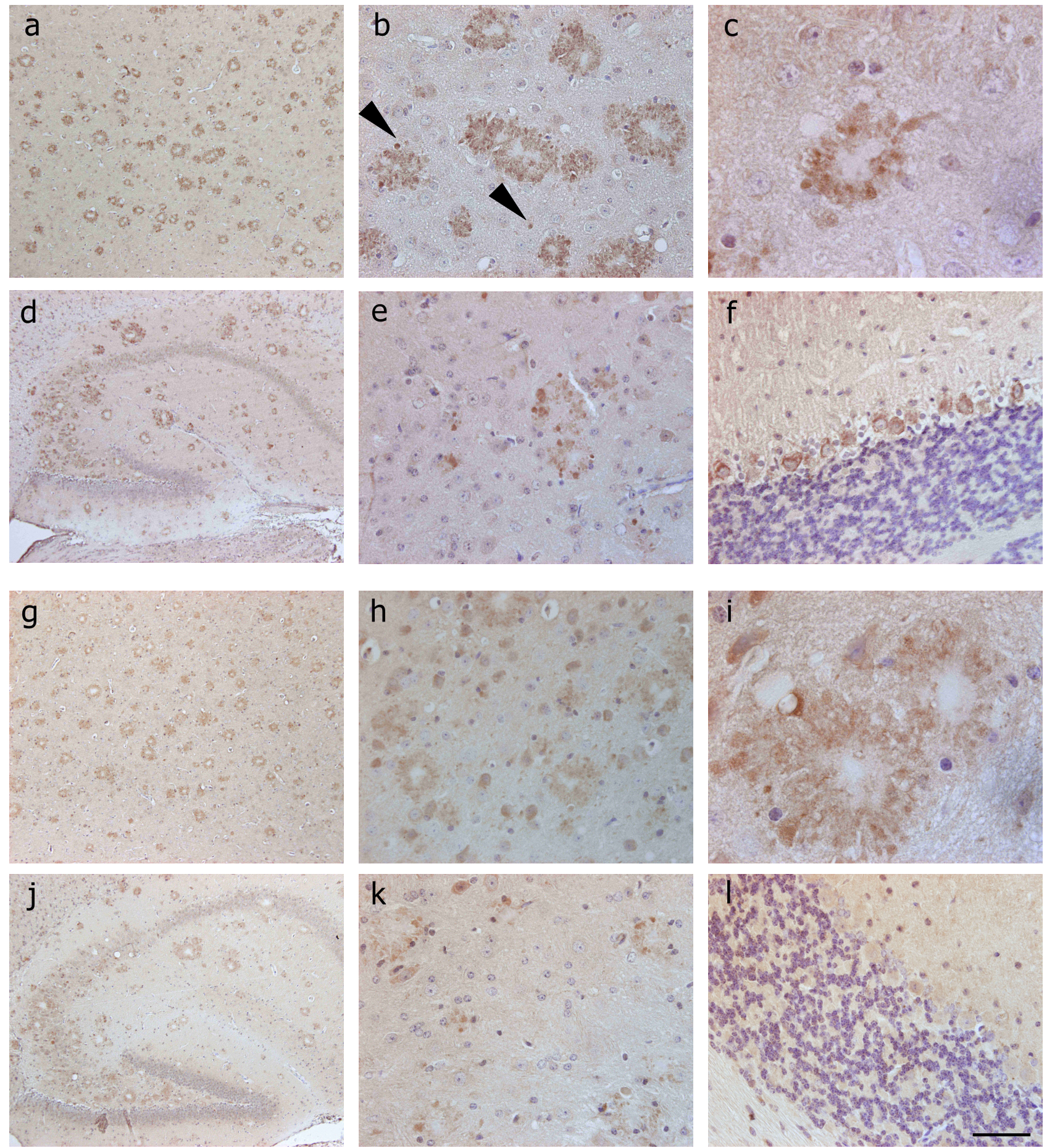

Abbildung 12: DAB-Immunfärbung von Syntaxin 13 (a-f) und Syntaxin 7 ( $g$-I) in der 6 Monate alten APPSLPS1KI-Maus. Starke Akkumulationen von Syntaxin 7 und 13 sind in dystrophen Neuriten des Kortex detektierbar, während der Amyloidkern der Plaques von der Immunfärbung ausgespart bleibt (a-c, g-i). Die Darstellung von Dilatationen dystropher Zellfortsätze der Plaqueperipherie gelingt in der Syntaxin-13-Färbung besonders gut (c). Ähnlich ausgeprägt erscheint die Pathologie im Hippokampus (d, j); hingegen sind im Thalamus nur wenige Plaques mit insgesamt schwachen Syntaxin-Akkumulationen in dystrophen Neuriten nachweisbar $(e, k)$. Ein intrazelluläres Syntaxin-13-Signal erscheint in Purkinje-Zellen des Kleinhirns (f), die in der Syntaxin-7-Färbung frei von Immunfärbung sind (I). In kortikalen Neuronen ist ein starkes intrazelluläres Syntaxin-7-Signal nachweisbar (h). Maßstab: a, d, g, j: $200 \mu m ; b, e, f, h$, k, l: $50 \mu \mathrm{m} ; \mathrm{c}$, i: $20 \mu \mathrm{m}$. 

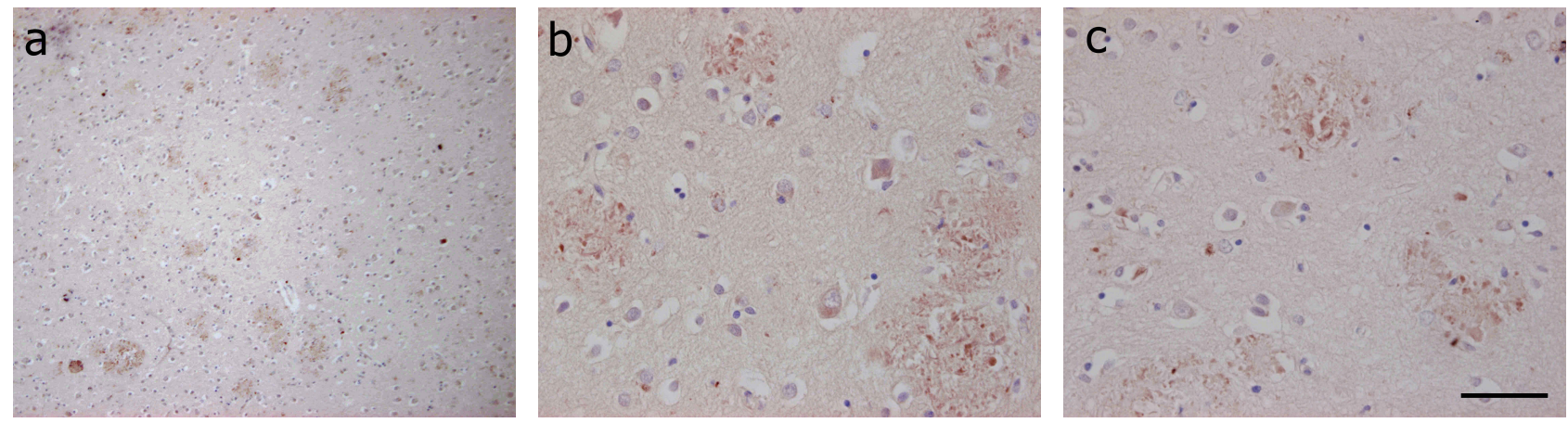

Abbildung 13: Akkumulationen von Syntaxin 13 (a, b) und Syntaxin 7 (c) sind in dystrophen Neuriten humaner AD-Plaques nachweisbar. Maßstab: a: $200 \mu \mathrm{m}$; b,c: $50 \mu \mathrm{m}$. 


\subsubsection{Synaptobrevin}

In der DAB-Immunfärbung von Synaptobrevin imponiert die Umgebung der AD-Plaques als ein Konglomerat kugelig aufgetriebener dystropher Neuriten. Dilatierte Zellfortsatzanteile liegen dicht an dicht und zeigen Akkumulationen des Proteins. Sie bilden in ihrer Gesamtheit das Äußere einer Plaque, während Plaquekerne auch in der Synaptobrevin-Färbung signalfrei bleiben. Abbildung 14 d zeigt einen weit aufgetriebenen, dystrophen Zellfortsatz in der Peripherie einer Plaque mit hoher Synaptobrevin-Signalintensität. Zudem sind Sphäroide unabhängig von Plaques darstellbar (s. Pfeil in Abbildung 14 b). Die hohe Signalstärke in pathologisch veränderten Zellfortsätzen lässt Synaptobrevin als einen sehr gut geeigneten Marker axonaler Pathologie erscheinen.

Insgesamt wirkt die äußere Umgebung der Plaques weniger kompakt als z.B. in der SyntaxinFärbung, in der dystrophe Neuriten eine eher homogene, geschlossene Ringstruktur um den Amyloidkern bilden. Weder der Übergang zum Kern noch zur äußeren Umgebung ist deutlich abgrenzbar. Grundsätzlich weisen die Plaques in der Anti-Synaptobrevin-Färbung ein im Verhältnis zum Gesamtdurchmesser kleines, signalfreies Plaquezentrum auf.

Im Hippokampus lassen sich nur wenige, kleine Plaques darstellen, die v.a. um den Gyrus dentatus lokalisiert sind (s. Abbildung 14 e).

Auch in anderen Hirnregionen wie z.B. im Thalamus sind Plaques nachweisbar, die dort aber aufgrund ihrer geringen Anzahl und des Antikörper-typischen Färbemusters relativ schwer als zusammenhängende Strukturen zu differenzieren sind. Pathologisch veränderte Neuriten sind aber auch hier gut darstellbar (s. Abbildung $14 \mathrm{f}$ ).

Eine weitere Besonderheit der Anti-Synaptobrevin-Färbung ist die fein granuliert erscheinende Färbung des Neuropils. Zellsomata sind ungefärbt und treten als weiße Aussparungen hervor.

Entgegen der positiven Resultate im murinen Gewebe, gelingt die Detektion neuritischer Pathologie in den untersuchten Fällen humaner AD nicht. Ein spezifisches Synaptobrevin-positives Signal ist in kleinsten, punktförmigen Akkumulationen des Proteins zu beobachten, die bei der Gegenfärbung mit Hämatoxylin von einer unspezifischen Blaufärbung überlagert werden (nicht gezeigt). Insgesamt erscheint dieser synaptische Marker für die Anwendung im humanen Alzheimer-Gehirn ungeeignet. 

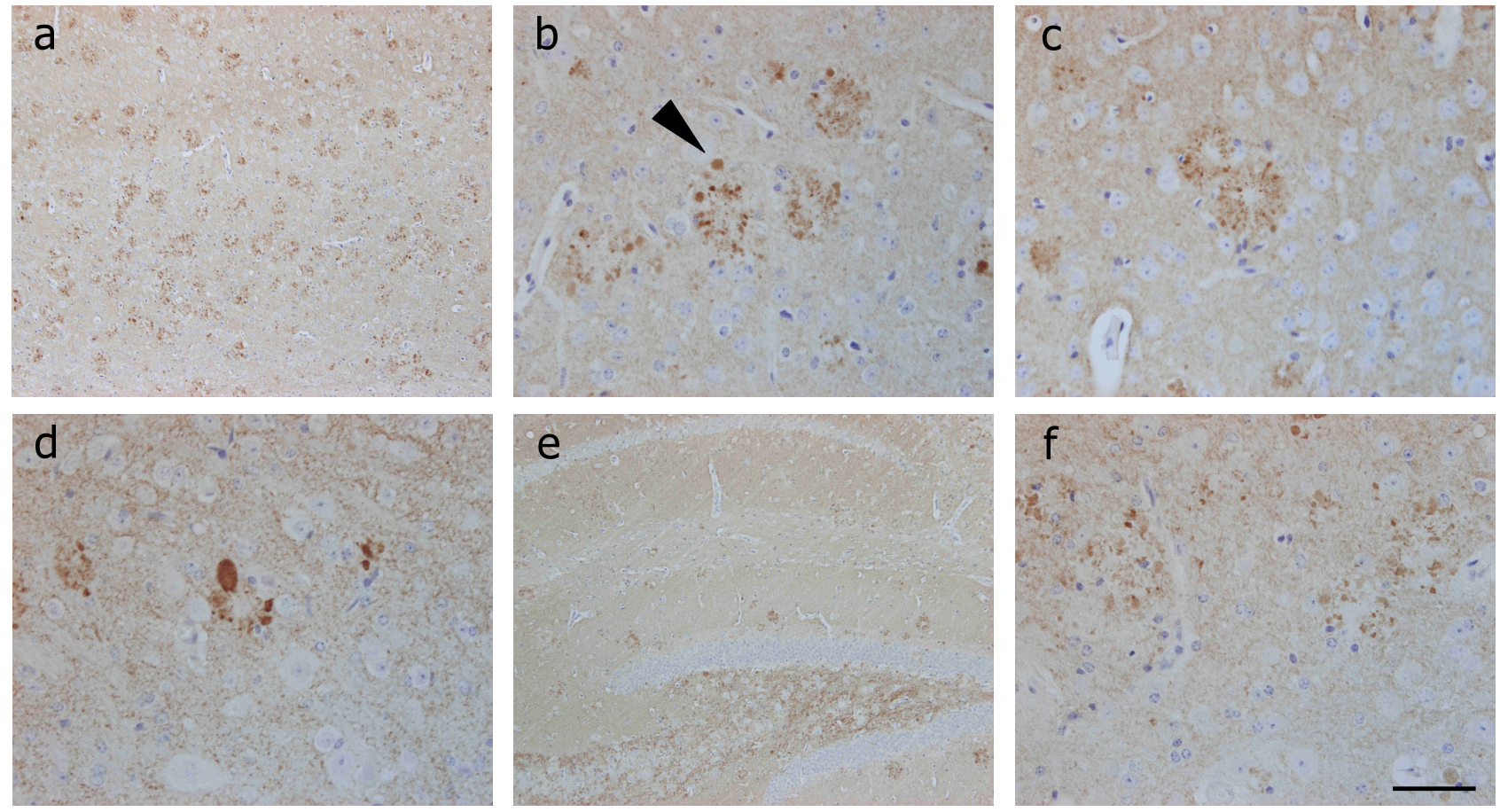

Abbildung 14: Kortikale Plaques (a-d) sind von dilatierten Zellfortsätzen mit starker Synaptobrevin-Immunreaktivität umgeben. Axonale Anschwellungen stellen sich in Form von Sphäroiden unabhängig von Plaques dar (b). Im Hippokampus fällt eine ausgeprägte synaptische Färbung auf (e). Thalamische Plaques weisen insgesamt weniger dystrophe Neuriten auf (f). Maßstab: a, e: $200 \mu$ m; b-d, f: $50 \mu \mathrm{m}$. 


\subsubsection{SNAP-25}

Für die Färbungen des SNARE-Proteins SNAP-25 wurden zwei verschiedene Primärantikörper verwendet. Einer der Antikörper wurde im Aszitesverfahren gewonnen (A); der zweite Antikörper entspricht aufgereinigtem Immunglobulin $\mathrm{G}(\mathrm{IgG})$.

Beide Antikörper weisen in der DAB-Färbung ein ähnliches Färbemuster auf. Kortikale Plaques stellen sich in der Anti-SNAP-25-Färbung als rundliche Verdichtungen vor dem Hintergrund einer diffusen Neuropilfärbung dar. Die Plaques zeigen keine prominente zentrale Aufhellung, die einem Plaquekern entsprechen könnte: Immunreaktivität liegt auch im Inneren der meisten Plaques vor; nur vereinzelt lassen sich freie Zentren ausmachen (s. Abbildungen 15 a-e). Die Plaques in der AntiSNAP-25-Färbung unterscheiden sich damit in ihrer Morphologie deutlich von Plaques, die sich mit anderen Primärantikörpern (z.B. Anti-Syntaxin-7, Anti-Syntaxin-13, Anti-Vti1b) als zirkuläre Strukturen mit einem signalarmen Zentrum darstellen lassen.

In der 100fachen Vergrößerung zeigen sich feine, faserartige Ausläufer in der Peripherie der mit Anti-SNAP-25 (A) gefärbten Plaques, die in ihrer Gesamtheit den Übergang zwischen Plaque und Umgebung verschwommenen erscheinen lassen (s. Abbildung 15 d). Sphäroide und dilatierte Axone mit hoher lokaler Signalintensität stellen sich daher nur schlecht dar.

Im Hippokampus werden Plaques in der Färbung mit Anti-SNAP-25 (A) bei insgesamt hoher Immunreaktivität des Gewebes relativ schlecht sichtbar. Sie lassen sich jedoch auch hier als verdichtete Bereiche nachweisen (s. Abbildung 15 f). Ein stärkeres Signal wird mit Anti-SNAP-25 (IgG) erzielt. Abbildung 15 g zeigt kompakte Plaques, die um den Gyrus dentatus verteilt liegen. Auch im Thalamus gelingt die Darstellung von Plaques mit dem aufgereinigten IgG-Antikörper besser (s. Abbildung 15 i), während bei guter Signalstärke im Kortex die Erfassung thalamischer Plaques mit Anti-SNAP-25 (A) schlecht möglich ist (s. Abbildung 15 h).

Ein intrazelluläres Signal wird mit keinem der beiden Antikörper erzielt, sodass von Neuropil umgebene Perikarya von der Färbung ausgespart bleiben und in ihrem blassen Zytoplasma den durch Gegenfärbung mit Hämatoxylin blau markierten Zellkern erkennen lassen.

Ein erfolgreicher Nachweis hoher Konzentrationen des Proteins SNAP-25 gelingt ebenfalls in senilen Plaques humaner AD-Gehirne (s. Abbildungen 16 a-c). Vor einer diffusen Neuropilfärbung imponieren große Plaques, in denen auch aufgetriebene Anteile einzelner Neuriten und Sphäroide sichtbar werden. Damit zeigt sich ein deutlicher Unterschied zum Färbemuster im murinen Gewebe: Während in der APPSLPS1KI-Maus zwar eine insgesamt erhöhte SNAP-25-Immunreaktivität in Plaquebereichen vorliegt, sind einzelne Neuriten und Sphäroide kaum auszumachen. Im humanen Präparat sind diese gut von der Umgebung zu differenzieren. 

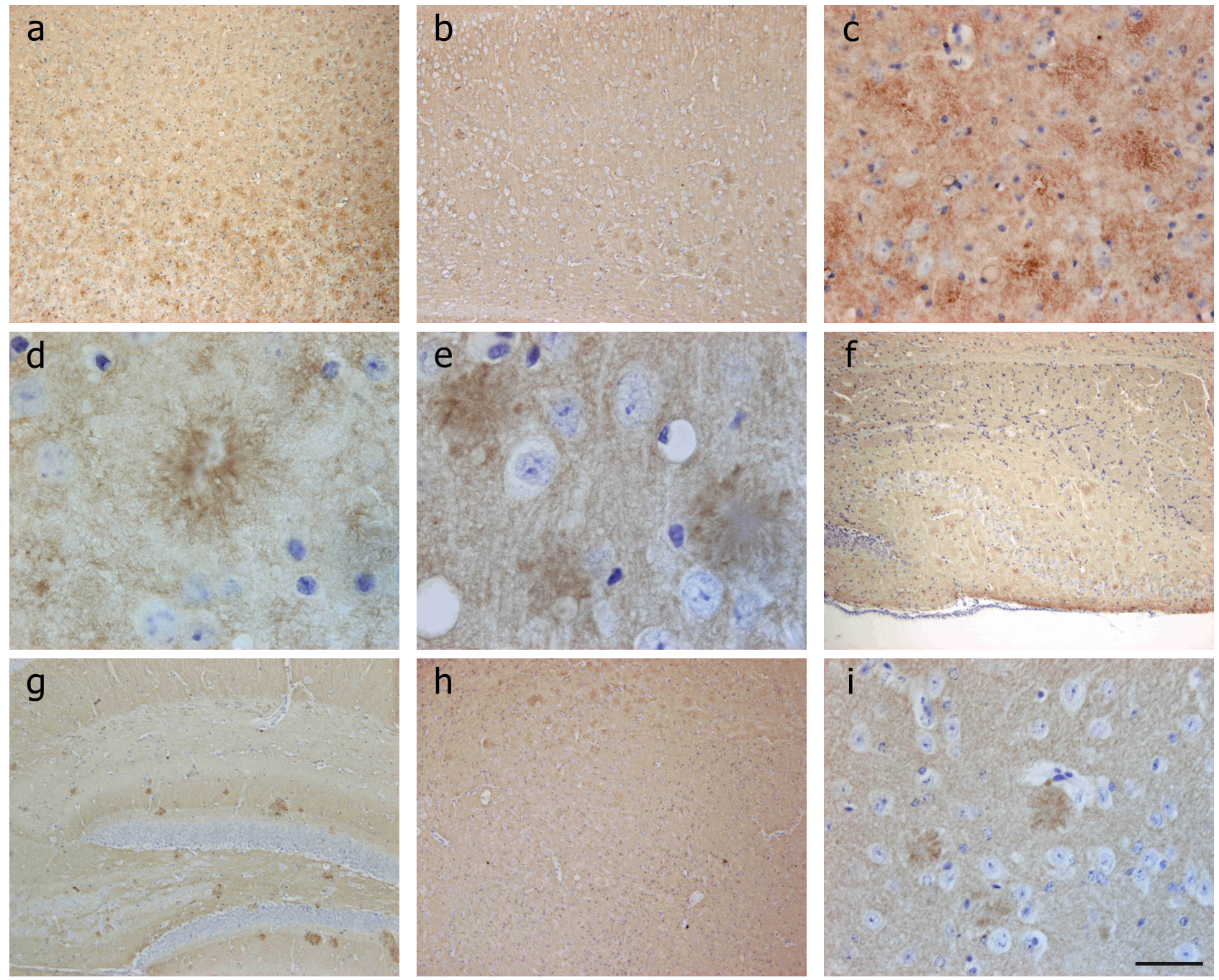

Abbildung 15: Über den gesamten Kortex der APP ${ }^{S L} P S 1 K I-M a u s$ verteilt lassen sich in der SNAP-25-Färbung Plaques nachweisen (a-e), die auch in ihrem Zentrum Immunreaktivität besitzen. Im Hippokampus $(f, g)$ lassen sich bei insgesamt relativ starker synaptischer Färbung die dystrophen Neuriten der Plaqueumgebung mit Anti-SNAP-25 (IgG) besser darstellen ( $g$ ). Auch im Thalamus ( $h$, i) zeigt Anti-SNAP-25 (IgG) bessere Ergebnisse in der Detektion neuritischer Plaques (i). SNAP-25 (A): a, $c, d, f, h ; \operatorname{SNAP-25}(I g G): b, e, g, i$. Maßstab: a, b, f, g, h: $200 \mu m ; c, i: 50 \mu m ; d$, e: $20 \mu m$.
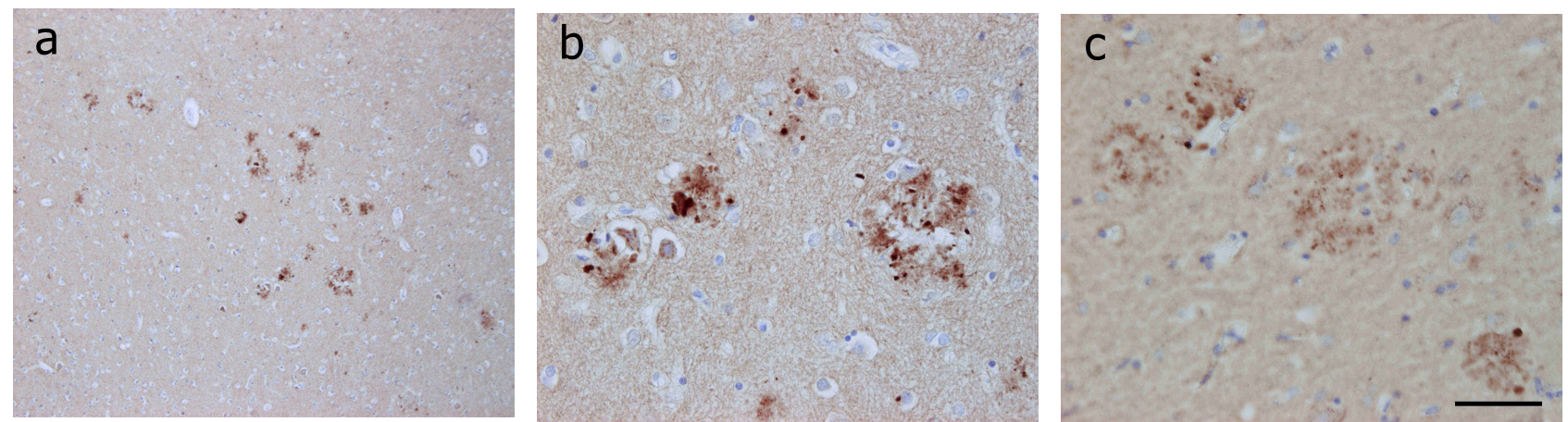

Abbildung 16: Dystrophe Neuriten und Sphäroide sind in humanen AD-Plaques mit Anti-SNAP-25-Antikörpern nachweisbar. Das Färbemuster unterscheidet sich deutlich von dem im murinen Gewebe. SNAP-25 (IgG): a, b; SNAP-25 (A): c. Maßstab: a: 200 um; b, c: $50 \mu \mathrm{m}$. 


\subsubsection{Vtilb}

DAB-Immunfärbung des SNARE-Proteins Vtilb erzeugt ein starkes Signal in Plaques der

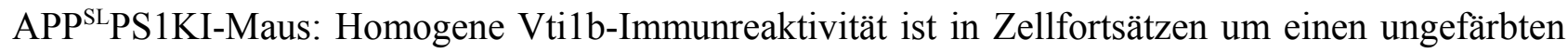
Plaquekern detektierbar.

Das Vtilb-Signal ist streng auf die Peripherie der Plaques beschränkt, sodass eine prominente zentrale Aussparung innerhalb der Plaques auffällt, die über die Hälfte des Plaquedurchmessers ausmachen kann. Gegen die Umgebung tritt der Saum aus dystrophen Neuriten als scharf begrenzte, im Anschnitt zirkuläre Struktur hervor (s. Abbildungen $17 \mathrm{a}, \mathrm{b}$ ).

Nur vereinzelt lassen sich die für andere Antikörper (z.B. Anti-Synaptobrevin, Anti-Syntaxin-13) beschriebenen bulbös aufgetriebenen Zellfortsätze nachweisen (s. Abbildung $17 \mathrm{e}$ ). Es dominiert vielmehr ein einheitliches, verschwommen erscheinendes Binnenmuster der Plaqueperipherie mit einzelnen punktförmigen Verdichtungen, die starken Vtilb-Akkumulationen entsprechen (s. Abbildung 17 b). Im Hippokampus zeigen sich Plaques unterschiedlicher Größe, die über das gesamte Ammonshorn diffus verteilt sind (s. Abbildung $17 \mathrm{c}$ ).

Im Thalamus sind Plaqueakkumulationen in geringer Dichte anzufinden (s. Abbildung $17 \mathrm{~d}$ ). Gut sichtbar ist zudem, dass die thalamischen Plaques im Mittel deutlich kleiner sind als kortikale Plaques. Abbildung 17 e zeigt relativ kleine, weit auseinander liegende Plaques des Thalamus. Charakteristisch für die Färbung des präsynaptisch exprimierten Vtilb ist zudem die prominente intrazelluläre Neuronenfärbung. Besonders im Kortex färbt sich intraneuronales Vtilb stark an, sodass ein starkes perinukleäres Signal entsteht (s. Abbildung 17 b). Intrazelluläre Färbung findet sich auch in anderen Gebieten, z. B. in den Purkinje-Zellen des Kleinhirns (s. Abbildung 17 f).

Das Neuropil, welches Plaques und intrazellulär gefärbte Neurone einbettet, wird mit dem AntiVtilb-Antikörper nicht angefärbt, sodass ein kontrastreiches Bild bei nur schwacher Hintergrundreaktion entsteht.

Plaques des humanen Alzheimer-Gehirns entgehen in allen untersuchten Fällen dem Nachweis durch den Vti-1b-Antikörper (s. Abbildung 18 a). Ein positives Signal erscheint intrazellulär in Pyramidenzellen (s. Abbildung 18 b), ohne dass pathologische Akkumulationen des Proteins in dystrophen Neuriten sichtbar werden. 

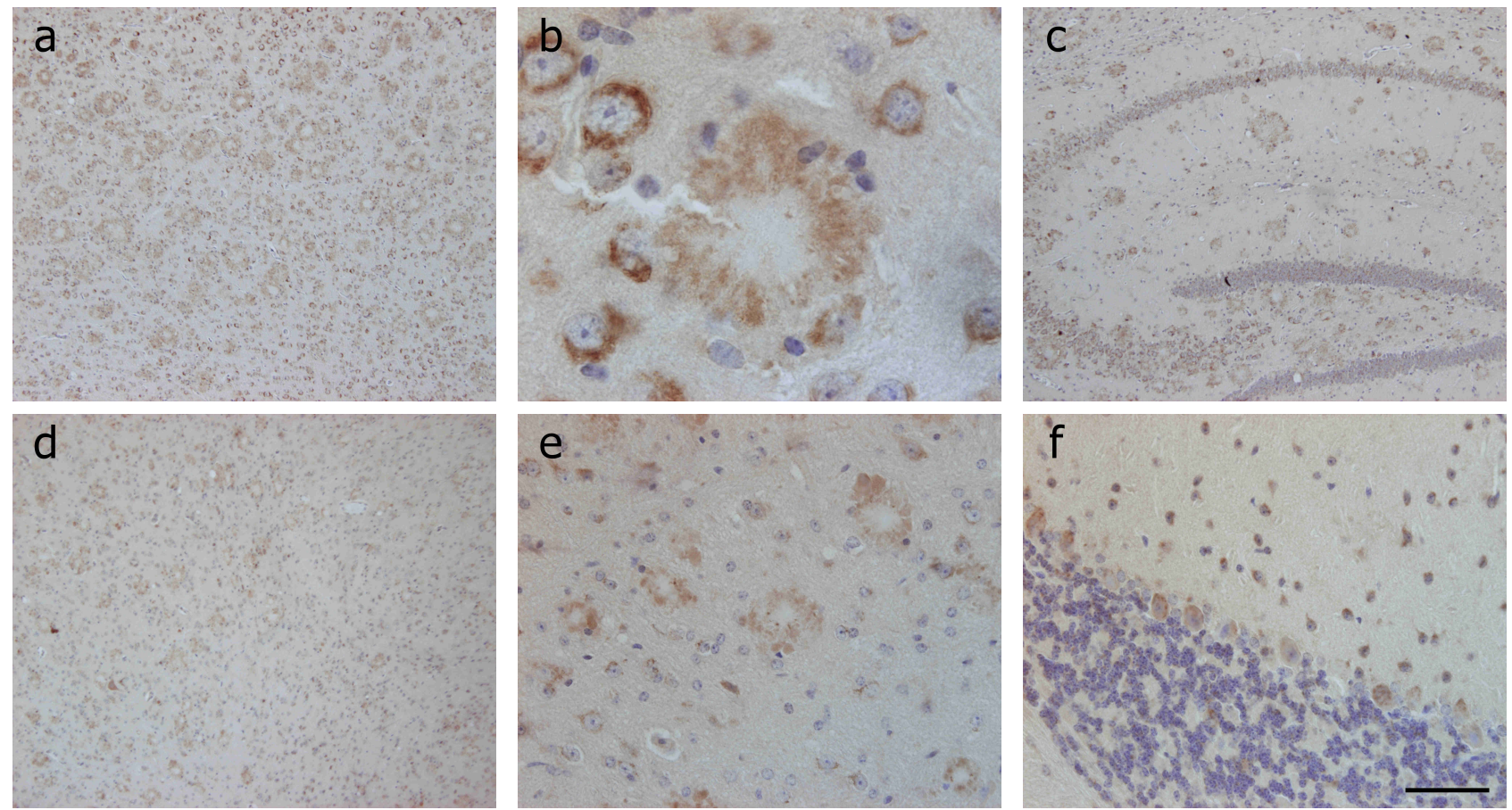

Abbildung 17: Eine ausgeprägte kortikale Plaquepathologie stellt sich in der Vti1b-Immunfärbung der APPSLPS1KI-Maus dar (a, b). Bei fehlender Synapsenfärbung des Neuropils treten Plaqueperipherie und intrazelluläres Vti1b prominent hervor (b). Starke Vti1bAkkumulationen sind auch im Hippokampus anzufinden (c). Nur wenige Plaques mit schwächeren Vti1b-Aggregationen in ihrer Umgebung aus dystrophen Neuriten sind im Thalamus nachweisbar (e). Intrazelluläre Vti1b-Immunreaktivität liegt auch in PurkinjeZellen vor (f). Maßstab: $a, c, d: 200 \mu m ; b: 20 \mu m ; e, f: 50 \mu m$.
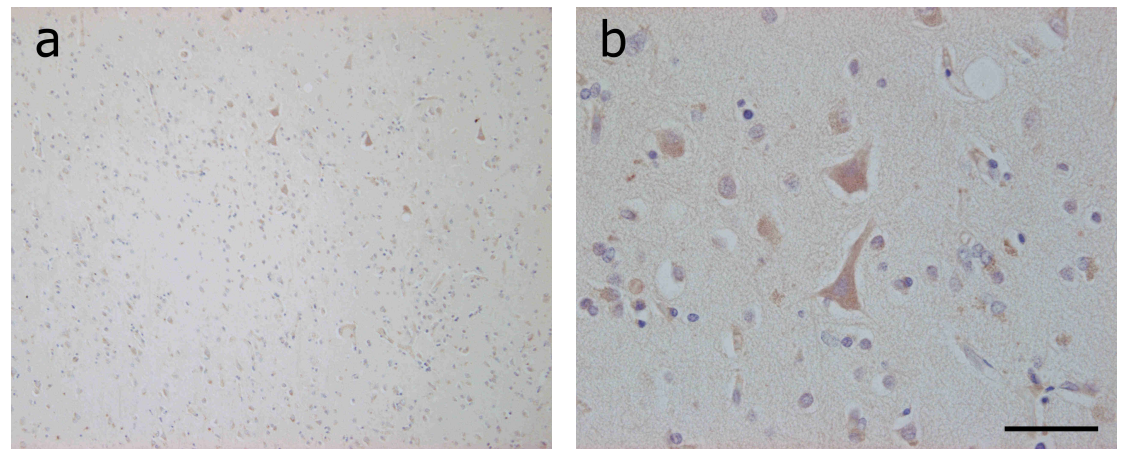

Abbildung 18: Der Nachweis pathologischer Vti1b-Akkumulationen im humanen $A D$ Gehirn gelingt mit dem getesteten Antikörper nicht (a). Pyramidenzellen des Kortex sind mit Anti-Vti1b anfärbbar (b). Maßstab: a: $200 \mu \mathrm{m} ;$ b: $50 \mu \mathrm{m}$. 


\subsection{2 $\alpha$ - und $\beta$-Synuclein}

Es wurden ein spezifischer $\alpha$-Synuclein-Antikörper (s. Abbildungen 19 a-d) sowie ein $\alpha$ - und $\beta$ Synuclein erkennender Primärantikörper (s. Abbildungen 19 e-i) getestet.

Beide Antikörper markieren in der APP ${ }^{\mathrm{SL}} \mathrm{PS} 1 \mathrm{KI}-\mathrm{Maus}$ starke Akkumulationen der SynucleinProteine um ein signalfreies Plaquezentrum. Während in der Färbung gegen $\alpha$ - und $\beta$-Synuclein dystrophe Neuriten benachbarter Plaques in der Übersichtsaufnahme miteinander zu verschmelzen scheinen (s. Abbildung 19 e), sind die in der Anti- $\alpha$-Synuclein-Färbung dargestellten Plaques deutlich voneinander abgrenzbar (s. Abbildung 19 a). Dilatationen dystropher Neuriten mit Akkumulationen der Zielproteine stellen sich besonders prominent in der Immunfärbung gegen $\alpha / \beta$ Synuclein dar. Die Peripherie der Plaques setzt sich aus einem Verband rundlicher Proteinaggregationen zusammen. Abbildung $19 \mathrm{~g}$ zeigt Anschwellungen dystropher Neuriten mit starkem $\alpha / \beta$-Synuclein-Signal in der Peripherie kortikaler Plaques (s. Pfeile).

In der spezifisch gegen $\alpha$-Synuclein gerichteten Färbung erscheinen die Auftreibungen kleiner, sodass die Plaqueperipherie insgesamt ein homogeneres Signal zeigt. Punktförmige Verdichtungen mit hoher $\alpha$-Synuclein-Signalstärke finden sich in jeder Plaque. Pathologisch veränderte Zellfortsätze, die in der Peripherie einer Plaque $\alpha$-Synuclein akkumulieren und dort in ihrem Verlauf unterbrochen werden, weist die in Abbildung $19 \mathrm{~b}$ dargestellte Plaque auf.

Weiterhin gelingt der Nachweis Synuclein-positiver Plaques im Hippokampus (s. Abbildungen 19 c, h), sowie im nur schwach betroffenen Thalamus (s. Abbildungen $19 \mathrm{~d}$, i).

Für beide Antikörper charakteristisch ist die Detektion ubiquitärer synaptischer Verschaltungen im Neuropil: In hoher Vergrößerung lässt sich ein fein granuliertes, diffus gefärbtes Umgebungsmuster ausmachen, das signalfreie Zellsomata umschließt (s. Abbildungen 19 b, g).

Plaques im Gehirn an Alzheimer-Demenz erkrankter Patienten stellen sich in der SynucleinFärbung als signalfreie Areale ohne Synuclein-Immunreaktivität dar (s. Abbildung 20). Einzelne punktförmige $\alpha$-Synuclein-positive Akkumulationen erscheinen in den Randbereichen der Plaques (s. Abbildung 20 b). Das Vorkommen $\alpha$-Synuclein-positiver dystropher Neuriten ist für senile Plaques bei der Demenz mit Lewy-Körperchen beschrieben (Wirths et al. 2000); diese Pathologie erscheint im Gehirn der an dieser Mischform der Demenzerkrankungen erkrankten Patienten jedoch weitaus ausgeprägter, sodass im vorliegenden Fall eher von einer im Rahmen der Alzheimertypischen synaptischen Dysfunktion auftretenden Proteinakkumulation ausgegangen werden muss als vom Vorliegen einer AD mit Lewy-Körperchen. Beide Antikörper verursachen entsprechend der synaptischen Funktion ihrer Zielproteine eine ausgeprägte Färbung des Neuropils. 

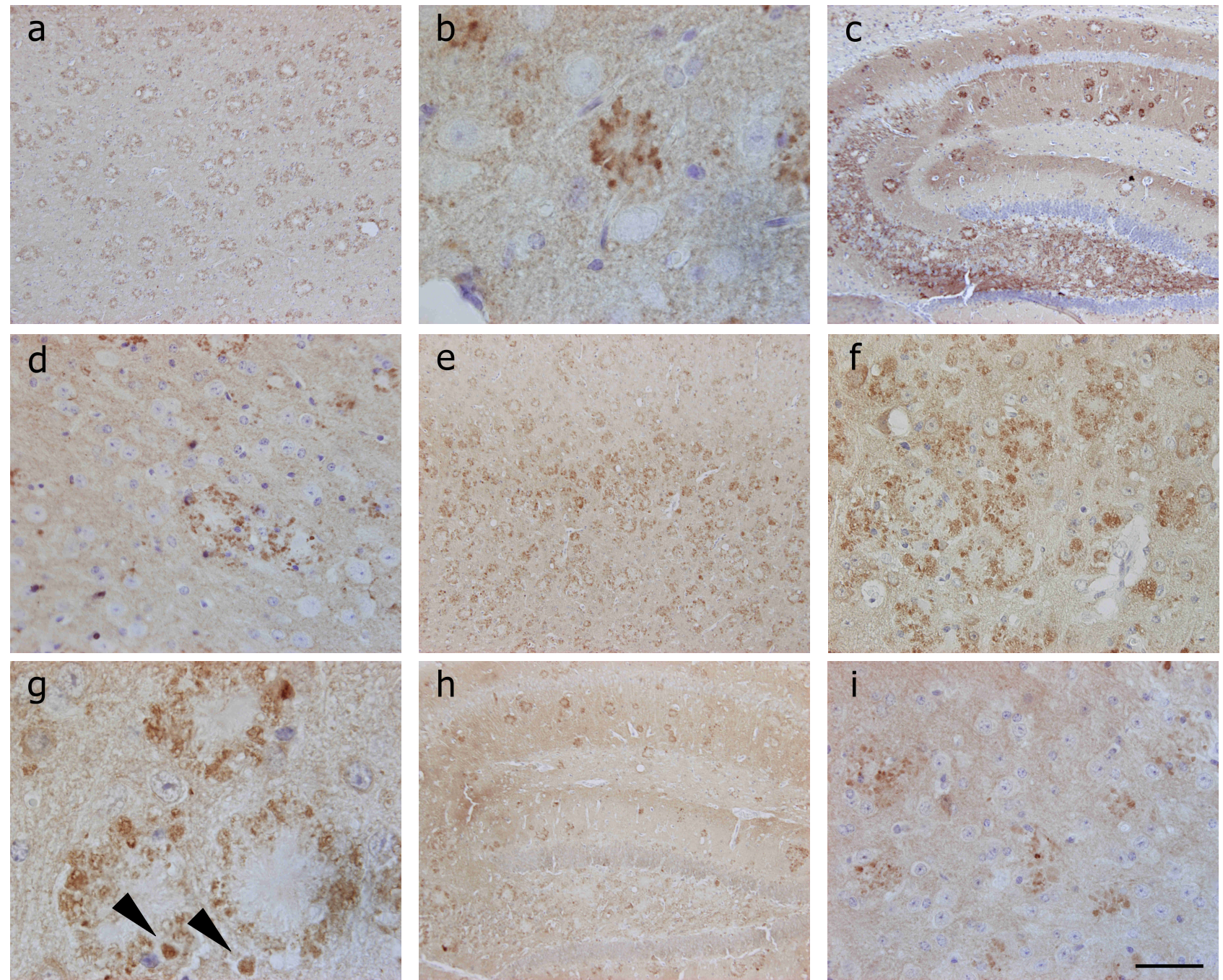

Abbildung 19: DAB-Immunfärbung von Synuclein $a(a-d)$ und Synuclein $a$ und $\beta$ (e-i) in der APPSLPS1KI-Maus markiert Akkumulationen der Proteine in dystrophen Neuriten der Plaqueperipherie. Der Plaquekern ist von Immunreaktivität ausgespart; eine diffuse synaptische Färbung verursacht ein fein granuliert wirkendes Umgebungsmuster. Plaques sind zahlreich im Kortex ( $a, b$, e-g) und Hippokampus darstellbar, während im Thalamus nur eine geringe Plaquedichte vorliegt $(d, i)$. Signalstarke Akkumulationen von Synuclein $a(b)$ und Synuclein $a$ und $\beta(g)$ sind in aufgetriebenen Zellfortsätzen der Plaqueperipherie und in Sphäroiden nachweisbar. Maßstab: a, c, e, h: $200 \mu m ; d, f$, i: $50 \mu m ; b, g: 20 \mu m$.
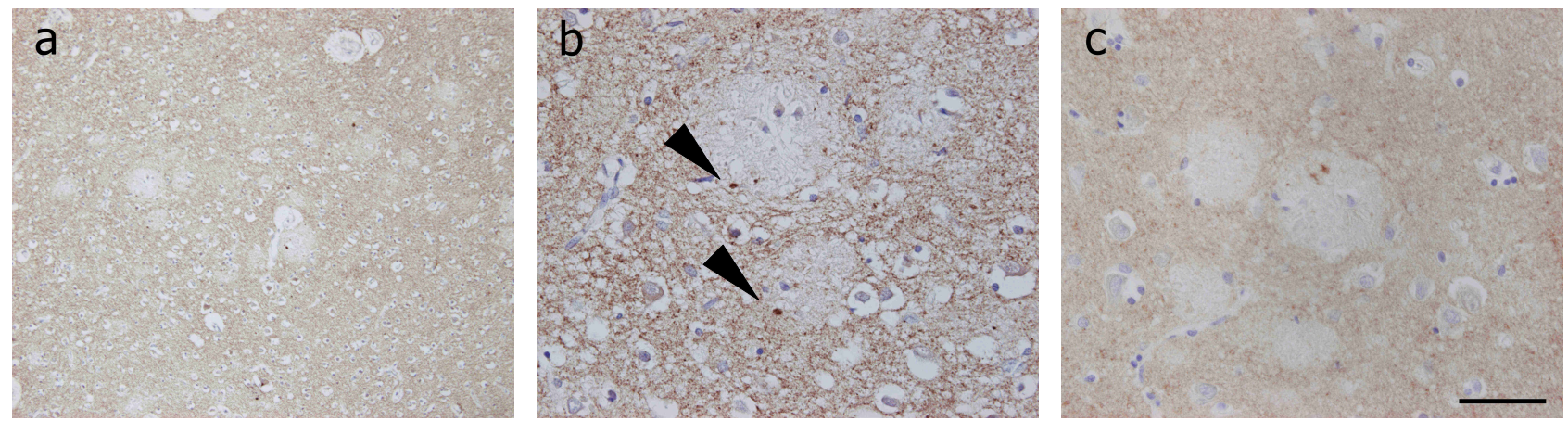

Abbildung 20: Plaques im humanen AD-Gehirn stellen sich in der DAB-Färbung von Synuclein $a(a, b)$ und Synuclein $a$ und $\beta$ (c) als signalfreie Areale dar. Das umgebende Neuropil ist angefärbt. Akkumulationen von Synuclein a sind in der Umgebung kortikaler Plaques nachweisbar. Maßstab: a: $200 \mu m$; b, c: $50 \mu m$. 


\subsubsection{Synaptopodin}

In der DAB-Färbung des Strukturproteins Synaptopodin im Gehirn der APPSLPS1KI-Maus imponieren Plaques als kreisrunde Aussparungen vor einem flächenhaft angefärbten Neuropil. Sie sind frei von Synaptopodin-Immunreaktivität und auch in ihren Randbereichen lassen sich keine prominenten Synaptopodin-Akkumulationen in dystrophen Neuriten nachweisen. Der Kortex zeigt eine besonders hohe Plaquedichte mit runden, dicht nebeneinander liegenden Plaques (s. Abbildungen 21 a-c). Höhere Vergrößerungen zeigen, dass Plaquebereiche sich scharf gegen ihre Umgebung abgrenzen (s. Abbildung $21 \mathrm{c}$ ). Filiforme Strukturen scheinen sich sternförmig im Zentrum der Plaque zu vereinen und bilden dort einen kompakten Kern aus. Allerdings gelingt diese Beobachtung unter direkter mikroskopischer Sicht besser und kann auf Fotografien nur unzureichend abgebildet werden (s. Abbildung $21 \mathrm{c}$ ). Teilweise ist in langen Zellfortsätzen in Nachbarschaft zu Plaques Synaptopodin-Immunreaktivität nachweisbar. Diese Neuriten winden sich in ihrem Verlauf um die signalfreien Plaques (s. Abbildung $21 \mathrm{c}$ ).

Plaques in der faserreichen Region des Thalamus sind ebenfalls umgeben von einem zarten Geflecht Synaptopodin-positiver Neuriten (s. Abbildung 21 e). Purkinje-Zellen und Faserzüge des zerebellären Marklagers zeigen ebenfalls starke Synaptopodin-Immunreaktivität (s. Abbildung 21 f). Auch im Hippokampus stellen sich Plaques in großer Anzahl als ungefärbte Areale ohne Synaptopodin-Immunreaktion dar (s. Abbildung $21 \mathrm{~d}$ ).

Im Gegensatz zum murinen Gewebe liegen hohe Konzentrationen des Proteins Synaptopodin in humanen Plaques vor, während nur der Plaquekern von der Färbung ausgespart bleibt. In der Umgebung der Plaque lassen sich Sphäroide darstellen (s. Abbildung 22 b). Die Anfärbbarkeit des Neuropils ist im Vergleich zum murinen Gewebe schwach ausgeprägt. Insgesamt werden jedoch nur wenige Plaques im humanen AD-Gehirn von der Synaptopodin-Färbung erfasst (s. Abbildung 22 a). 

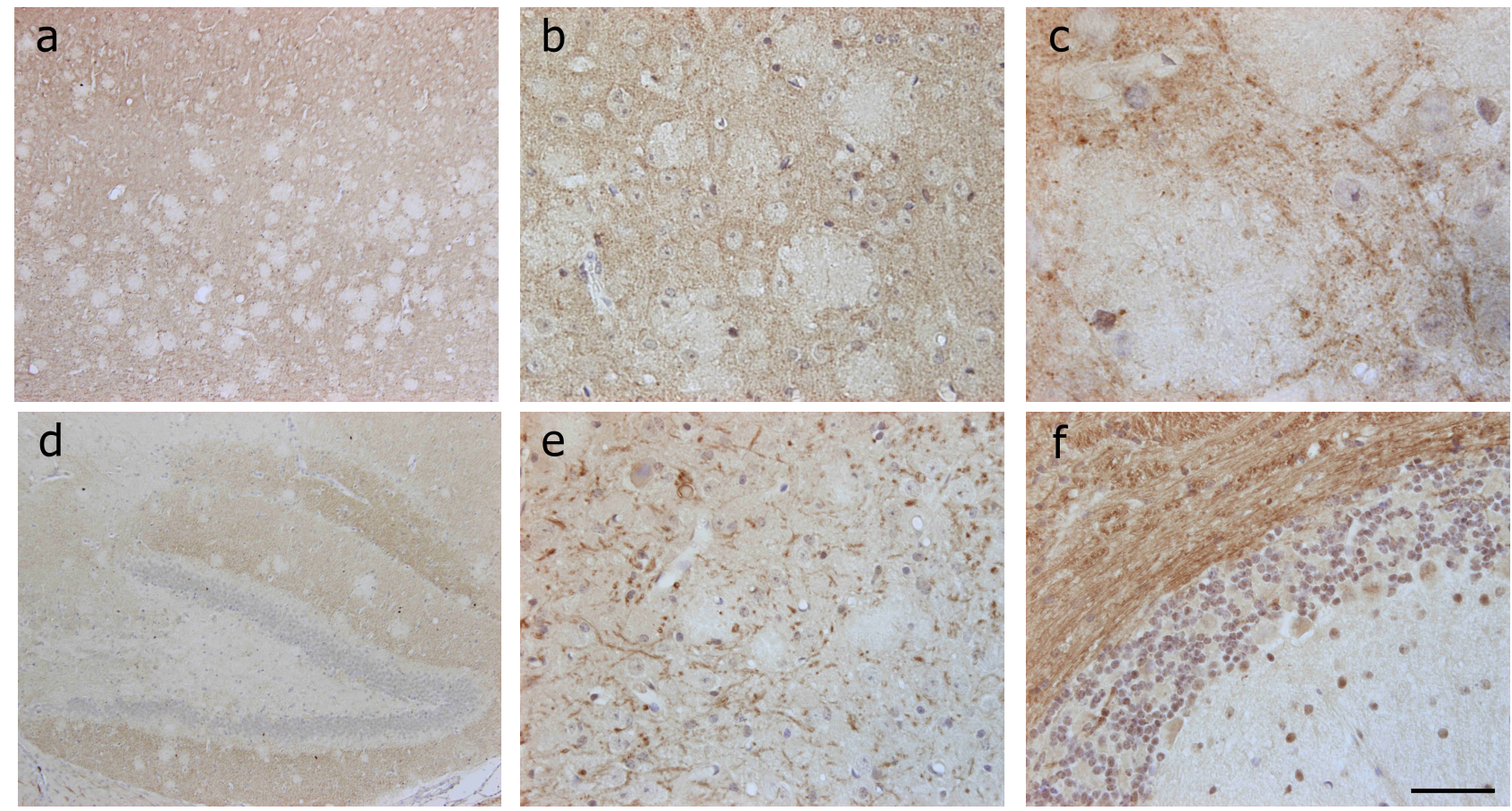

Abbildung 21: Kortikale (a-c) und hippokampale (d) Plaques stellen sich in der Immunfärbung von Synaptopodin in der APP ${ }^{S L} P S 1 K I-$ Maus als signalfreie Areale dar, die von gefärbtem Neuropil umgeben sind. Synaptopodin-Färbung detektiert Zellfortsätze ohne pathologische Veränderungen im umgebenden Neuropil kortikaler (c) und thalamischer (e) Plaques sowie im Marklager des Kleinhirns (f). Maßstab: a, d: $200 \mu m ; b, e, f: 50 \mu m ; c: 20 \mu m$.
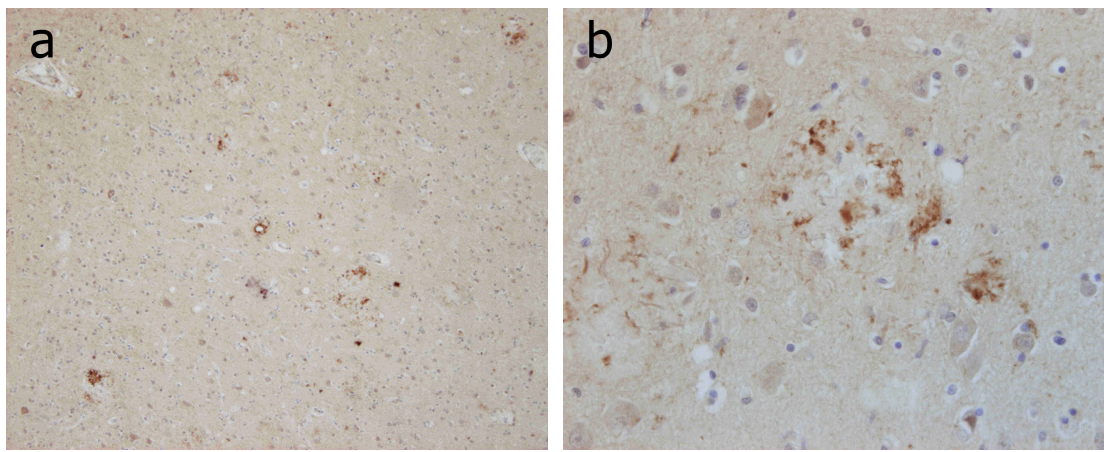

Abbildung 22: Synaptopodin-Immunreaktivität in dystrophen Neuriten humaner $A D$ Plaques und Sphäroiden (b). Ingesamt sind nur wenige Plaques mit Anti-Synaptopodin detektierbar (a). Maßstab: a: $200 \mu \mathrm{m} ;$ b: $50 \mu \mathrm{m}$. 


\subsubsection{Proton-ATPase}

Mit dem Antikörper gegen die 116-kDa-Untereinheit der Proton-ATPase gelingt der Nachweis zahlreicher pathologisch dilatierter Neuriten der Plaqueperipherie: Ein signalfreies Plaquezentrum wird von vielen bulbös aufgetriebenen Zellfortsätzen mit starker Immunreaktivität umsäumt. Abbildung 23 c zeigt einen dystrophen Neuriten mit starker Anreicherung des Zielproteins, der in Richtung des Plaquezentrums verläuft und abzubrechen scheint. Weitere verdichtete Bereiche innerhalb der Plaque sind auszumachen und sprechen für eine lokale Akkumulation der ProtonATPase. Die Binnenstruktur der Plaques ähnelt dem für Synaptobrevin beschriebenen Bild nebeneinander liegender bulböser Auftreibungen dystropher Neuriten. Das helle Zentrum der Plaques erscheint nicht leer; vielmehr entsteht auch hier (v.a. unter direkter mikroskopischer Sicht) der Eindruck, dass Ausläufer aus der Plaqueperipherie in das Innere der Plaque reichen (s. Abbildung $23 \mathrm{c}$ ). Prominente Plaques erstrecken sich über die gesamte Hippokampusformation (s. Abbildung 23 d). Plaqueformationen mit schwachen Akkumulationen der Proton-ATPaseUntereinheit werden im Thalamus sichtbar (s. Abbildung 23 e).

Vor nur schwach angefärbtem Neuropil treten die Plaques kontrastreich hervor. Vereinzelt lassen sich Zellsomata anfärben. Abbildung 23 b zeigt eine Pyramidenzelle mit hoher intrazellulärer Immunreaktivität. Auch die zerebellären Purkinje-Zellen weisen ein deutliches intrazelluläres Signal auf (s. Abbildung 23 f).

Entgegen der guten Darstellbarkeit neuritischer Pathologie im murinen Gewebe durch den ProtonATPase-Antikörper ist die DAB-Immunfärbung humaner AD-Plaques in allen untersuchten Fällen wenig erfolgreich. Nur vereinzelt lassen sich Akkumulationen des Proteins nachweisen, die jedoch nicht eindeutig plaqueassoziiert sind. Abbildung 24 b zeigt DAB-Färbung, die möglicherweise aus dystrophen Neuriten einer Plaque stammt. Intrazelluläre DAB-Färbung ist auch im humanen Gewebe zu detektieren (s. Abbildung 24 a). 

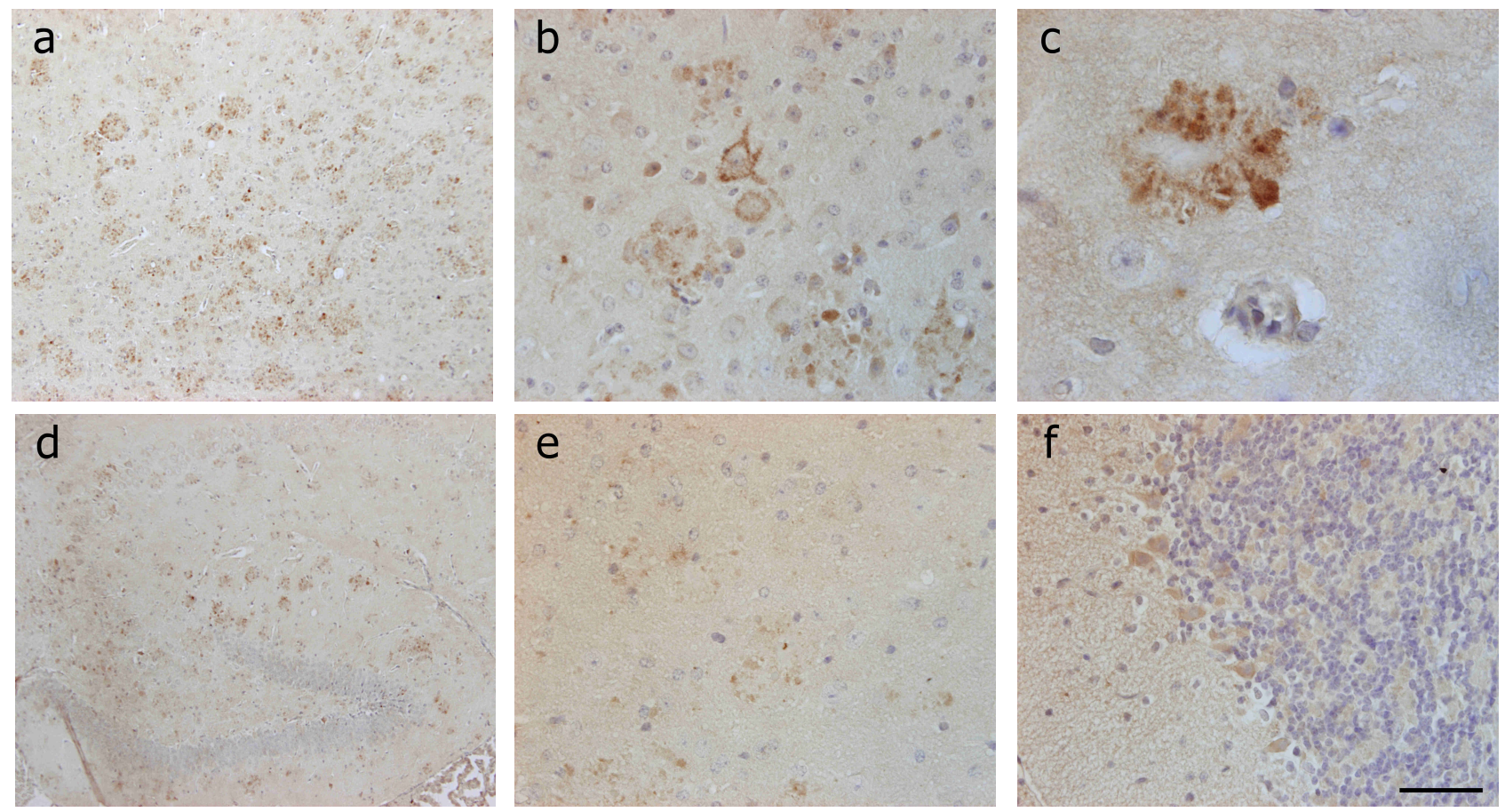

Abbildung 23: In der APPSLPS1KI-Maus sind große Anschwellungen dystropher Neuriten in der DAB-Immunfärbung mit dem Antikörper gegen die 116kDA-Untereinheit der Proton-ATPase darstellbar. Besonders ausgeprägt stellt sich die Pathologie im Kortex (a-c) und Hippokampus dar. Einzelne stark aufgetriebene Fortsätze werden in der Plaqueperipherie sichtbar. Starke intrazelluläre Anfärbbarkeit liegt in Pyramidenzellen (b) und in Purkinje-Zellen ( $f$ ) vor. Nur wenige Plaques mit signalarmer Umgebung sind im Thalamus nachweisbar. Maßstab: a, d: $200 \mu m ; b, e, f: 50 \mu m ; c: 20 \mu m$.
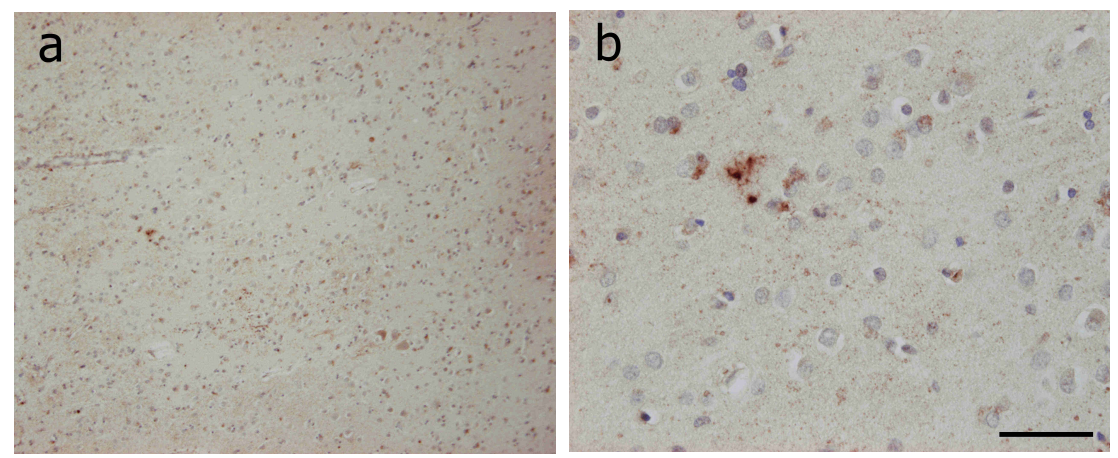

Abbildung 24: Humane AD-Plaques entgehen in allen untersuchten Fällen weitgehend der Detektion durch den Primärantikörper gegen die Proton-ATPase-Untereinheit. Ein intrazelluläres Signal erscheint in Pyramidenzellen (a). Nur vereinzelt lassen sich Akkumulationen des Proteins nachweisen, die jedoch nicht eindeutig plaqueassoziiert sind (b). Maßstab: a: $200 \mu \mathrm{m} ;$ b: $50 \mu \mathrm{m}$. 


\subsubsection{APP}

Die Färbung mit einem affinitätsgereinigten Primärantikörper gegen APP bestätigt das Vorliegen ausgeprägter neuritischer Pathologie in der 6 Monate alten APP ${ }^{\mathrm{SL}} \mathrm{PS} 1 \mathrm{KI}-\mathrm{Maus}$ : Kortikal lassen sich reichlich dystrophe Zellfortsätze mit starken APP-Anreicherungen nachweisen (s. Abbildungen 25 a-d). Der Kern der Plaques bleibt signalfrei, sodass die kugelförmig aufgetriebenen Neuriten der Plaqueperipherie der Detektion der Plaques dienen. Im Vergleich mit synaptischen Markern fällt auf, dass sich pathologisch deformierte Zellfortsätze in der APP-Färbung besonders prominent darstellen. Neben den nicht direkt in Beziehung zu Plaques stehenden Sphäroiden (s. Abbildung 25 b) mit hoher APP-Signalintensität werden perlschnurartig aufgereihte APP-Akkumulationen in axonalen Anschwellungen sichtbar (s. Abbildung 25 d).

Es bestätigt sich zudem das charakteristische Expressionsmuster des APP-Transgens im Gehirn der

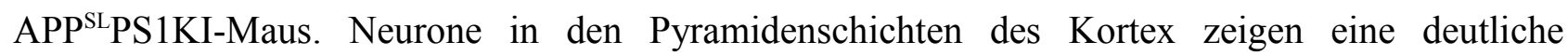
intrazelluläre APP-Färbung (s. Abbildung 25 c), die die für das Mausmodell beschriebene kortikale APP-Expression bestätigt (Casas et al. 2004). Im Thalamus hingegen färbt sich lediglich das in dystrophen Neuriten akkumulierende APP der Plaqueumgebung an, während ein intrazelluläres Signal fehlt (s. Abbildung 25 f). Der pathologische Befund APP-positiver Sphäroide und dystropher Neuriten ist im Thalamus - entsprechend den Resultaten aus den DAB-Färbungen der Synapsenmarker - sehr viel schwächer ausgeprägt als im Kortex. Auch im Hippokampus sind massive APPAkkumulationen darstellbar (s. Abbildung 25 e).

Eine diffuse Hintergrundfärbung des Neuropils bleibt aus.

APP-positive Akkumulationen in dystrophen Neuriten sind mit dem APP-Antikörper auch in humanen AD-Plaques nachweisbar. Die neuritische Pathologie der Plaqueperipherie zeigt in den untersuchten humanen Fällen einen sehr viel geringeren Ausprägungsgrad als im murinen Gewebe, sodass sich allenfalls APP-verdichtete, rundliche Auftreibungen vor einem diffus angefärbten, als Plaque auszumachenden Hintergrund anfärben (s. Abbildungen 26 a, b). Auch eine intraneuronale Anfärbbarkeit liegt vor (s. Abbildung 26 c). 

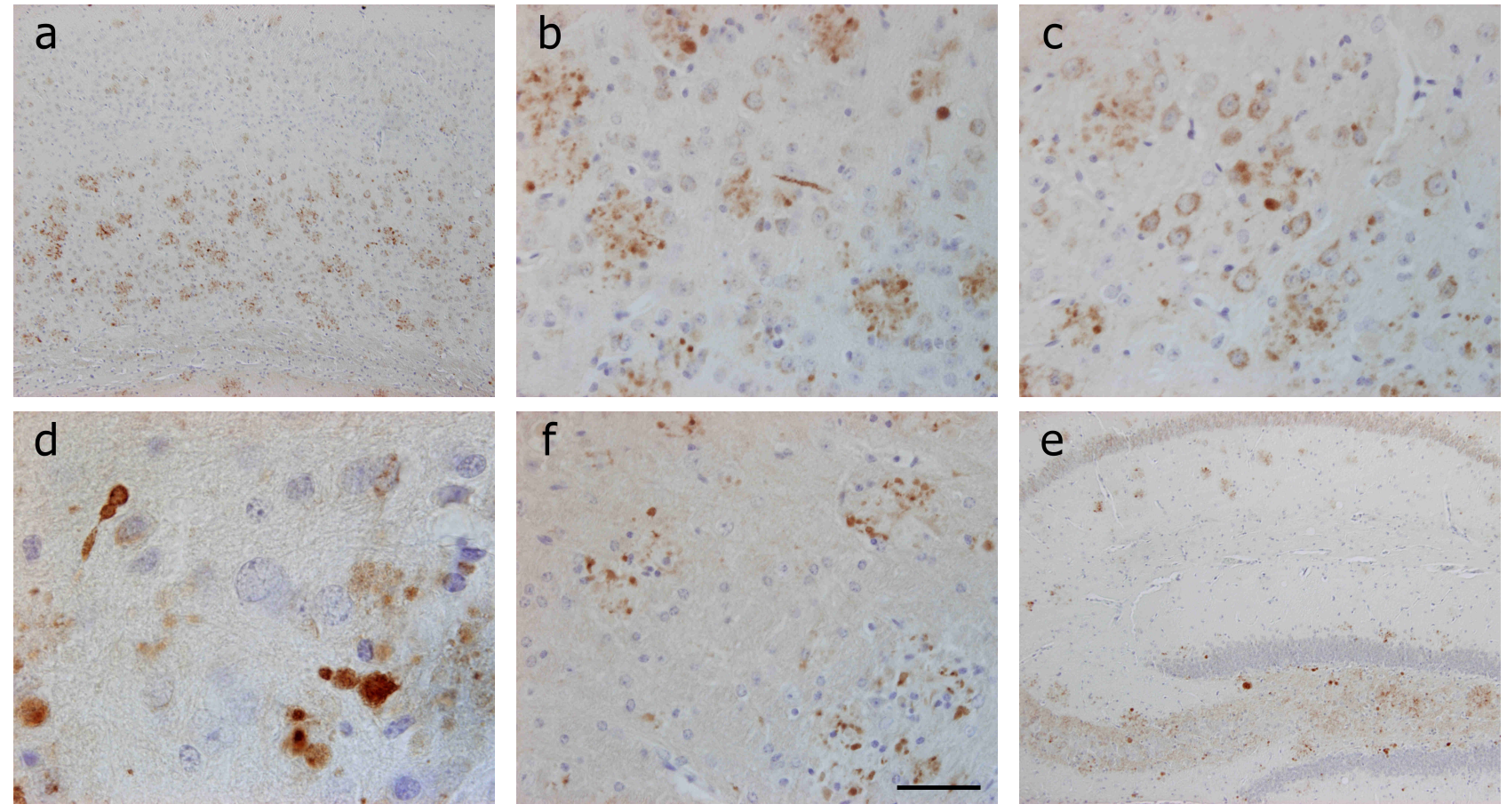

Abbildung 25: In der APPSLS1KI-Maus akkumuliert APP in dystrophen Neuriten und Sphäroiden des Kortex (a-d), Hippokampus (e) und Thalamus ( $f$ ). Der A $\beta$-Kern ist von bulbös aufgetriebenen Zellfortsätzen eingeschlossen. Axonale Anschwellungen weisen hohe APPImmunreaktivität auf und markieren pathologische Akkumulationen des Proteins (d). APP-Expression liegt in kortikalen Neuronen vor (c). Im Thalamus ist keine intrazelluläre Färbung detektierbar; APP-Akkumulationen in der Umgebung thalamischer Plaques sind schwächer ausgeprägt (f). Maßstab: a, e: $200 \mu \mathrm{m} ;$ b, c, f: $50 \mu \mathrm{m} ;$ d: $20 \mu \mathrm{m}$.
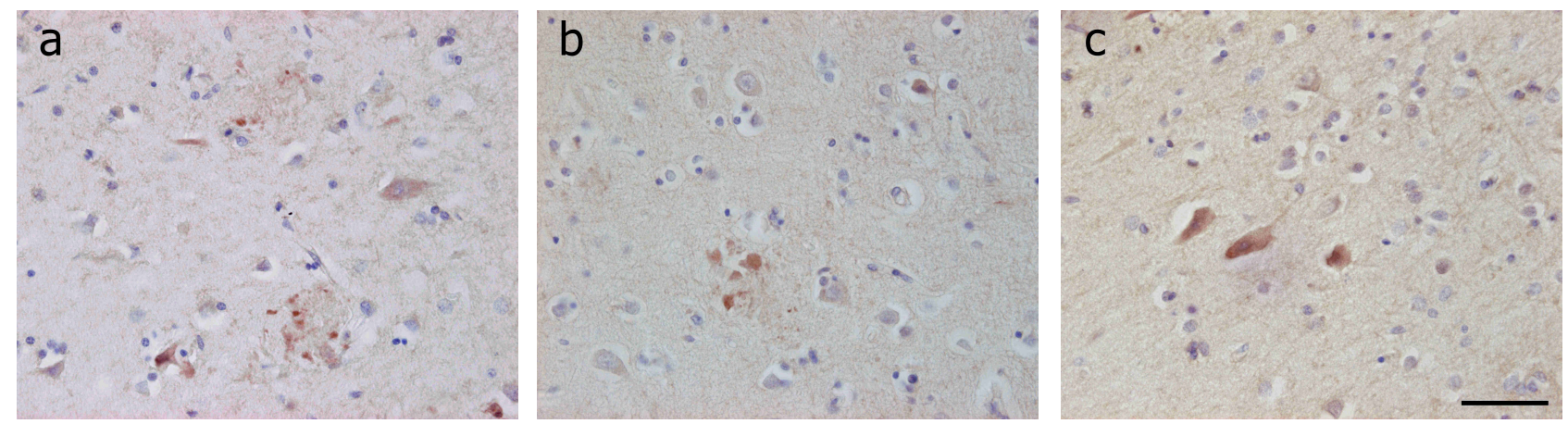

Abbildung 26: APP-Akkumulationen sind auch in dystrophen Neuriten der Umgebung humaner AD-Plaques nachweisbar ( $a, b)$. Auch intraneuronales APP färbt sich an (c). Maßstab: $50 \mu \mathrm{m}$. 


\subsection{Immunfluoreszenzfärbung von A $\beta$, APP und Vti1b}

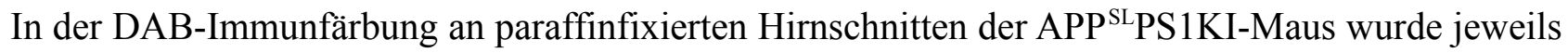
ein einzelnes Zielprotein mit einem Antikörper markiert. Die Fluoreszenzdoppelfärbung ermöglicht die gleichzeitige Lokalisationsbestimmung zweier Zielproteine. Fluoreszenzdoppelfärbungen wurden an paraffinfixierten Präparaten des Kortex und des Thalamus 6 Monate alter APP ${ }^{\text {SLPS1KI- }}$ Mäuse durchgeführt. Dabei wurden Primärantikörper zur Detektion von $A \beta$, seinem Vorläufermolekül APP und dem präsynaptischen Protein Vtilb eingesetzt und jeweils zwei dieser Antikörper miteinander kombiniert. Die Färbung erlaubt eine qualitative Beurteilung der unterschiedlichen Verteilungsmuster der Proteine in den ausgewählten Hirnregionen. Vtilb wurde aus den getesteten synaptischen Markern exemplarisch für die Fluoreszenzdoppelfärbungen ausgewählt.

Die Doppelfärbung mit dem gegen A $\beta$ gerichteten 4G8-Antikörper und dem 23850-APP-Antikörper zeigt im Kortex der 6 Monate alten Maus einen dicht kompaktierten A $\beta$-Plaquekern, der von APPAkkumulationen in dystrophen Neuriten umgeben ist (s. Abbildung 27 a). Es lassen sich zahlreiche APP-positive Sphäroide darstellen, die nicht in unmittelbarer Beziehung zu A $\beta$-Ablagerungen stehen (s. Pfeile in Abbildung 27 a). Weiterhin gelingt der positive Nachweis von intraneuronalem APP, das als perinukleäres Signal erscheint (s. Abbildungen $27 \mathrm{c}, \mathrm{d}$ ). A $\beta$ ist fast ausschließlich in Form von Plaques anzufinden und nur vereinzelt lässt sich intrazelluläres $A \beta$ in der Umgebung der Zellkerne nachweisen.

Vtilb ist wie APP in dystrophen Neuriten der Plaqueperipherie nachweisbar: Die Doppelfärbung

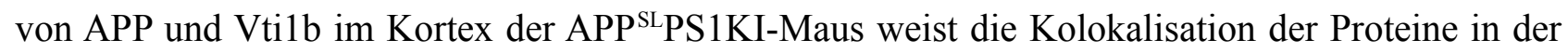
Umgebung des A $\beta$-Kerns nach (s. Abbildung 28 a). Zudem fallen Unterschiede im Akkumulationsverhalten von Vtilb und APP in der Umgebung der Amyloidplaques auf: Während sich Vtilb-Aggregationen eher homogen-flächig um einen $A \beta$-Plaquekern verteilen und einzelnen Zellfortsätzen nicht zugeordnet werden können (s. Abbildung 29 a), stellen sich APP-haltige dystrophe Neuriten der Plaqueperipherie als bulbös aufgetriebene Strukturen dar.

Des Weiteren lässt sich eine kortikale Expression des Proteins Vtilb durch starke intrazelluläre Immunreaktivität bestätigen (s. Abbildungen 29 a, 28 c). Die Doppelfärbung von APP und Vtilb weist das Vorliegen beider Proteine in Neuronen und deren Fortsätzen nach (s. Abbildungen 28 a, d).

Die $A \beta / A P P-$ und A $\beta / V$ tilb-Doppelfärbungen zeigen kompaktes Amyloid in thalamischen Plaques der 6 Monate alten Maus, während ein intrazelluläres A $\beta$-Signal fehlt (s. Abbildungen 27 f, h; 29 f, 
h). APP ist in thalamischen Neuronen ebenfalls nicht detektierbar (s. Abbildungen $27 \mathrm{~g}, \mathrm{~h}$ ).

Weiterhin scheint auch die Umgebung der in Abbildung 27 e gezeigten Plaques des Thalamus allenfalls schwache APP-Akkumulationen aufzuweisen. Ein deutliches APP-Signal aus dystrophen Neuriten der Plaqueperipherie, das für kortikale Plaques eindeutig nachzuweisen ist (s. Abbildungen 27 a, d), fehlt im Thalamus. Auch in der Vtilb-Fluoreszenzfärbung können Akkumulationen des Proteins in der Umgebung von A $\beta$ nicht eindeutig nachgewiesen werden (s. Abbildungen 29 e, h): Die Peripherie der gezeigten Plaques ist frei von Vtilb-Immunreaktivität. 
Kortex

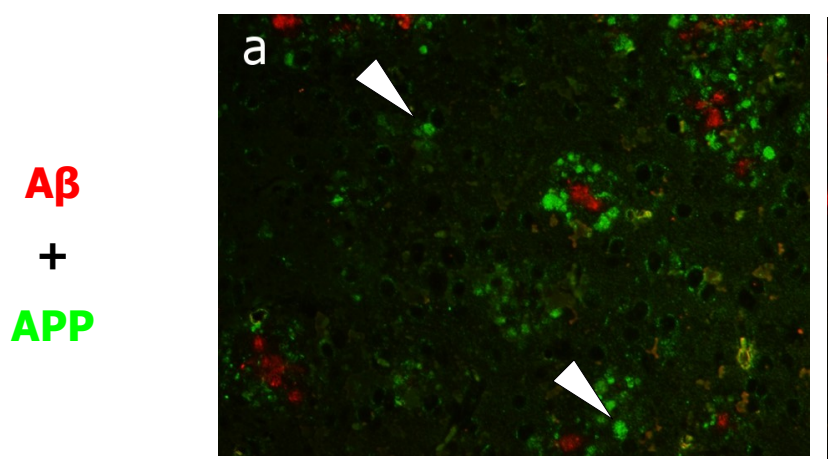

b

$\mathbf{A} \boldsymbol{\beta}$

$+$

Zellkerne

APP

$+$

\section{Zellkerne}

$\mathbf{A} \boldsymbol{\beta}$

$+$

APP

$+$

Zellkerne
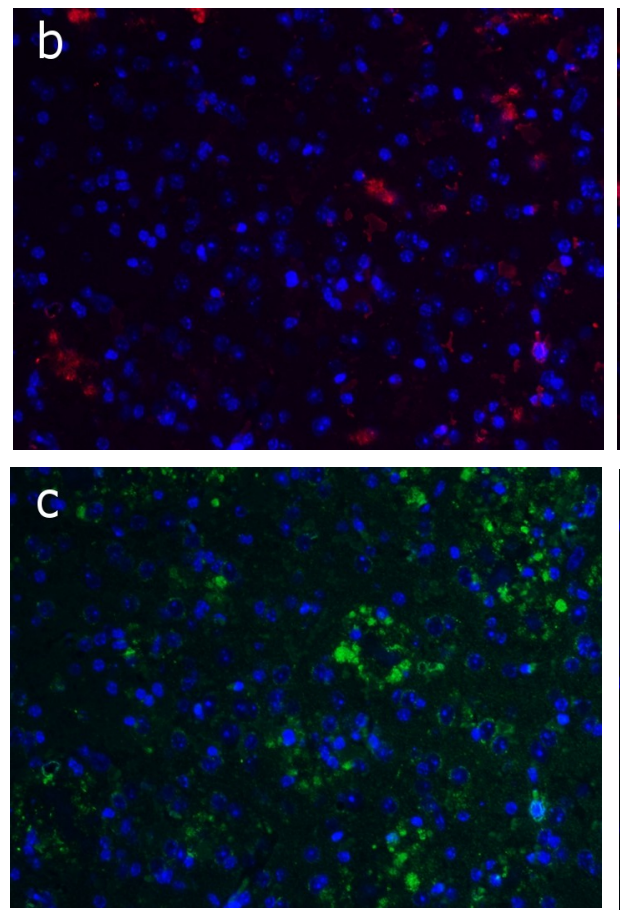
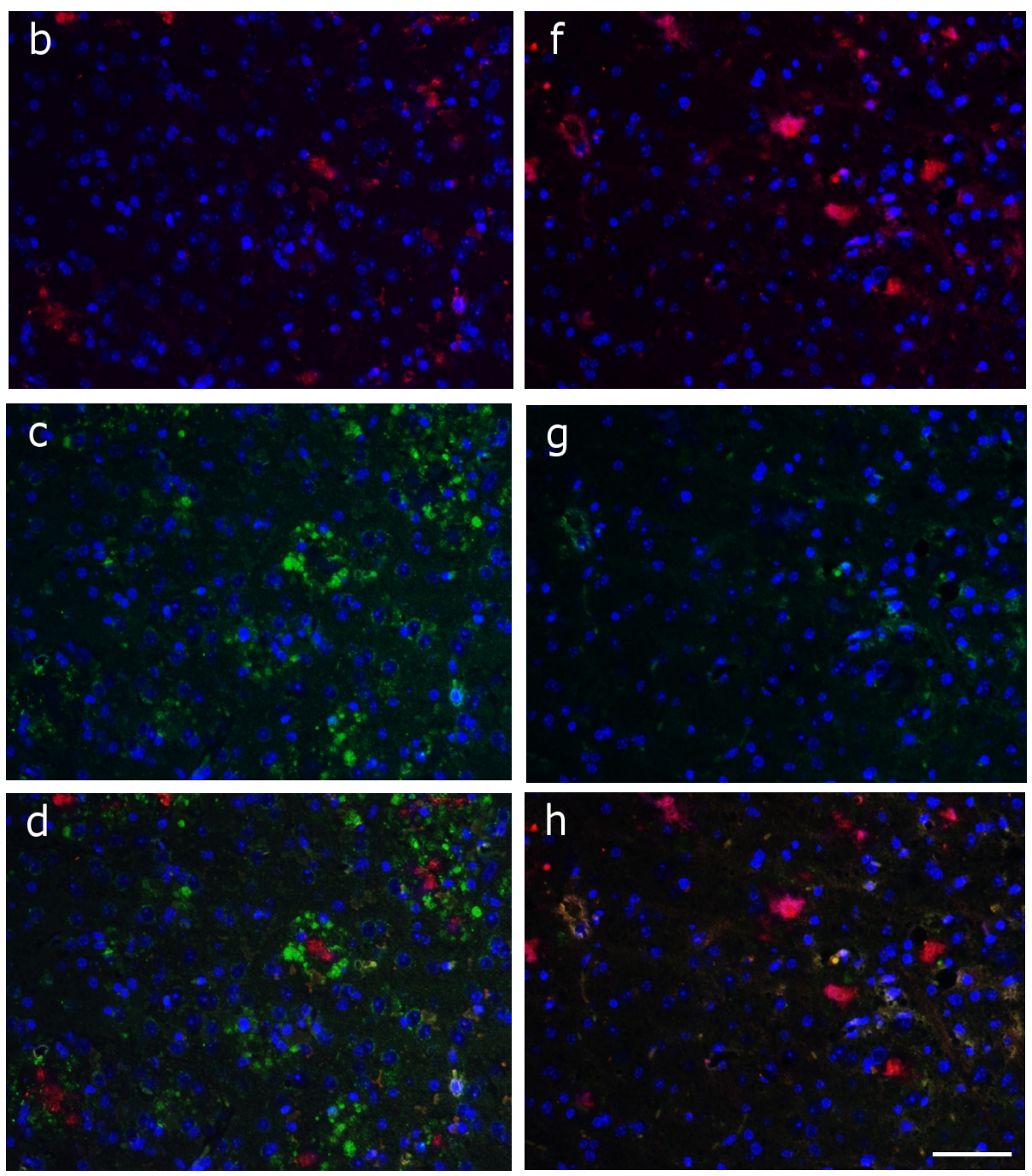

Abbildung 27: Immunfluoreszenzfärbung von $A \beta$ und APP im Kortex (a-d) und Thalamus (e- $h$ ) der 6 Monate alten APPSLS1KI-Maus. Aß-Färbung markiert Amyloidkerne kortikaler (b) und thalamischer (f) Plaques. APP akkumuliert im Kortex in der Umgebung des Plaquekerns; die Anschwellungen einzelner dystropher Neuriten sind gut zu erkennnen (c, d). Das starke APPSignal fehlt im Thalamus. Maßstab: $50 \mu \mathrm{m}$. 

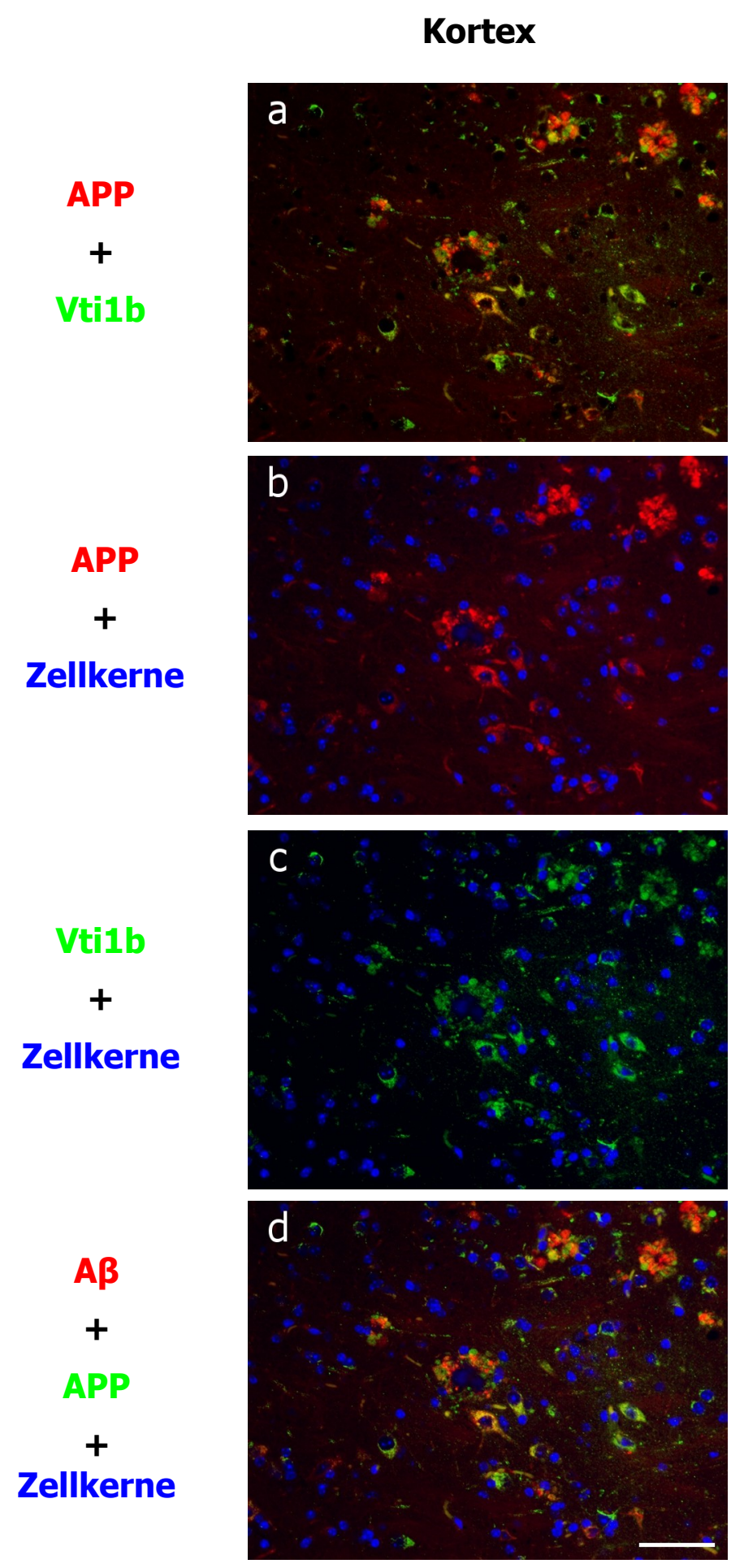

Abbildung 28: Immunfluoreszenzfärbung von APP und Vti1b im Kortex der 6 Monate alten $A P P^{S L} P S 1 K I-M a u s$. APP und Vti1b liegen gemeinsam in der Umgebung kortikaler Plaques vor $(a, d)$ und sind intraneuronal nachweisbar. Maßstab: $50 \mu \mathrm{m}$. 


\section{Kortex}
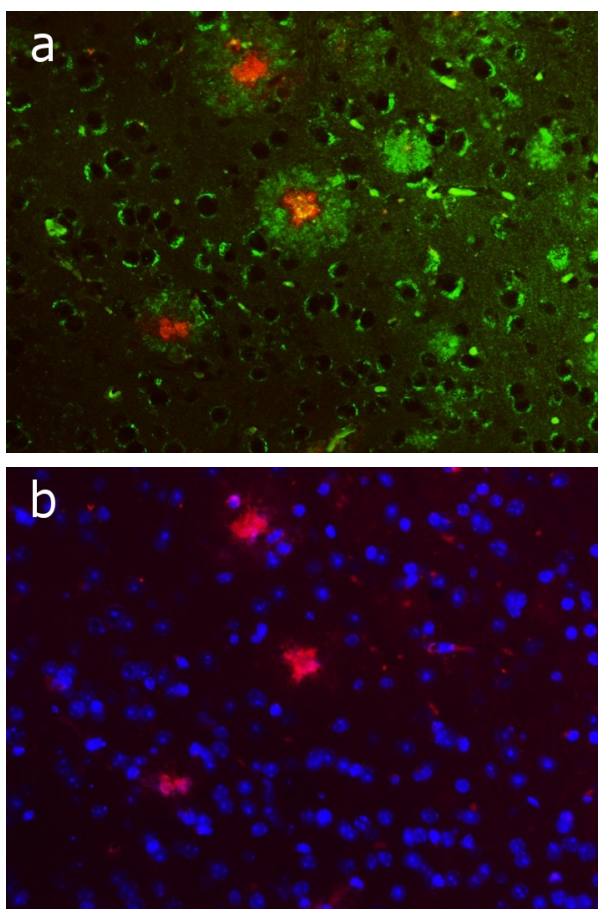

\section{Zellkerne}

Vtilb

$+$

\section{Zellkerne}

$\mathbf{A} \boldsymbol{\beta}$

$+$

Vti1b

$+$

Zellkerne
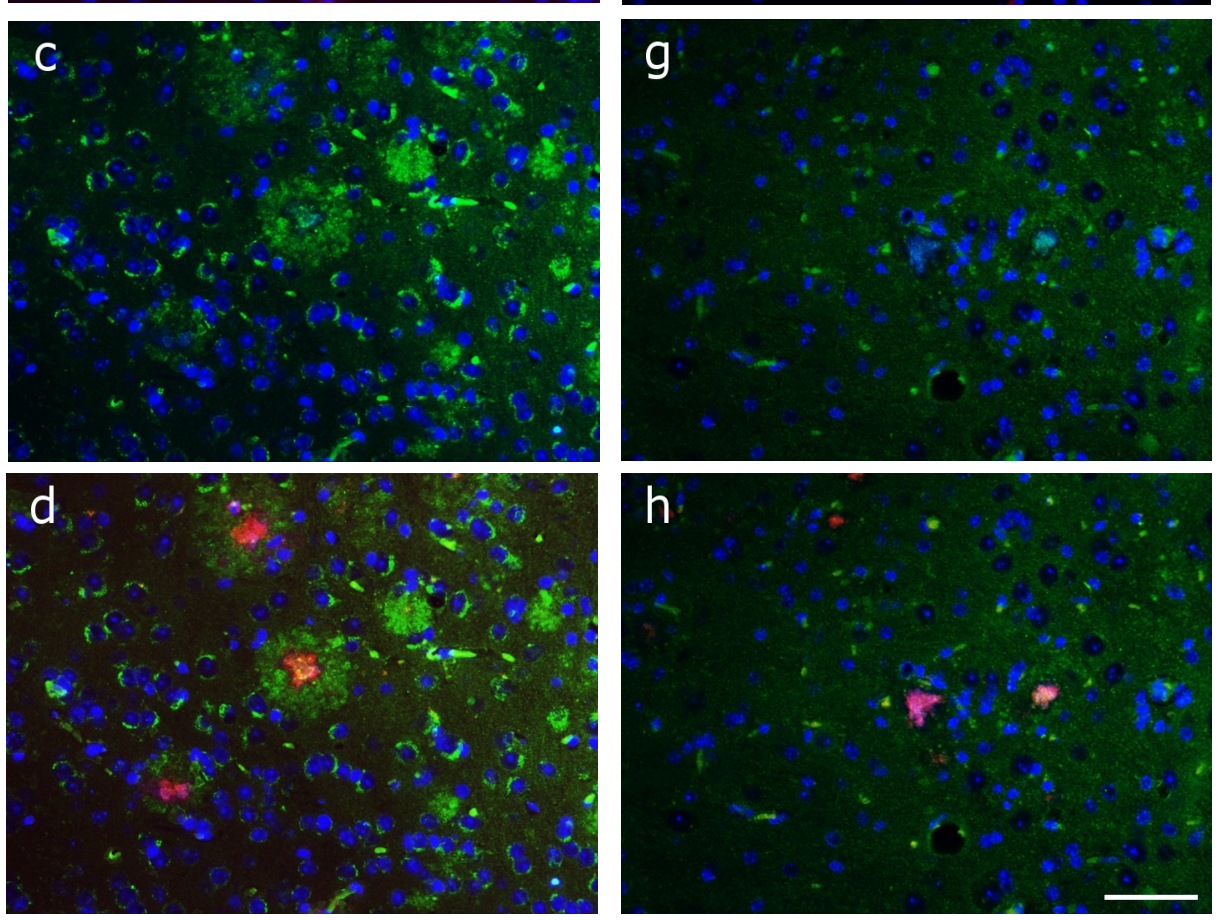

Abbildung 29: Immunfluoreszenzfärbung von $A \beta$ und Vti1b im Kortex (a-d) und Thalamus (e- $h$ ) der 6 Monate alten APPSLPS1KI-Maus. A $\beta$-Färbung markiert Amyloidkerne kortikaler (b) und thalamischer (f) Plaques. Vti1b akkumuliert im Kortex in der Umgebung des Plaquekerns und zeigt dort ein homogenes Signal, sodass sich lokale Anschwellungen einzelner Neuriten kaum darstellen $(a, d)$. Das Vti1b-Signal fehlt in Plaques des Thalamus. Ein perinukleäres Vti1b-Signal ist in kortikalen Neuronen nachweisbar. Maßstab: $50 \mu \mathrm{m}$. 


\subsection{Quantifizierung dystropher Neuriten}

Die Quantifizierung dystropher Neuriten erfolgte im Kortex 6 und 10 Monate alter APP ${ }^{\text {SLPS1KI- }}$ Mäuse. Um eine quantitative Aussage über die von dystrophen Neuriten eingenommene Gesamtfläche des Kortex treffen zu können, wurde der von dystrophen Neuriten bedeckte prozentuale Anteil an der Gesamtfläche ermittelt. Zur Beurteilung des Ausmaßes des neuritischens Schadens über die Zeit wurden zwei Altersstufen (6 und 10 Monate) untersucht und jeweils vier Tiere jeder Alterstufe analysiert; von jedem der Tiere gehen mindestens drei Schnitte in die Berechnung ein. Zur Markierung dystropher Neuriten wurden Antikörper gegen Syntaxin 13, Vtilb und Synuclein $\alpha$ verwendet.

Die Berechnung der Mittelwerte der von Immunfärbung bedeckten Fläche ergibt in Abhängigkeit vom untersuchten Protein unterschiedliche Prozentwerte der von dystrophen Neuriten bedeckten Fläche. So nehmen Syntaxin-13-Akkumulationen in der 6 Monate alten Maus im Mittel einen Anteil von 20,65\% an der Gesamtfläche ein; für Vti1b ergibt sich ein Mittelwert von 23,09\% und für Synuclein $\alpha$ ein Mittelwert von 17,31\%. Der Vergleich mit den Ergebnissen für 10 Monate alte Mäuse zeigt, dass sich diese Anteile über den untersuchten Zeitraum nicht signifikant verändern. Für Syntaxin-13-markierte dystrophe Neuriten ergibt sich ein Mittelwert von 20,33\%, in der Vti1bMarkierung liegt der Anteil bei 24,35\% und in der Synuclein- $\alpha$-Markierung bei 17,45\%. In allen

drei Fällen kann keine signifikante $\mathrm{Zu}$ - oder Abnahme der von dystrophen Neuriten eingenommenen Flächenanteile nachgewiesen werden (s. Abbildung 30).

Einzel- und Mittelwerte der Tiere befinden sich im Anhang der Arbeit. 
a

Syntaxin 13

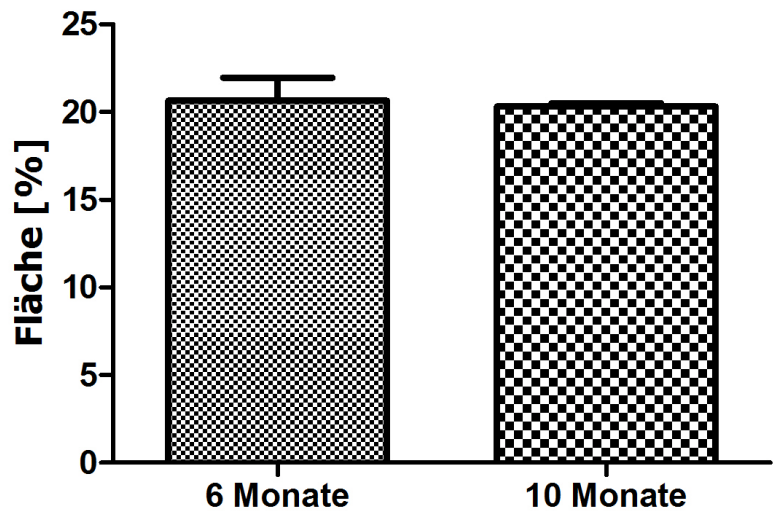

b

\section{Vti1b}

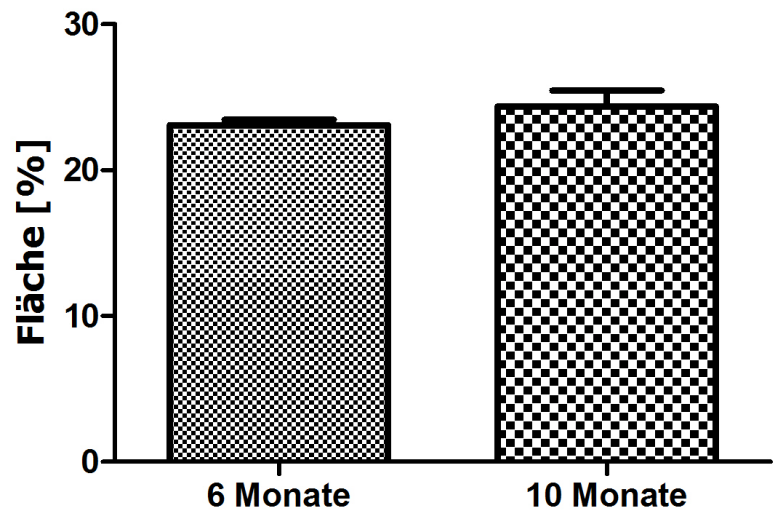

C

Synuclein alpha

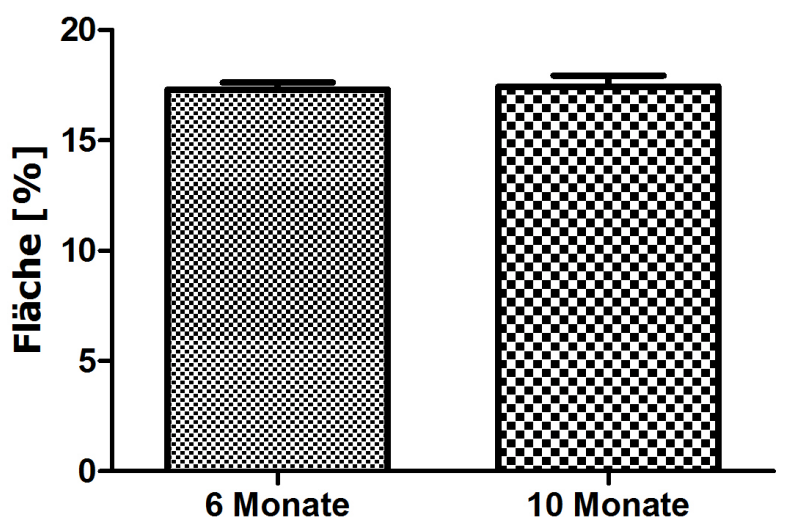

Abbildung 30: Quantifizierung von Syntaxin-13-, Vti1b- und Synuclein-a-Akkumulationen im Kortex der 6 und 10 Monate alten APPSLS1KI-Maus. Der von Proteinakkumulationen in dystrophen Neuriten bedeckte Flächenanteil verändert sich im Zeitraum von 6 bis 10 Monaten nicht (Mittelwerte \pm Standardfehler). 


\section{Diskussion}

Dystrophe Neuriten und axonale Sphäroide stellen neben extrazellulären Amyloidplaques und neurofibrillären Tangles wesentliche histologische Kennzeichen der Alzheimer-Pathologie dar. Sie entsprechen axonalen Auftreibungen und Akkumulationen axonal transportierter Proteine. Das pathogenetisch bedeutsame Amyloidvorläuferprotein APP unterliegt physiologischerweise einem axonalen Transportmechanismus. Seine Akkumulation in axonalen Anschwellungen und dystrophen Neuriten des AD-Gehirns machen das Protein zu einem etablierten Marker axonaler Schädigung (Coleman 2005). Neben anderen axonal transportierten Zellbestandteilen wie Zellorganellen, Zytoskelettbausteinen und Lipiden erreichen verschiedene synaptische Proteine mittels axonalen Transports ihren Bestimmungsort an der synaptischen Membran und wurden in der vorliegenden Arbeit als Markerproteine axonaler Schädigung im APPSLPS1KI-Mausmodell getestet.

Die Markierung der synaptisch exprimierten Proteine erfolgte unter der Zielsetzung, pathologische Akkumulationen dieser Proteine in geschädigten Zellfortsätzen murinen Hirngewebes zu detektieren. Die zu diesem Zweck ausgewählten Proteine unterscheiden sich sowohl in ihrer Funktion als auch in ihrer Lokalisation an der Synapse. Während die Proteine Syntaxin 7 und 13, Vtilb, SNAP-25 und Synaptobrevin als Mitglieder des SNARE-Komplexes Membranfusionsprozesse zwischen Vesikeln und synaptischer Membran vermitteln, wird den Synucleinen eine Beteiligung an der Modulation synaptischer Plastizität zugeschrieben. Die vakuoläre Protonenpumpe ist ein vesikelassoziiertes Enzym der Präsynapse. Das Strukturprotein Synaptopodin ist am Aufbau dendritischer Dornen beteiligt und liegt als einziges Protein an der postsynaptischen Membran vor.

\subsection{Akkumulation synaptischer Proteine in dystrophen Zellfortsätzen der APP ${ }^{\text {SL }}$ PS1KI-Maus}

In der immunhistochemischen Färbung synaptischer Proteine im Gehirn der 6 Monate alten

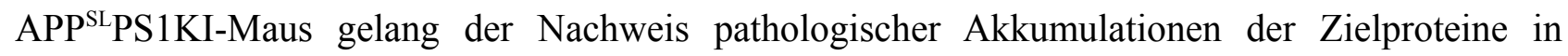
dystrophen Neuriten der Plaqueperipherie und axonalen Sphäroiden. Pathologisch veränderte Neuriten in der Umgebung der Plaques enthalten lokal erhöhte Konzentrationen der präsynaptischen Proteine Syntaxin 7 und 13, Vti1b, Synaptobrevin, SNAP-25, Synuclein $\alpha$ und $\beta$ und 
Proton-ATPase, die auf histologischer Ebene die äußeren Anteile einer Plaque markieren. Die zentrale Aufhellung im Zentrum der Plaque, die dem kompakten Amyloidkern entspricht, blieb in sämtlichen Färbungen von Immunreaktivität ausgespart.

Im Vergleich der Färbemuster zeigten sich markante Unterschiede im Akkumulationsverhalten der verschiedenen Proteine. Während SNAP-25-positives Material bis weit in das Plaquezentrum hinein nachzuweisen war und nur ein relativ kleines Areal ohne Immunreaktivität im Inneren der Plaque verblieb, war das positive Signal der Proteine Syntaxin 7 und 13, Vtilb, Synaptobrevin, Synuclein $\alpha$ und $\beta$ und Proton-ATPase strikt auf die äußeren Bereiche der Plaque beschränkt. Sie markierten einen Saum aus dystrophen Neuriten, der sich morphologisch eindeutig vom ungefärbten Plaquekern differenzieren ließ. In der Färbung des einzigen postsynaptischen Proteins Synaptopodin stellten sich Plaques im Gegensatz zu den Färbungen der präsynaptischen Markerproteine als signalfreie Areale dar. Im Vergleich zu den Ergebnissen aus allen anderen Färbungen wurden Plaques in der Synaptopodin-Färbung so in Form eines Negativbildes sichtbar. Plaquekern und dystrophe Neuriten blieben frei von Immunreaktivität und erschienen als Aussparungen in einer diffus angefärbten Umgebung aus Neuropil.

Die Markierung einzelner pathologisch aufgetriebener Neuriten in der Plaqueperipherie gelang besonders eindrucksvoll in der Färbung der Proteine Syntaxin 13, Synaptobrevin, Synuclein $\alpha$ und $\beta$ und Proton-ATPase. Im Gegensatz dazu färbten sich die Proteine Vtilb und SNAP-25 in der Plaqueumgebung eher diffus-flächig an, sodass die Dilatationen einzelner Zellfortsätze weniger gut zur Darstellung kamen.

Es sei darauf hingewiesen, dass der Nachweis anderer synaptischer Proteine in dystrophen Neuriten nicht gelang (s. Tabelle 6). Diese Proteine üben zum Teil ähnliche Funktionen an der Synapse aus wie die Proteine, deren Vorkommen in dystrophen Neuriten nachgewiesen werden konnte. Die Tatsache, dass pathologische Akkumulationen dieser Proteine in dystrophen Neuriten nicht nachgewiesen werden konnten, kann darin begründet liegen, dass Akkumulationen dieser Proteine der Erkennung durch die eingesetzten Antikörper entgehen. Es ist andererseits möglich, dass dystrophe Neuriten diese Proteine nicht akkumulieren und folglich keine spezifische Immunreaktivität in der Plaqueumgebung vorliegt.

Im Vergleich der synaptischen Markerproteine mit APP als etabliertem Marker für axonales Mistrafficking (Coleman 2005) lassen sich Gemeinsamkeiten und Unterschiede im Akkumulationsverhalten ausmachen. In der DAB-Färbung imponierten starke APP-Akkumulationen in dystrophen Neuriten und Sphäroiden, die unabhängig von Plaques auftraten. Anders als in den Färbungen der 
synaptischen Proteine blieb eine flächenhafte Neuropilfärbung aus.

Mit der Fluoreszenzdoppelfärbung von APP und Vtilb als exemplarisch ausgewähltem Vertreter der synaptischen Marker gelang der Nachweis ihrer Kolokalisation in der Umgebung kompakter A $\beta$ Kerne kortikaler und thalamischer Plaques. Entsprechend der Ergebnisse aus den DAB-Färbungen konnte in der Plaqueperipherie ein Vtilb-Signal von gleichmäßiger Intensität beobachtet werden, ohne dass die Identifizierung fokaler Anschwellungen einzelner dystropher Neuriten gelang. Mit APP hingegen konnten signalstarke, bulbös aufgetriebene Neuriten in der Nähe sowie in einiger Distanz zu Plaques dargestellt werden. Dieser Befund spricht für die morphologische Vielfalt dystropher plaqueassoziierter Neuriten, die auch für Fälle humaner AD beschrieben wurde (Dickson et al. 1999).

Während plaqueassoziierte dystrophe Neuriten eindeutig Immunreaktivität sowohl für die synaptischen Marker als auch für APP aufwiesen, stellten sich axonale Sphäroide, die axonalen Anschwellungen unabhängig vom Vorliegen amyloider Plaques entsprechen, eindeutig besser in der APP-Färbung dar. Diesen axonalen APP-haltigen Anschwellungen wird eine pathogentische Bedeutung als Vorläuferläsionen von Amyloidplaques beigemessen (Wirths et al. 2007, Stokin et al. 2005).

\subsection{Akkumulation synaptischer Proteine in dystrophen Zellfortsätzen humaner Alzheimer-Gehirne}

Antikörper, die zu guten Resultaten im murinen Gewebe führten, wurden in Hirnschnitten dreier humaner AD-Fälle getestet. Bei zwei Patienten lag das Stadium IV nach Braak vor. Für den dritten Patienten war eine Krankheitsdauer von 10 Jahren bekannt, eine Zuordnung zu einem BraakStadium hatte postmortal nicht stattgefunden.

Die Darstellung neuritischer Schäden gelang mit den meisten der im Mausmodell erfolgreich eingesetzten Markern ebenfalls im humanen Gewebe. Als einzige Ausnahmen müssen die Immunfärbungen von Vtilb, Synaptobrevin und Proton-ATPase genannt werden. Die Detektion pathologischer Akkumulationen dieser Zielproteine in dystrophen Neuriten gelang in den untersuchten Fällen humaner AD nicht.

Der positive Nachweis der synaptischen Markerproteine in dystrophen Zellfortsätzen des menschlichen Alzheimer-Gehirns unterstreicht die Gültigkeit des APP ${ }^{\text {SL }}$ PS1KI-Mausmodells in der Erforschung humaner $\mathrm{AD}$, das v.a. aufgrund der charakteristischen intrazellulären $\mathrm{A} \beta$ Akkumulationen $\mathrm{zu}$ einem frühen Zeitpunkt des Krankheitsprozesses und des dramatischen Neuronenverlusts im ersten Lebensjahr der Mäuse als wertvolles Krankheitsmodell bewertet wird 
(Casas et al. 2004). In den Übersichtsfärbungen fiel hingegen auf, dass die Pathologie im humanen Gehirn wesentlich schwächer ausgeprägt war als im Gehirn der 6 Monaten alten APP ${ }^{\text {SLPS1KI- }}$ Maus. Während der gesamte Kortex der Maus von dystrophen Neuriten übersät war, konnten allenfalls vereinzelte dystrophe Neuriten im Ausschnitt des humanen Kortex detektiert werden. Die Ursache hierfür könnte zum einen darin liegen, dass nicht alle dystrophen Neuriten des humanen Alzheimer-Gehirns positiv für sämtliche synaptische Markerproteine sind und deshalb der Erkennung durch den spezifischen Antikörper entgehen. Zum anderen offenbart sich in der Diskrepanz der Befunde des humanen und murinen Gewebes, dass das Mausmodell der AD nicht mit Fällen humaner AD gleichzusetzen ist. APPSLPS1KI-Mäuse tragen gleich mehrere Mutationen der familiären Form der Alzheimer-Demenz und entwickeln innerhalb von Monaten massive pathologische Veränderungen, die sich im humanen Krankheitsprozess der meist sporadisch auftretenden $\mathrm{AD}$ über Jahrzehnte entwickeln. Darüber hinaus können eine unterschiedliche Fixierungsdauer und Post-mortem-Intervalle eine Rolle spielen. Während Mausgewebe unmittelbar nach dem Töten der Tiere fixiert werden, sind bei humanen Proben Post-mortem-Intervalle von einigen Stunden nach dem Ableben der Patienten die Regel. Des Weiteren gibt es Unterschiede in den untersuchten Krankheitsstadien zwischen Mausmodellen und humanen AD-Fällen. Während die Mausgewebe zu unterschiedlichen Zeitpunkten im Krankheitsverlauf entnommen wurden (6 und 10 Monate), repräsentieren die humanen Fälle immer Endstadien der Erkrankung. Die präsentierten Ergebnisse im murinen AD-Modell und humanen AD-Gehirn unterstreichen eindrücklich die wichtige Bedeutung der transgenen Mausmodelle für die Untersuchung der Alzheimer-Pathologie und verdeutlichen zugleich ihre eingeschränkte Aussagekraft bezüglich der pathologischen Vorgänge in Fällen humaner AD.

\subsection{Regionale Unterschiede im Ausprägungsgrad der neuritischen Schädigung}

Die Ergebnisse aus den Färbungen der synaptischen Markerproteine zeigten, dass dystrophe Neuriten in der Umgebung von Alzheimer-Plaques ein wesentliches pathologisches Merkmal im Gehirn der 6 Monate alten APP ${ }^{\text {SL}}$ PS1KI-Maus darstellten. In der Beurteilung der verschiedenen Hirnregionen fielen zudem regionale Besonderheiten im Ausprägungsgrad der neuritischen Schädigung auf. In primär von der Alzheimer-Erkrankung betroffenen Regionen wie dem Kortex und dem Hippokampus lagen dystrophe Neuriten, die die äußeren Bereiche der Plaques markieren, besonders zahlreich vor. Der Thalamus repräsentiert eine Region, die erst im späteren Krankheitsverlauf von pathologischen Veränderungen betroffen ist. Hier zeigte sich eine im Vergleich zum Kortex und Hippokampus nur mild ausgeprägte Pathologie. Aus den Übersichts- 
färbungen wurde ersichtlich, dass thalamische Plaques insgesamt seltener waren und weniger dystrophe Neuriten um sich versammelten als kortikale und hippokampale Plaques.

Die Beobachtungen aus den Übersichtsfärbungen und die Quantifizierung der dystrophen Neuriten in der Umgebung kortikaler Plaques korrelieren mit Ergebnissen von Christensen et al., die das Vorliegen von A $\beta$-Peptiden im Frontalkortex und Thalamus der APP ${ }^{S L}$ PS1KI-Maus quantifizierten (Christensen et al. 2008): Im Alter von 2 Monaten sind 5\% der Fläche des frontalen Kortex von A $\beta$ Peptid bedeckt; mit 6 Monaten steigt dieser Anteil auf 12,1\% der Gesamtfläche des Frontalkortex an. In der 12 Monate alten Maus nimmt die A $\beta$-bedeckte Fläche nicht weiter an Größe zu. Die Ergebnisse resultieren aus einer starken Zunahme der Plaquepathologie im Zeitraum von 2 bis 6 Monaten, während sich ein deutlicher Rückgang intrazellulärer A $\beta$-Akkumulationen - deren Auftreten bereits ab einem Lebensalter von 1,5 Monaten beobachtet wird - vollzieht. Intrazellulären A $\beta$-Akkumulationen wird eine zentrale Rolle in der Pathogenese der Erkrankung zugeschrieben, die bereits in Neuronen 2 Monate alter Mäuse vorliegen und damit extrazellulären A $\beta$-Akkumulationen vorausgehen. Die Ergebnisse mehrerer Untersuchungen am APPSLPS1KI-Mausmodell stützen die These, dass intraneuronales $\mathrm{A} \beta$ als ein Trigger des neuronalen Zelltods wirkt (Christensen et al. 2010, Casas et al. 2004). Ein dementsprechend schwaches intraneuronales A $\beta$-Signal bei gleichzeitig starker extrazellulärer A $\beta$-Immunreaktivität ließ sich mittels Immunfluoreszenzfärbung im Kortex der 6 Monate alten Maus detektieren. A $\beta$ liegt fast ausschließlich in Form von Plaques vor; die intrazelluläre A $\beta$-Akkumulation stellt nicht mehr das dominierende pathologische Merkmal dar.

Die Ergebnisse aus der Quantifizierung dystropher Neuriten der Plaqueumgebung im Kortex 6 und 10 Monate alter APP ${ }^{\text {SL } P S 1 K I-M a ̈ u s e ~ k o r r e l i e r e n ~ m i t ~ d e r ~ o b e n ~ b e s c h r i e b e n e n ~ C h r o n o l o g i e ~ d e r ~}$

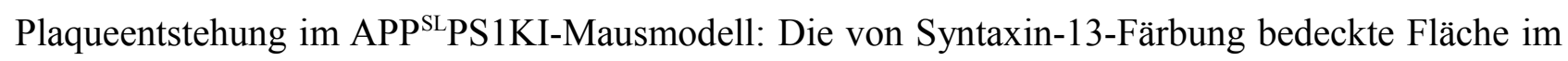
Kortex der 6 Monate alten Maus entspricht einem Anteil von 20,65\% an der Gesamtfläche des Kortex. Dieser Wert zeigte für die 10 Monate alte Maus keine signifikante Veränderung. Die von Vtilb- und Synuclein- $\alpha$-Akkumulationen bedeckten Flächenanteile wiesen im untersuchten Zeitraum ebenfalls konstante Werte ohne signifikante Veränderungen auf. Diese Resultate deuten darauf hin, dass das pathologische Merkmal dystropher Neuriten in der Umgebung kortikaler Plaques bereits im Alter von 6 Monaten eine maximale Ausprägung zeigt und in den folgenden Lebensmonaten keine wesentliche Progredienz aufweist.

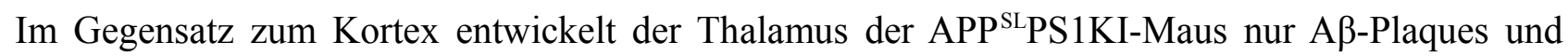
weist zu keinem Zeitpunkt des pathologischen Prozesses intraneuronale A $\beta$-Aggregate auf. Nach 
Christensen et al. steigt die Plaquemenge, die der A $\beta$-bedeckten Fläche an der Gesamtfläche des Thalamus entspricht, im Zeitraum von 2 bis 6 Monaten von 1,5\% auf 8,5\% an. Im Alter von 12 Monaten wird ein weiterer Anstieg auf 13,9\% registriert. Die Plaquepathologie beginnt im Thalamus folglich insgesamt später als im Kortex und nimmt bis zum 12. Lebensmonat weiterhin deutlich zu (Christensen et al. 2008).

Die Immunfärbung synaptischer Marker bestätigte sowohl die Unterschiede im Zeitpunkt des Auftretens pathologischer Veränderungen als auch in deren Ausprägungsgrad in Abhängigkeit von der untersuchten Region. Die Beobachtung, dass dystrophe Neuriten in der Umgebung kortikaler und hippokampaler Plaques ein wesentliches pathologisches Korrelat der neuritischen Schädigung darstellen und die Plaques des Thalamus eine im Vergleich schwach ausgeprägte Akkumulation synaptischer Proteine in dystrophen Zellfortsätzen aufweisen, legt den Schluss nahe, dass im Kortex der 6 Monate alten Maus nicht nur mehr extrazelluläres Amyloid (s.o.) vorliegt, sondern dass auch das Ausmaß der neuritischen Schädigung der Entwicklung im Thalamus vorausgeht bzw. dass dort nicht das Ausmaß der pathologischen Veränderungen des Kortex erreicht wird.

Ein wichtiger Grund für die regional unterschiedlich stark ausgeprägte neuritische Pathologie ist im Expressionsmuster des transgenen APP zu sehen. Während Nervenzellen in kortikalen Schichten und im Hippokampus APP überexprimieren, finden sich im Thalamus keine APP-überexprimierenden Zellen, sodass APP hier lediglich in Faserbahnen zu finden ist. Die Abwesenheit eines intrazellulären APP-Signals im Thalamus der APP ${ }^{\mathrm{SL}} \mathrm{PS} 1 \mathrm{KI}-\mathrm{Maus}$ bestätigte Ergebnisse, nach denen in dieser Region keine APP-Expression stattfindet (Christensen et al. 2008).

Interessanterweise lieferte die Quantifizierung der Synapsenmarker in dystrophen Zellfortsätzen des Thalamus, die analog zur Quantifizierung im Kortex versucht wurde, für keinen der ausgewählten Marker sinnvolle Ergebnisse. Aufgrund der im Vergleich zum Kortex schwach ausgeprägten Pathologie werden dystrophe Neuriten mit der angewandten Methode im Thalamus nicht eindeutig erkannt, sodass eine quantitative Abschätzung der von dystrophen Neuriten bedeckten Fläche im Thalamus nicht möglich war.

\subsection{Phänotypische Auffälligkeiten der 6 Monate alten APP ${ }^{\text {SL }}$ PS1KI-Maus in Bezug zur neuritischen Schädigung}

Für das APPSLPS1KI-Mausmodell wurde ein schwerwiegender neurologischer Phänotyp beschrieben, der u.a. durch Gewichtsverlust, Wachstumsretardierung, Gangstörungen und die Entwicklung einer thorakolumbalen Kyphose gekennzeichnet ist (Wirths et al. 2007). Dieser Phänotyp resultiert vermutlich aus einer progressiven motorischen Dysfunktion, die auf eine 
altersabhängige axonale Degeneration im Gehirn und Rückenmark zurückzuführen ist. Motorische Defizite wie Gangunsicherheit und posturale Instabilität wurden auch für Alzheimer-Patienten bereits zu einem frühen Stadium des Krankheitsprozesses beschrieben (Pettersson et al. 2002). Weiterhin konnte für die APP ${ }^{\text {SL}} \mathrm{PS} 1 \mathrm{KI}-\mathrm{Maus}$ ein altersabhängiger Verlust des Arbeitsgedächtnisses in einer Reihe von Verhaltenstests nachgewiesen werden (Bayer und Wirths 2008a, Wirths et al. 2008).

Die dramatisch ausgeprägte neuritische Pathologie im Alter von 6 Monaten, die sich mit Hilfe der synaptischen Marker darstellte, korreliert mit den für das Mausmodell beschriebenen krankheitsassoziierten phänotypischen Veränderungen. Gestörter axonaler Transport wird als Ursache motorischer Auffälligkeiten im Phänotyp der APP ${ }^{\text {SL }}$ PS1KI-Maus angesehen und wurde auch für andere transgene Mausmodelle als Ursache motorischer Defizite beschrieben (Probst et al. 2000, Tesseur et al. 2000). Die intrazellulären Akkumulationen von A $\beta$-Peptiden in verschiedenen

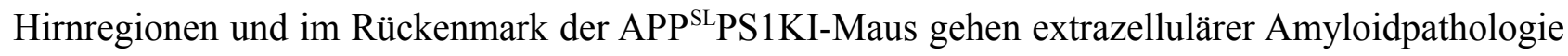
voraus (Casas et al. 2004) und gelten als Auslöser der axonalen Degeneration (Wirths et al. 2008). Besonders die im APP ${ }^{\mathrm{SL}} \mathrm{PS} 1 \mathrm{KI}-M a u s m o d e l l$ überwiegend vorliegende intraneuronale $\mathrm{A} \beta_{\mathrm{x}-42}$-Isoform wird dafür verantwortlich gemacht, axonale Degeneration im Gehirn und Rückenmark und den Neuronenverlust im Hippokampus zu induzieren (Casas et al. 2004, Wirths et al. 2008).

Die Defizite im Arbeitsgedächtnis der 6 Monate alten Maus finden ihre morphologische Entsprechung u.a. im beschriebenen Verlust hippokampaler Neurone. Als ein weiteres Korrelat der beeinträchtigten Funktion des Hippokampus kann die dort vorliegende ausgeprägte neuritische Schädigung angesehen werden: Dystrophe Neuriten lassen sich in sämtlichen Färbungen über die gesamte Hippokampusformation nachweisen und sind sehr wahrscheinlich eine Ursache gestörter Gedächtnisprozesse. Der massive neuritische Schaden, der sich im Kortex der APP ${ }^{\text {SL } P S 1 K I-M a u s ~ i n ~}$ Form zahlreicher dystropher Neuriten darstellt, könnte darüber hinaus eine ursächliche Beteiligung an motorischen Fehlleistungen und den Defiziten im Arbeitsgedächtnis 6 Monate alter Mäuse haben.

\subsection{Neuritische Dystrophie als Folgeerscheinung und möglicher Auslöser pathologischer Prozesse der AD}

Dystrophe Neuriten säumen reife neuritische Plaques und repräsentieren den schwerwiegenden neuritischen Schaden, der vermutlich degenerierte Fasern sowie abnormal regenerierende Zellfortsätze einbezieht (Masliah et al. 1993). Zudem stellt der Verlust von Synapsen das wichtigste neuropathologische Substrat der kognitiven Dysfunktion im Rahmen der Alzheimer-Erkrankung dar 
(Terry RD et al. 1991). Die Ergebnisse der vorliegenden Arbeit belegen, dass zahlreiche synaptische Proteine in dystrophen Neuriten der transgenen Maus akkumulieren.

Dystrophe Neuriten wurden im humanen Alzheimer-Gehirn und in verschiedenen Mausmodellen untersucht. Sie sind immunreaktiv für eine Reihe synaptischer und zytoskelettaler Proteine. Immunreaktivität in dystrophen Neuriten humaner Gehirne wurde u.a. beschrieben für Chromogranin A (Muñoz 1991), Synaptophysin (Brion et al. 1991), SNAP-25, Synaptotagmin und Rab3a (Ferrer et al. 1998). Dickson et al. untersuchten dystrophe Neuriten in frühen und späten Stadien der Alzheimer-Erkrankung, indem sie Tau-Protein, Neurofilament und den synaptischen Marker Chromogranin A in dystrophen Zellfortsätzen immunhistochemisch darstellten. Die neurochemische und morphologische Vielfalt der dystrophen Neuriten erklärten sie mit einem möglicherweise sequenziellen Mechanismus der Entstehung dystropher Neuriten, deren frühe Formen Neurofilament enthalten und schließlich als reife Formen das Zytoskelettprotein Tau in sich tragen. Sie stellten weiterhin die Hypothese auf, dass der Nachweis synaptischer Marker in pathologisch veränderten Axonen für eine reaktive Synaptogenese sprechen könne (Dickson et al. 1999). Letztlich bleibt der sequenzielle Mechanismus der Entstehung dystropher Neuriten jedoch unklar. Die Frage, ob dystrophe Neuriten eher als reaktives Phänomen zu werten sind oder vielmehr zur Amyloidablagerung beitragen, bedarf weiterer Klärung.

Blanchard et al. wiesen traubenförmige Muster abnorm dilatierter dystropher Neuriten in drei APP/PS1-Mausmodellen nach. Die Neuriten akkumulierten neben APP, Synaptophysin, Ubiquitin und phosphoryliertem Tau-Protein Marker mitochondrialer und proapoptotischer Prozesse wie Cytochrom C, Cytochromoxidase 1 und Bax (Blanchard et al. 2003). Die neuronalen Stressmarker ließen sich zeitgleich mit frühen intraneuronalen Akkumulationen von A $\beta$-Protein im doppelttransgenen APP/PS1-Mausmodell nachweisen (Wirths et al. 2001, Wirths et al. 2002). Ihr gemeinsames Vorkommen stützt die Hypothese, dass intrazelluläres $\mathrm{A} \beta$ in frühen Phasen der AD toxische Effekte auf Neurone auslöst (Blanchard et al. 2003).

Intrazelluläre Akkumulationen von oligomerisierten, fibrillären und N-terminal-modifizierten $A \beta$ Spezies, die der extrazellulären Plaquepathologie vorausgehen, stellen ein wesentliches Kennzeichen des APP ${ }^{\text {SL }}$ PS1KI-Mausmodells dar. Ihre frühe Akkumulation in CA1-Neuronen des Hippokampus wird für den im Alter von 6 Monaten beginnenden Neuronenuntergang

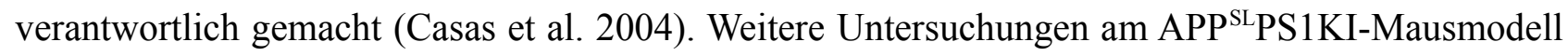
deuten auf die pathogenetisch bedeutsame Rolle intrazellulären A $\beta$-Peptids hin. So konnte ein Neuronenverlust in cholinergen motorischen Kernen der APP ${ }^{\text {SL }}$ PS1KI-Maus ausschließlich in Anwesenheit intrazellulären $A \beta$-Proteins nachgewiesen werden. Cholinerge Neurone, die kein $A \beta$ enthielten und nur von extrazellulären $\mathrm{A} \beta$-Plaques umgeben waren, zeigten keinen Zelluntergang 
(Christensen et al. 2010). Die Ergebnisse von Breyhan et al. lieferten Hinweise auf eine Korrelation intraneuronaler $A \beta$-Akkumulation mit Hippokampusatrophie und Defiziten in synaptischer

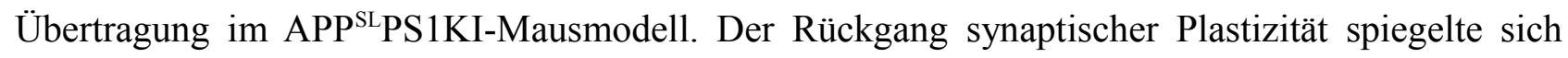
u.a. in einem dramatischen Verlust der Langzeitpotenzierung im Hippokampus der 6 Monate alten

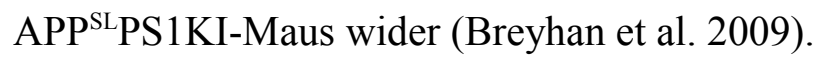

Intraneuronales $\mathrm{A} \beta$ wird darüber hinaus als Auslöser axonaler Schädigung in den zerebralen Hemisphären, im Hirnstamm und im Rückenmark der APP ${ }^{\text {SL }}$ PS1KI-Maus verantwortlich gemacht. Wirths et al. beschrieben Amyloidablagerungen in der Hintersäule der weißen Substanz des Rückenmarks. Da diese Region reich an axonalen Fortsätzen ist, scheint ein axonaler Ursprung der A $\beta$-Peptide, die entweder aus kortikalen Gebieten transportiert oder während des axonalen Transportprozesses aus APP prozessiert wurden, wahrscheinlich (Wirths et al. 2007). Das Vorkommen A $\beta$-positiver axonaler Sphäroide ist ein weiterer wichtiger Befund, der die Hypothese stützt, dass axonale Anschwellungen Amyloidplaques vorausgehen und an ihrer Entstehung beteiligt sind. Diese Funde untermauern die Vorstellung vom Axon als Produktions- und Freisetzungsort von A $\beta$ (Kamal et al. 2001), welches möglicherweise als Folge gestörten axonalen APP-Transports aus präsynaptischen Kompartimenten freigesetzt wird (Lazarov et al. 2002). Nach Untersuchungen von Stokin et al. an Mausmodellen und Fällen humaner AD resultieren Amyloidablagerungen möglicherweise aus der fokal gesteigerten Sekretion von $A \beta$ oder der Freisetzung aus $A \beta$-reichen axonalen Auftreibungen. Da diese axonalen Auftreibungen also dem Auftreten extrazellulären Amyloids vorausgehen, werden sie nicht als Reaktion auf die Amyloidbildung gewertet. Axonale Sphäroide gelten vielmehr als eine Vorläuferläsionen dystropher Neuriten, die neben axonalen Sphäroiden eine wesentliche Form axonaler Schädigung darstellen und mit Amyloidplaques assoziiert sind (Stokin et al. 2005). Takahashi et al. konnten zudem zeigen, dass $A \beta_{42}$ in transgenen Mausmodellen und im humanen AD-Gehirn in mulitivesikulären Körperchen (multivesicular bodies) prä- und postsynaptischer Kompartimente akkumuliert und pathologische Veränderungen der synaptischen Morphologie induziert (Takahashi et al. 2002).

Diese und andere Ergebnisse deuten auf den komplexen Entstehungsmechanismus dystropher Neuriten hin. Verschiedene Studien beschäftigten sich insbesondere mit der chronologischen Reihenfolge der Ereignisse, die ursächlich am Auftreten dystropher Neuriten beteiligt sind. Die Lokalisation dystropher Neuriten in der Plaqueperipherie hat zu der Annahme geführt, dass diese als direktes Resultat fibrillärer Amyloidentstehung zu werten sind. Diese Vermutung fand Bestätigung in mehreren Untersuchungen. So konnte die intrazerebrale Injektion von $A \beta_{1-40}$ im Kortex der Ratte die Bildung dystropher Neuriten auslösen (Emre et al. 1992). Mittels transkranieller 2-Photonenmikroskopie gelang Tsai et al. die in vivo-Darstellung progressiver neuritischer Degeneration in 
einem doppelt-transgenen APP/PS1-Mausmodell. Dendriten in unmittelbarer Nähe amyloider Plaques zeigten pathologische Merkmale wie den Verlust dendritischer Dornen und eine Atrophie ihres Schaftdurchmessers und Axone entwickelten große Varikositäten. Diese Veränderungen resultieren nicht nur in einer Störung synaptischer Übertragung, sondern auch in einem dauerhaften Bruch neuritischer Fortsätze und werfen die Frage auf, in welchem Ausmaß Amyloidplaques - als direkte Auslöser synaptischer und neuritischer Schädigung - doch als Ursache kognitiver Defizite im Verlauf der Alzheimer-Erkrankung verantwortlich sind (Tsai et al. 2004).

Die Dynamik im Entstehungsprozess dystropher Neuriten spiegelt sich in der sequenziellen Einbeziehung der verschiedenen Transmittersysteme wider. Nach Bell et al. existiert eine Neurotransmitter-spezifische Vulnerabilität als Antwort auf Amyloidplaques. Das cholinerge System reagiert dabei am empfindlichsten, sodass in frühen Stadien hauptsächlich cholinerge dystrophe Neuriten auftreten. Erst im weiteren Verlauf sind auch das glutamaterge und zuletzt das GABAerge System involviert (Bell et al. 2005, Bell und Cuello 2006).

Der unmittelbar schädigende Effekt dystropher Neuriten auf die synaptische Übertragung wurde durch Korrelationsanalysen zwischen der Häufigkeit dystropher Neuriten und des Schweregrades der Demenz in Fällen humaner AD bestätigt (McKee et al. 1991). Knowles et al. zeigten, dass Dendriten als Reaktion auf das Vorliegen von Amyloidplaques von ihrem linearen Verlauf abweichen und dass sich aus dieser Abweichung eine elektrophysiologische Verzögerung von mehreren Millisekunden pro Plaque ergibt. Diese Beeinflussung zeitlich korrekt ablaufender Aktionspotenziale durch Tausende neokortikaler Plaques im humanen AD-Gehirn kann auf diese Weise zur Manifestation der Demenz beitragen (Knowles et al. 1999).

In der Zusammenschau der Ergebnisse aus jüngerer Zeit rücken dystrophe Neuriten als Entstehungsorte extrazellulären Amyloids ins Zentrum des Interesses. Der exakte Entstehungsmechanismus ist trotz zahlreicher Erklärungsansätze bis heute nicht vollständig verstanden. Die Hypothese, dass dystrophe Neuriten Ursprung extrazellulären Amyloids sind, gründet sich v.a. auf die Zusammenschau der Ergebnisse aus Studien an traumatisch geschädigten Gehirnen und transgenen Mausmodellen. Traumatische Hirnschädigung induziert axonale Anschwellungen, die dystrophen Neuriten in AD-Plaques ähneln (Smith et al. 1999). APP akkumuliert posttraumatisch in axonalen Sphäroiden und Varikositäten vor der Unterbrechung des Axolemms und gilt wie bei der $\mathrm{AD}$ als Indikator gestörten axonalen Transports (Stone et al. 2004). Die Beobachtung, dass neben APP auch A $\beta$-Protein in axonalen Anschwellungen traumatisch geschädigten Gewebes vorliegt, legt weiterhin den Schluss nahe, dass posttraumatische Amyloidplaques in Folge der Amyloidfreisetzung aus geschädigten Axonen entstehen. Über das Vorkommen axonaler Anschwellungen im 
AD-Mausmodell und ihre mögliche Bedeutung als Vorläuferläsionen wurde an anderer Stelle bereits berichtet (s.o.).

Die Hypothese, dass die Lyse dystropher Axone in der Entstehung fibrillären Amyloids resultiert, umfasst die Bildung von Amyloidprotofibrillen in Autophagosomen dystropher Neuriten und seine konsekutive Freisetzung durch Ruptur einer axonalen Anschwellung. Das extrazelluläre Amyloid könnte im Sinne einer positiven Rückkopplung auf angrenzende Axone eine Unterbrechung axonalen Transports und die Entstehung weiterer dystropher Neuriten bewirken (Fiala 2007). Während diese Annahme durchaus sinnvolle Erklärungsansätze für axonale Degeneration und die Beteiligung dystropher Neuriten an der Pathogenese amyloider Plaques liefert, bedarf die Frage nach dem initial auslösenden Ereignis weiterer Klärung. Aus den Ausführungen wird ersichtlich, dass sowohl intrazelluläre

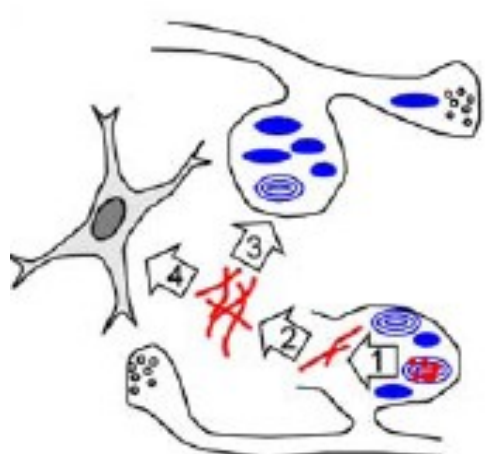

\section{Dystrophic axon lysis}

Abbildung 31: Möglicher Mechanismus der Amyloidentstehung. Amyloid entsteht in Autophagosomen dystropher Neuriten (1) und wird durch Ruptur einer axonalen Anschwellung freigesetzt (2). Extrazelluläres Amyloid führt zur Entstehung weiterer dystropher Neuriten (3) und verursacht eine gliale Reaktion (4) (Fiala 2007, S. 555).

Prozesse wie die Akkumulation von A $\beta$-Peptiden und die Störung neuronaler Transportprozesse als auch extrazelluläre Prozesse wie die Entstehung von Amyloidplaques an neuritischer Degeneration beteiligt sind und einer gegenseitigen Beeinflussung unterliegen.

Die Ergebnisse der vorliegenden Arbeit belegen, dass neuritische Schädigung in Form dystropher

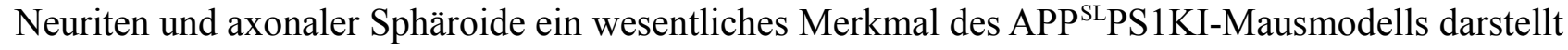
und somit ein wichtiges Kennzeichen humaner Alzheimer-Erkrankung imitiert. Dystrophe Neuriten weisen in der immunhistochemischen Untersuchung eine große morphologische und neurochemische Vielfalt auf. Sie akkumulieren eine Vielzahl synaptischer Proteine. Ungeachtet der Besonderheiten im Akkumulationsverhalten der Synapsenmarker erscheinen alle gezeigten Markerproteine für die Darstellung neuritischer Schädigung im Gehirn der APP ${ }^{\text {SLPS1KI-Maus }}$ geeignet. Ihre strukturelle und funktionelle Diversität deutet dabei auf den Schweregrad der neuritischen Schädigung hin, die sich sekundär auf eine Vielzahl physiologischer Prozesse auswirkt und die Funktion von Proteinen beeinflusst, die primär keine Beteiligung am Krankheitsprozess der AD zeigen. Neuritische Degeneration führt so u.a. zu einer Schädigung des synaptischen Apparates und zur Desintegrität seiner strukturellen Bausteine. 


\section{ZUSAMMENFASSUNG}

Die Alzheimer-Demenz (AD) ist eine schwere neurodegenerative Erkrankung und repräsentiert mit einem Anteil von etwa zwei Dritteln die häufigste Ursache einer Demenzerkrankung. Charakteristische neuropathologische Kennzeichen der AD sind extrazelluläre senile Plaques aus $\beta$ Amyloid-Peptid und neurofibrilläre Tangles aus hyperphosphoryliertem Tau-Protein. Die Degeneration von Axonen und Synapsen stellt ein weiteres wichtiges Merkmal der pathologischen Veränderungen der $\mathrm{AD}$ dar. Gestörten axonalen Transportprozessen wird eine wesentliche pathogenetische Bedeutung für die AD beigemessen. Sie manifestieren sich auf morphologischer Ebene als axonale Auftreibungen oder Sphäroide, die axonal transportierte Zellbestandteile enthalten, und als dystrophe Neuriten, die in der Peripherie der Alzheimer-Plaques vorkommen. Interessanterweise scheint der Verlust von Synapsen und das Auftreten dystropher Neuriten besser mit dem kognitiven Abbau im Krankheitsprozess der $\mathrm{AD}$ zu korrelieren als die Menge extrazellulärer Amyloidplaques.

Der Nachweis seltener familiärer AD-Mutationen führte zur Entwicklung zahlreicher Mausmodelle, die in unterschiedlicher Ausprägung pathologische Merkmale der Alzheimer-Demenz abbilden. Gegenstand dieser Arbeit war die Untersuchung neuritischer Dystrophie im doppelt-transgenen

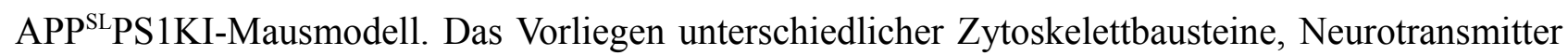
und axonal transportierter Proteine wie des pathogenetisch bedeutsamen Amyloidvorläuferproteins (APP) in dystrophen Zellfortsätzen wurde bisher beschrieben und zur Markierung neuritischer Schädigung eingesetzt. In der vorliegenden Arbeit wurden spezifische Enzym-markierte Antikörper gegen synaptisch exprimierte Proteine in immunhistochemischen Färbungen an Paraffinschnitten des Mausgehirns getestet. Es gelang der Nachweis pathologischer Akkumulationen der zum synaptischen SNARE-Komplex gehörenden Proteine Synaptobrevin, SNAP-25, Syntaxin 7, Syntaxin 13 und Vtilb sowie der Proteine $\alpha$ - und $\beta$-Synuclein, Synaptopodin und Proton-ATPase in dystrophen Neuriten in der Umgebung neuritischer Plaques. Die Mehrzahl dieser Proteine konnte ebenfalls in dystrophen Neuriten humaner AD-Fälle nachgewiesen werden.

Die Ergebnisse der Arbeit belegen, dass diverse synaptische Proteine in pathologische Veränderungen des AD-Gehirns einbezogen werden und aufgrund ihres Akkumulationsverhaltens als Marker neuritischer Schädigung eingesetzt werden können. Die morphologische und neurochemische Vielfalt der dystrophen Neuriten deutet auf den Schweregrad der neuritischen Schädigung im APPSLPS1KI-Mausmodell hin. 


\section{Anhang}

\subsection{Färbeprotokolle}

\subsubsection{DAB-Immunfärbung Paraffin-fixierter Hirnschnitte}

\section{TAG 1}

\section{Deparaffinieren, Rehydrieren und Blockade endogener Peroxidaseaktivität:}

Deparaffinieren:

Hydrierung:

Peroxidase-Block:

\section{Antigen-Retrieval:}

Antigen-Retrieval:

Waschen:
Enfernen des Paraffins aus Gehirnschnitten 2 x 5 min Xylol

Hydrierung des Gewebes in aufsteigender Alkoholreihe 10 min $100 \%$ Ethanol 5 min $95 \%$ Ethanol $1 \mathrm{~min} 70 \%$ Ethanol 1 min deionisiertes $\mathrm{H}_{2} \mathrm{O}$

Blockade der endogenen Peroxidaseaktivität des Gewebes

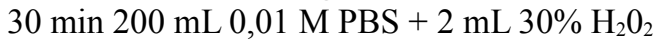

Wiederherstellen der Immunreaktivität des formalinfixierten und paraffineingebetteten Gewebes

$10 \mathrm{mM}$ Citratpuffer

10 min Mikrowelle: bei $800 \mathrm{~W}$ bis zum Sieden (nach etwa $2 \mathrm{~min}$ ), dann $80 \mathrm{~W}$ 15 min Abkühlen

Spülen der Schnitte und Permeabilisierung der Membranen 1 min deionisiertes $\mathrm{H}_{2} \mathrm{O}$

$3 \times 5 \min 0,01 \mathrm{M}$ PBS $+0,1 \%$ Triton X-100

$1 \min 0,01 \mathrm{M}$ PBS

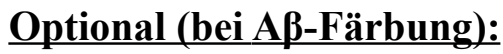

Antigen-Retrieval: Vorbehandlung des Gewebes mit Ameisensäure 3 min $88 \%$ Ameisensäure $1 \min 0,01 \mathrm{M}$ PBS

Waschen:

$5 \min 0,01 \mathrm{M}$ PBS

\section{Indirekte Immunhistochemie:}

Unspezifischer Block:

Primärantikörper:
Blockade unspezifischer Proteininteraktionen $0,01 \mathrm{M} \mathrm{PBS}+10 \% \mathrm{FCS}+4 \%$ Milchpulver Inkubation für 60 min bei Raumtemperatur

Inkubation mit unmarkiertem Primärantikörper Verdünnung des Primärantikörpers in $0,01 \mathrm{M}$ PBS $+10 \%$ FCS Inkubation über Nacht bei Raumtemperatur 


\section{$\underline{T_{A G} 2}$}

Waschen:

Sekundärantikörper:

Waschen:

ABC-Inkubation:

Waschen:

DAB-Färbung:

Waschen:

Gegenfärbung:

Dehydrierung:

Einbettung:
$3 \times 5 \min 0,01 \mathrm{M}$ PBS $+0,1 \%$ Triton $\mathrm{X}-100$ $1 \min 0,01 \mathrm{M}$ PBS

Inkubation mit biotinyliertem Sekundärantikörper Verdünnung der Sekundärantikörper (Verhältnis 1:200) in 0,01 M PBS + 10\% FSC

Inkubation für $60 \mathrm{~min}$ bei $37^{\circ} \mathrm{C}$

$3 \times 5 \min 0,01 \mathrm{M}$ PBS

Inkubation mit Avidin-Biotin-Enzym-Komplex (ABC)

$0,01 \mathrm{M}$ PBS $+10 \%$ FCS + Lösung A (Verhältnis 1:100) + Lösung B (Verhältnis 1:100)

Inkubation für $90 \mathrm{~min}$ bei $37^{\circ} \mathrm{C}$

$3 \times 5 \min 0,01 \mathrm{M}$ PBS

Zugabe des Chromogens DAB (3,3'-Diaminobenzidin) $5 \mathrm{~mL} 50 \mathrm{mM}$ Tris-HCl pH 7,5 + $100 \mu \mathrm{L}$ DAB-Lösung $+2,5 \mu \mathrm{L} 30 \% \mathrm{H}_{2} \mathrm{O}_{2}$ (DAB-Lösung: $25 \mathrm{mg} / \mathrm{mL}$ in $\mathrm{H}_{2} 0$ )

Dauer der Färbung je nach eingesetzem Primärantikörper

3 x $5 \min 0,01 \mathrm{M}$ PBS

Zellkernfärbung mit Hämatoxylin

$40 \mathrm{sec}$ Hämatoxylin

kurz in deionisiertem $\mathrm{H}_{2} 0$ waschen

5 min unter fließendem Wasser waschen

Dehydrierung in aufsteigender Alkoholreihe

$1 \min 70 \%$ Ethanol

$5 \min 95 \%$ Ethanol

10 min $100 \%$ Ethanol

2 x 5 min Xylol

Einbettung der Schnitte in Einschlussmedium und Abdeckung mit Deckglas

\subsubsection{Fluoreszenz-Immunfärbung Paraffin-fixierter Hirnschnitte}

\section{$\underline{\text { TAG } 1}$}

\section{Deparaffinieren und Rehydrieren:}

Deparaffinieren:

Hydrierung:
Entfernen des Paraffins aus Gehirnschnitten 2 x 5 min Xylol

Hydrierung des Gewebes in aufsteigender Alkoholreihe 10 min $100 \%$ Ethanol

$5 \min 95 \%$ Ethanol

$1 \mathrm{~min} 70 \%$ Ethanol

1 min deionisiertes $\mathrm{H}_{2} \mathrm{O}$ 


\section{Antigen-Retrieval:}

Antigen-Retrieval:

Waschen:
Wiederherstellen der Immunreaktivität des formalinfixierten und paraffineingebetteten Gewebes

$10 \mathrm{mM}$ Citratpuffer

10 min Mikrowelle: bei $800 \mathrm{~W}$ bis zum Sieden (nach etwa $2 \mathrm{~min}$ ), dann $80 \mathrm{~W}$ 15 min Abkühlen

Spülen der Schnitte und Permeabilisierung der Membranen 1 min deionisiertes $\mathrm{H}_{2} \mathrm{O}$

$15 \min 0,01 \mathrm{M}$ PBS $+0,1 \%$ Triton $\mathrm{X}-100$

$1 \min 0,01 \mathrm{M}$ PBS

\section{Optional (bei A $\beta$-Färbung):}

Antigen-Retrieval: Vorbehandlung des Gewebes mit Ameisensäure

3 min $88 \%$ Ameisensäure

1 min $0,01 \mathrm{M}$ PBS

Waschen:

5 min $0,01 \mathrm{M}$ PBS

\section{Indirekte Immunhistochemie:}

Unspezifischer Block:

Primärantikörper:
Blockade unspezifischer Proteininteraktionen $0,01 \mathrm{M} \mathrm{PBS}+10 \% \mathrm{FCS}+4 \%$ Milchpulver Inkubation für $60 \mathrm{~min}$ bei Raumtemperatur

Inkubation mit unmarkiertem Primärantikörper

Verdünnung des Primärantikörpers in $0,01 \mathrm{M} \mathrm{PBS}+10 \%$ FCS

Inkubation über Nacht bei Raumtemperatur

\section{$\underline{\text { TAG } 2^{2}}$}

Waschen:

Sekundärantikörper:

Waschen:

Gegenfärbung:

Einbettung:
$15 \min 0,01 \mathrm{M}$ PBS $+0,1 \%$ Triton X-100 1 min $0,01 \mathrm{M}$ PBS

Inkubation mit fluoreszenzmarkiertem Sekundärantikörper Verdünnung der Sekundärantikörper (Verhältnis 1:200) in 0,01 M PBS + 10\% FSC (Antikörper vor Licht schützen)

Inkubation für $90 \mathrm{~min}$ bei $37^{\circ} \mathrm{C}$

3 x 5 min 0,01 M PBS (Antikörper vor Licht schützen)

Zellkernfärbung mit DAPI (4',6-Diamidino-2-phenylindol) $1 \mathrm{~min}$ DAPI $(1,5 \mathrm{mg} / \mathrm{L})$

1 min PBS

(Antikörper vor Licht schützen)

Einbettung der Schnitte in Einschlussmedium und Abdeckung mit Deckglas 


\subsection{Einzelwerte der Quantifizierung dystropher Neuriten}

Angegeben sind die von Syntaxin-13-, Vtilb- bzw. Synuclein- $\alpha$-Immunreaktivität bedeckten Flächenanteile in \% der betrachteten Gesamtfläche (Area Fraction) im Kortex 6 bzw. 10 Monate alter APP ${ }^{\mathrm{SL} P S 1 K I-M a ̈ u s e . ~ F u ̈ r ~ j e d e s ~ T i e r ~(H o / H e-N u m m e r) ~ w u r d e n ~ m i n d e s t e n s ~} 3$ Schnitte analysiert und die Mittelwerte pro Tier und Altersstufe ermittelt.

Syntaxin 13 - 6 Monate

\begin{tabular}{|c|c|}
\hline $\begin{array}{l}\text { APP }{ }^{\mathrm{SL}} \mathrm{PS} 1 \mathrm{KI}-\mathrm{M}_{\mathrm{AuS}} \\
6 \text { Monate }\end{array}$ & $\begin{array}{l}\text { Area Fraction [\%] } \\
\text { Syntaxin } 13\end{array}$ \\
\hline \multirow[t]{3}{*}{ Ho/He-131: } & 22,2 \\
\hline & 23,6 \\
\hline & 24,2 \\
\hline Mittelwert Ho/He-131: & 23,3 \\
\hline \multirow[t]{3}{*}{ Ho/He-132: } & 19,5 \\
\hline & 17,1 \\
\hline & 16,7 \\
\hline Mittelwert Ho/He-132: & 17,8 \\
\hline \multirow[t]{4}{*}{ Ho/He-133: } & 18,6 \\
\hline & 22,6 \\
\hline & 16,5 \\
\hline & 18,6 \\
\hline Mittelwert Ho/He-133: & 19,1 \\
\hline \multirow[t]{4}{*}{ Ho/He-134: } & 22,9 \\
\hline & 21,9 \\
\hline & 22,4 \\
\hline & 22,3 \\
\hline Mittelwert Ho/He-134: & 22,4 \\
\hline Mittelwert aller Mäuse: & 20,6 \\
\hline
\end{tabular}


Syntaxin 13 - 10 Monate

\begin{tabular}{|c|c|}
\hline $\begin{array}{l}\text { APP }{ }^{S L} \text { PS1KI-Maus } \\
10 \text { Monate }\end{array}$ & $\begin{array}{l}\text { Area Fraction [\%] } \\
\text { Syntaxin } 13\end{array}$ \\
\hline \multirow[t]{4}{*}{ Но/He-36: } & 22,1 \\
\hline & 19,5 \\
\hline & 21,4 \\
\hline & 19,0 \\
\hline Mittelwert Ho/He-36: & 20,5 \\
\hline \multirow[t]{3}{*}{ Ho/He-37: } & 18,5 \\
\hline & 21,6 \\
\hline & 20,7 \\
\hline Mittelwert Ho/He-37: & 20,4 \\
\hline \multirow[t]{4}{*}{ Ho/He-38: } & 20,9 \\
\hline & 18,0 \\
\hline & 22,3 \\
\hline & 21,3 \\
\hline Mittelwert Ho/He-38: & 20,6 \\
\hline \multirow[t]{3}{*}{ Ho/He-47: } & 16,9 \\
\hline & 21,0 \\
\hline & 21,5 \\
\hline Mittelwert Ho/He-47: & 19,8 \\
\hline Mittelwert aller Mäuse: & 20,3 \\
\hline
\end{tabular}




\begin{tabular}{|c|c|}
\hline \multicolumn{2}{|c|}{ Vti1b - 6 Monate } \\
\hline APP $^{\text {SL PS1 KI-MAUS }}$ & Area Fraction [\%] \\
\hline 6 Monate & Vті 1в \\
\hline \multirow[t]{6}{*}{ Ho/He-131: } & 22,4 \\
\hline & 24,5 \\
\hline & 22,1 \\
\hline & 21,0 \\
\hline & 25,7 \\
\hline & 23,8 \\
\hline Mittelwert Ho/He-131: & 23,25 \\
\hline \multirow[t]{4}{*}{ Ho/He-132: } & 22,7 \\
\hline & 24,0 \\
\hline & 24,0 \\
\hline & 19,3 \\
\hline Mittelwert Ho/He-132: & 22,5 \\
\hline \multirow[t]{5}{*}{ Ho/He-133: } & 21,6 \\
\hline & 28,8 \\
\hline & 23,8 \\
\hline & 23,5 \\
\hline & 22,7 \\
\hline Mittelwert Ho/He-133: & 24,08 \\
\hline \multirow[t]{7}{*}{ Ho/He-134: } & 19,5 \\
\hline & 21,2 \\
\hline & 19,8 \\
\hline & 22,5 \\
\hline & 22,8 \\
\hline & 23,7 \\
\hline & 28,3 \\
\hline Mittelwert Ho/He-134: & 22,54 \\
\hline Mittelwert aller Mäuse: & 23,09 \\
\hline
\end{tabular}




\begin{tabular}{|c|c|}
\hline \multicolumn{2}{|c|}{ Vti1b - 10 Monate } \\
\hline $\begin{array}{l}\text { APP }{ }^{\mathrm{SL}} \mathrm{PS1KI} \text {-Maus } \\
10 \text { Monate }\end{array}$ & $\begin{array}{l}\text { Area Fraction [\%] } \\
\text { Vti1 b }\end{array}$ \\
\hline \multirow[t]{5}{*}{ Ho/He-36: } & 22,7 \\
\hline & 23,3 \\
\hline & 21,2 \\
\hline & 20,7 \\
\hline & 21,0 \\
\hline Mittelwert Ho/He-36: & 21,8 \\
\hline \multirow[t]{4}{*}{ Ho/He-37: } & 23,0 \\
\hline & 27,4 \\
\hline & 25,0 \\
\hline & 23,1 \\
\hline Mittelwert Ho/He-37: & 24,6 \\
\hline \multirow[t]{4}{*}{ Ho/He-38: } & 22,4 \\
\hline & 21,0 \\
\hline & 25,7 \\
\hline & 26,0 \\
\hline Mittelwert Ho/He-38: & 23,8 \\
\hline \multirow[t]{3}{*}{ Ho/He-47: } & 25,8 \\
\hline & 28,5 \\
\hline & 27,2 \\
\hline Mittelwert Ho/He-47: & 27,2 \\
\hline Mittelwert aller Mäuse: & 24,3 \\
\hline
\end{tabular}


Synuclein $\alpha-6$ Monate

\begin{tabular}{|c|c|}
\hline $\begin{array}{l}\text { APP }{ }^{S L} \text { PS1KI-Maus } \\
6 \text { Monate }\end{array}$ & $\begin{array}{l}\text { Area Fraction [\%] } \\
\text { Synuclein a }\end{array}$ \\
\hline \multirow[t]{5}{*}{ Ho/He-131: } & 19,2 \\
\hline & 20,0 \\
\hline & 16,3 \\
\hline & 19,4 \\
\hline & 16,4 \\
\hline Mittelwert Ho/He-131: & 18,26 \\
\hline \multirow[t]{3}{*}{ Ho/He-132: } & 18,6 \\
\hline & 15,5 \\
\hline & 16,4 \\
\hline Mittelwert Ho/He-132: & 16,83 \\
\hline \multirow[t]{5}{*}{ Ho/He-133: } & 17,4 \\
\hline & 15,8 \\
\hline & 18,9 \\
\hline & 16,0 \\
\hline & 17,1 \\
\hline Mittelwert Ho/He-133: & 17,04 \\
\hline \multirow[t]{5}{*}{ Ho/He-134: } & 17,7 \\
\hline & 18,7 \\
\hline & 15,2 \\
\hline & 17,3 \\
\hline & 16,6 \\
\hline Mittelwert Ho/He-134: & 17,1 \\
\hline Mittelwert aller Mäuse: & 17,31 \\
\hline
\end{tabular}


Synuclein $\alpha-10$ Monate

\begin{tabular}{|c|c|}
\hline $\begin{array}{l}\text { APP }{ }^{S L} \text { PS1KI-Maus } \\
10 \text { Monate }\end{array}$ & $\begin{array}{l}\text { Area Fraction [\%] } \\
\text { Synuclein a }\end{array}$ \\
\hline \multirow[t]{5}{*}{ Ho/He-36: } & 14,5 \\
\hline & 14,4 \\
\hline & 14,4 \\
\hline & 17,4 \\
\hline & 19,7 \\
\hline Mittelwert Ho/He-36: & 16,08 \\
\hline \multirow[t]{5}{*}{ Ho/He-37: } & 16,6 \\
\hline & 20,9 \\
\hline & 17,8 \\
\hline & 19,3 \\
\hline & 17,3 \\
\hline Mittelwert Ho/He-37: & 18,38 \\
\hline \multirow[t]{6}{*}{ Ho/He-38: } & 19,1 \\
\hline & 19,3 \\
\hline & 16,4 \\
\hline & 17,7 \\
\hline & 18,8 \\
\hline & 15,8 \\
\hline Mittelwert Ho/He-38: & 17,85 \\
\hline \multirow[t]{3}{*}{ Ho/He-47: } & 18,0 \\
\hline & 19,7 \\
\hline & 14,7 \\
\hline Mittelwert Ho/He-47: & 17,47 \\
\hline Mittelwert aller Mäuse: & 17,45 \\
\hline
\end{tabular}




\section{LiteraturVERZEICHNIS}

Alafuzoff I, Pikkarainen M, Arzberger T, Thal DR, Al-Sarraj S, Bell J, Bodi I, Budka H, CapetilloZarate E, Ferrer I (2008): Inter-laboratory comparison of neuropathological assessments of beta-amyloid protein: a study of the BrainNet Europe consortium. Acta Neuropathol $\underline{115}$, 533-546

Alzheimer's Association Report 2009: Alzheimer's Association: 2009 Alzheimer's Disease - Facts and Figures; abrufbar unter: http://www.alz.org/national/documents/report_alzfactsfigures 2009.pdf

Antonin W, Fasshauer D, Becker S, Jahn R, Schneider TR (2002): Crystal structure of the endosomal SNARE complex reveals common structural principles of all SNAREs. Nat Struct Biol $\underline{9}, 107-111$

Armstrong DM, Terry RD (1985): Substance P immunoreactivity within neuritic plaques. Neurosci Lett $\underline{58}, 139-144$

Armstrong DM, Bruce G, Hersh LB, Terry RD (1986): Choline acetyltranferase immunoreactivity in in neuritic plaques of Alzheimer brain. Neurosci Lett $\underline{71}, 229-234$

Armstrong DM, Benzing WC, Evans J, Terry RD, Shields D, Hansen LA (1989): Substance P and somatostatin coexist within neuritic plaques: implacations for the pathogenesis of Alzheimer's disease. Neuroscience $\underline{31}, 663-671$

Bandelow B, Gruber O, Falkai P: Kurzlehrbuch Psychiatrie. 1. Auflage; Steinkopff Verlag, Heidelberg 2008

Bayer TA, Wirths O (2008a): Review on the APP/PS1KI mouse model: intraneuronal A $\beta$ accumulation triggers axonopathy, neuron loss and working memory impairment. Genes Brain Behav ㄱ, 2-7

Bayer TA, Wirths O (2008b): Alzheimer-Demenz - Molekulare Pathologie, Tiermodelle und Therapiestrategien. Nervenarzt $\underline{79}, 117-128$

Bell KF, Cuello AC (2006): Altered synaptic function in Alzheimer's disease. Eur J Pharmacol $\underline{545}$, $11-21$

Bell KF, Ducatenzeiler A, Ribeiro-da-Silva A, Duff K, Bennet DA, Cuello AC (2005): The amyloid pathology progresses in a neurotransmitter-specific manner. Neurobiol Aging $\underline{27}, 1644-1657$

Bickel H (2001): Demenzen im höheren Lebensalter: Schätzung des Vorkommens und der Versorgungskosten. Z Gerontol Geriatr $\underline{34}$, 108-115 
Bickel H (2010): Deutsche Alzheimer Gesellschaft e.V.: Die Epidemiologie der Demenz, Informationsblatt erstellt von Dr. H. Bickel 08/2010; abrufbar unter: http://www.deutschealzheimer.de/fileadmin/alz/pdf/factsheets/FactSheet01_10.pdf

Blanchard V, Moussaoui S, Czech C, Touchet N, Bonici B, Planche M, Canton T, Jedidi I, Gohin M, Wirths O (2003): Time sequence of maturation of dystrophic neurites associated with Abeta deposits in APP/PS1 transgenic mice. Exp Neurol 184, 247-263

Blennow K, Hampel H (2003): CSF markers for incipient Alzheimer's disease. Lancet Neurol $\underline{2}$, 605-613

Blennow K, de Leon MJ, Zetterberg H (2006): Alzheimer's disease. Lancet 368, 387-403

Block MR, Glick BS, Wilcox CA, Wieland FT, Rothman JE (1988): Purification of an Nethylmaleimide-sensitive protein catalyzing vesicular transport. Proc Natl Acad Sci USA $\underline{85}$, $7852-7856$

Braak H, Braak E (1991): Neuropathological stageing of Alzheimer-related changes. Acta Neuropathol $\underline{82}, 239-259$

Braak H, Alafuzoff I, Arzberger T, Kretzschmar H, Del Tredici K (2006):Staging of Alzheimer disease-associated neurofibrillary pathology using paraffin sections and immunocytochemistry. Acta Neuropathol 112, 389-404

Breyhan H, Wirths O, Duan K, Marcello A, Rettig J, Bayer TA (2009): APP/PS1KI bigenic mice develop early synaptic deficits and hippocampus atrophy. Acta Neuropathol 117, 677-685

Brion JP, Chouk AM, Bruce M, Anderton B, Flament-Durant J (1991): Synaptophysin and chromogranin A immunoreactivities in senile plaques of Alzheimer's disease. Brain Res $\underline{539}$, $143-150$

Brody DL, Holtzmann DM (2008): Active and passive immunotherapy for neurodegenerative disorders. Annu Rev Neurosci $\underline{31}, 175-193$

Bullock R, Touchon J, Bergman H, Gambina G, He Y, Rapatz G, Nagel J, Lane R (2005): Rivastigmine and donepezil treatment in moderate to moderately-severe Alzheimer's disease over a 2-year period. Curr Med Res Opin 21, 1317-1327

Buxbaum JD, Liu KN, Luo Y, Slack JL, Stocking KL, Peschon JJ, Jahnson RS, Castner BJ, Cerretti DP, Black RA (1998): Evidence that tumor necrosis factor alpha converting enzyme is involved in regulated alpha-secretase cleavage of the Alzheimer amyloid protein precursor. $\mathrm{J}$ Biol Chem 273, 27765-27767

Cai XD, Golde TE, Younkin SG (1993): Release of excess amyloid beta protein from a mutant beta protein precursor. Science $\underline{259}, 514-516$

Casas C, Sergeant N, Itier JM, Blanchard V, Wirths O, van der Kolk N, Vingtdeux V, van de Steeg 
E, Ret G, Canton T et al. (2004): Massive CA1/2 neuronal loss with intraneuronal and Nterminal truncated $\mathrm{A} \beta_{42}$ accumulation in a novel Alzheimer transgenic model. Am J Pathol $\underline{165}, 1289-1300$

Chang WP, Koelsch G, Wong S, Downs D, Da H, Weerasena V, Gordon B, Devasamudram T, Bilcer G, Ghosh AK (2004): In vivo inhibition of Abeta production by memapsin 2 (betasecretase) inhibitors. J Neurochem $\underline{89}, 1409-1416$

Chartier-Harlin MC, Crawford F, Houlden H, Warren A, Hughes D, Fidani L, Goate A, Rossor M, Roques P, Hardy J et al. (1991): Early-onset Alzheimer's disease caused by mutations at codon 717 of the beta-amyloid precursor protein gene. Nature $\underline{353}, 844-846$

Christensen DZ: Pathological Alterations Induced by Intraneuronal A $\beta$ in Alzheimer's Disease. Doctoral Thesis (Ph.D.), Faculty of Medicine, Göttingen 2009

Christensen DZ, Kraus SL, Flohr A, Cotel MC, Wirths O, Bayer TA (2008): Transient intraneuronal $\mathrm{A} \beta$ rather than extracellular plaque pathology correlates with neuron loss in the frontal cortex of APP/PS1KI mice. Acta Neuropathol 116, 647-655

Christensen DZ, Bayer TA, Wirths O (2010): Intracellular Abeta triggers neuron loss in the cholinergic system of the APP/PS1KI mouse model of Alzheimer's disease. Neurobiol Aging $31,1153-1163$

Citron M, Oltersdorf T, Haass C, McConlogue L, Hung AY, Seubert P, Vigo-Pelfrey C, Lieberburg I, Selkoe DJ (1992): Mutation of the beta-amyloid precursor protein in familial Alzheimer's disease increases beta-protein production. Nature $\underline{360}, 672-674$

Citron M, Vigo-Pelfrey C, Teplow DB, Miller C, Schenk D, Johnston J, Winblad B, Venizelos N, Lannfelt L, Selkoe DJ (1994): Excessive production of amyloid beta-protein by peripheral cells of symptomatic and presymptomatic patients carrying the Swedish Familial Alzheimer's disease mutation. Proc Natl Acad Sci USA 91, 11993-11997

Clary DO, Griff IC, Rothman JE (1990): SNAPs, a family of NSF attachment proteins involved in intracellular membrane fusion in animals and yeast. Cell $\underline{61}, 709-721$

Cole GM, Masliah E, Shelton ER, Chan H, Terry RD, Saitoh T (1991): Accumulation of N-terminal sequence of beta-protein precursor in the neuritic component of Alzheimer disease senile plaque. Neurobiol Aging $\underline{12}, 85-91$

Coleman M (2005): Axon degeneration mechanisms: commonality amid diversity. Nat Rev Neurosci $\underline{6}, 889-898$

Corder EH, Saunders AM, Strittmatter WJ, Schmechel DE, Gaskell PC, Small GW, Roses AD, Haines JL, Pericak-Vance MA (1993): Gene dose of apolipoprotein E type 4 allele and the risk of Alzheimer's disease in late onset families. Science 261, 921-923 
Cras P, Kawai M, Lowery D, Gonzalez-DeWhitt P, Greenberg B, Perry G (1991): Senile plaque neurites in Alzheimer disease accumulate amyloid precursor protein. Proc Natl Acad Sci USA $\underline{88}, 7552-7556$

Davies CA, Mann DMA, Sumpter PQ, Yates PO (1987): A quantitative morphometric analysis of the neuronal and synaptic content of the frontal and temporal cortex in patients with Alzheimer's disease. J Neurol Sci $\underline{78}, 151-164$

Deller T, Merten T, Roth SU, Mundel P, Frotscher M (2000): Actin-associated protein synaptopodin in the rat hippocampal formation: localization in the spine neck and close association with the spine apparatus of principal neurons. J Comp Neurol 418, 164-181

Deller T, Korte M, Chabanis S, Drakew A, Schwegler H, Stefani GG, Zuniga A, Schwarz K, Bonhoeffer T, Zeller R et al. (2003): Synaptopodin-deficient mice lack a spine apparatus and show deficits in synaptic plasticity. Proc Natl Acad Sci USA $100,10494-10499$

Dickson TC, King CE, McCormack GH, Vickers JC (1999): Neurochemical diversity of dystrophic neurites in the early and late stages of Alzheimer's disease. Exp Neurol 156, 100-110

Duff K, Eckman C, Zehr C, Yu X, Prada CM, Perez-Tur J, Hutton M, Buee L, Harigaya Y, Yager D et al. (1996): Increased amyloid- $\beta 42(43)$ in brains of mice expressing mutant presenilin 1. Nature $\underline{383}, 710-713$

Emre M, Geula C, Ransil BJ, Mesulam MM (1992): The acute neurotoxicity and effects upon cholinergic axons of intracerebrally injected beta-amyloid in the rat brain. Neurobiol Aging $\underline{13}, 553-559$

Etcheberrigaray R, Tan M, Dewachter I, Kuipéri C, Van der Auwera I, Wera S, Qiao L, Bank B, Nelson TJ, Kozikowski AP (2004): Therapeutic effects of PKC activators in Alzheimer's disease transgenic mice. Proc Natl Acad Sci USA $\underline{101}$, 11141-11146

Fasshauer D, Sutton RB, Brunger AT, Jahn R (1998): Conserved structural features of the synaptic fusion complex: SNARE proteins reclassified as Q- and R-SNAREs. Proc Natl Acad Sci USA $\underline{95}, 15781-15786$

Fernandez-Vizarra P, Fernandez AP, Castro-Blanco S, Serrano J, Bentura ML, Martinez-Murillo R, Martinez A, Rodrigo J (2004): Intra- and extracellular Abeta and PHF in clinically evaluated cases of Alzheimer's disease. Histol Histopathol $\underline{19}, 823-844$

Ferrer I, Martí E, Tortosa A, Blasi J (1998): Dystrophic neurites of senile plaques are defective in proteins involved in exocytosis and neurotransmission. J Neuropathol Exp Neurol $\underline{57}, 218$ 225

Fiala JC (2007): Mechanisms of amyloid plaque pathogenesis. Acta Neuropathol 114, 551-571

Folstein MF, Folstein SE, McHugh PR (1975): "Mini-mental state". A practical method for grading 
the cognitive state of patients for the clinician. J Psychiatr Res $\underline{12}, 189-198$

Galvin JE, Uryu K, Lee VM, Trojanowski JQ (1999): Axon pathology in Parkinson's disease and Lewy body dementia hippocampus contains alpha-, beta-, and gamma-synuclein. Proc Natl Acad Sci USA 무, 13450-13455

Games D, Adams D, Alessandrini R, Barbour R, Berthelette P, Blackwell C, Carr T, Clemens J, Donaldson T, Gillespie F et al. (1995): Alzheimer-type neuropathology in transgenic mice overexpressing V717F $\beta$-amyloid precursor protein. Nature $\underline{373}$, 523-527

George JM (2001): The synucleins. Genome Biol $\underline{3}$, Reviews 3002.1-3002.6

George JM, Jin H, Woods WS, Clayton DF (1995): Characterization of a novel protein regulated during the critical period for song learning in the zebra finch. Neuron $\underline{15}, 361-372$

Glenner GG, Wong CW (1984): Alzheimer's disease: initial report of the purification and characterization of a novel cerebrovascular amyloid protein. Biochem Biophys Res Commun $\underline{120}, 885-890$

Goate A, Chartier-Harlin MC, Mullan M, Brown J, Crawford F, Fidani L, Giuffra L, Haynes A, Irving N, James L et al. (1991): Segregation of a missense mutation in the amyloid precursor protein gene with familial Alzheimer's disease. Nature $\underline{349}$, 704-706

Gonatas NK, Anderson A, Evangelista I (1967): The contribution of altered synapses in the senile plaque: an electron microscopic study in Alzheimer's dementia. J Neuropathol Exp Neurol $\underline{26}, 25-39$

Haass C, Schlossmacher MG, Hung AY, Vigo-Pelfrey C, Mellon A, Ostaszewski BL, Lieberburg I, Koo EH, Schenk D, Teplow DB et al. (1992): Amyloid beta-peptide is produced by cultured cells during normal metabolism. Nature $\underline{359}, 322-325$

Haass C, Hung AY, Selkoe DJ, Teplow DB (1994): Mutations associated with a locus for familial Alzheimer's disease result in alternative processing of amyloid beta-protein precursor. J Biol Chem $\underline{269}, 17741-17748$

Hansen L, Salmon D, Galasko D, Masliah E, Katzman R, DeTeresa R, Thal L, Pay MM, Hofstetter R, Klauber M et al. (1990): The Lewy body variant of Alzheimer's disease: a clinical and pathologic entity. Neurology $\underline{40}, 1-8$

Hardy J, Allsop D (1991): Amyloid deposition as the central event in the aetiology of Alzheimer's disease. Trends Pharmacol Sci $\underline{12}, 383-388$

Holcomb L, Gordon MN, McGowan E, Yu X, Benkovis S, Jantzen P, Wright K, Saad I, Mueller R, Morgan D et al. (1998): Accelerated Alzheimer-type phenotype in transgenic mice carrying both mutant amyloid precursor protein and presenilin 1 transgenes. Nat Med $\underline{4}, 97-100$

Honer WG, Dickson DW, Gleeson J, Davies P (1992): Regional synaptic pathology in Alzheimer's 
disease. Neurobiol Aging $\underline{13}, 375-382$

Hsiao K, Chapman P, Nilsen S, Eckman C, Harigaya Y, Younkin S, Yang F, Cole G (1996): Correlative memory deficits, $A \beta$ elevation, and amyloid plaques in transgenic mice. Science 274, 99-102

http://www.ahaf.org/alzheimers/about/understanding/brain-with-alzheimers.html http://www.sysy.com/flash-synapse/index2.html

Irizarry MC, Growdon W, Gomez-Isla T, Newell K, George JM, Clayton DF, Hyman BT (1998): Nigral and cortical Lewy bodies and dystrophic nigral neurites in Parkinson's disease and cortical Lewy body disease contain alpha-synuclein immunoreactivity. J Neuropathol Exp Neurol 57, 334-337

Ishii T, Kametani F, Haga S, Sato M (1989): The immunohistochemical demonstration of subsequences of the precursor of the amyloid A4 protein in senile plaques in Alzheimer's disease. Neuropathol Appl Neurobiol 15, 135-147

Iwai A, Masliah E, Yoshimoto M, Ge N, Flanagan L, de Silva HA, Kittel A, Saitoh T (1995a): The precursor protein of non-A beta component of Alzheimer's disease amyloid is a presynaptic protein of the central nervous system. Neuron $\underline{14}, 467-475$

Iwai A, Yoshimoto M, Masliah E, Saitoh T (1995b): Non-A beta component of Alzheimer's disease amyloid (NAC) is amyloidogenic. Biochemistry $\underline{34}$, 10139-10145

Jahn R, Südhof TC (1994): Synaptic vesicles and exocytosis. Annu Rev Neurosci 17, 219-246

Jarrett JT, Berger EP, Lansbury PT Jr (1993): The carboxy terminus of the beta amyloid protein is critical for the seeding of amyloid formation: implications for the pathogenesis of Alzheimer's disease. Biochemistry $\underline{32}, 4693-4697$

Jessen F (2008): Neue Perspektiven der Bildgebung in der Diagnostik bei Demenzen. Nervenarzt 79, $129-138$

Joachim CL, Morris JH, Selkoe DJ, Kosik KS (1987): Tau epitopes are incorporated into a range of lesions in Alzheimer's disease. J Neuropathol Exp Neurol 46, 611-622

Joachim C, Games D, Morris J, Ward P, Frenkel D, Selkoe D (1991): Antibodies to non-beta regions of the $\beta$-amyloid precursor protein detect a subset of senile plaques. Am J Pathol $\underline{138}, 373-$ 384

Kamal A, Stokin GB, Yang Z, Xia CH, Goldstein LS (2000): Axonal transport of amyloid precursor protein is mediated by direct binding to the kinesin light chain subunit of kinesin-I. Neuron $\underline{28}, 449-459$

Kamal A, Almenar-Queralt A, LeBlanc JF, Roberts EA, Goldstein LS (2001): Kinesin-mediated axonal transport of a membrane compartment containing beta-secretase and presenilin-1 
requires APP. Nature $\underline{414}, 643-648$

Knowles RB, Wyart C, Buldyrev SV, Cruz L, Urbanc B, Hasselmo ME, Stanley HE, Hyman BT (1999): Plaque-induced neurite abnormalities: implications for disruption of neural networks in Alzheimer's disease. Proc Natl Acad Sci USA $\underline{96}$, 5274-5279

Kreykenbohm V, Wenzel D, Antonin W, Atlachkine V, von Mollard GF (2002): The SNAREs vtila and vtilb have distinct localization and SNARE complex partners. Eur J Cell Biol $\underline{81}, 273-$ 280

Lammich S, Kojro E, Postina R, Gilbert S, Pfeiffer R, Jasionowski M, Haass C, Fahrenholz F (1999): Constitutive and regulated alpha-secretase cleavage of Alzheimer's amyloid

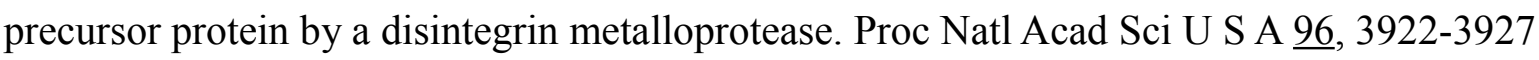

Lazarov O, Lee M, Peterson DA, Sisodia SS (2002): Evidence that synaptically released betaamyloid accumulates as extracellular deposits in the hippocampus of transgenic mice. $\mathrm{J}$ Neurosci $\underline{22}, 9785-9793$

Levy-Lahad E, Wasco W, Poorkaj P, Romano DM, Oshima J, Pettingell H, Yu C, Jondro PD, Schmidt SD, Wang K et al. (1995): Candidate gene for the chromosome 1 familial Alzheimer's disease locus. Science 269, 973-977

Lin RC, Scheller RH (2000): Mechanisms of synaptic vesicle exocytosis. Annu Rev Cell Dev Biol $\underline{16}, 19-49$

Masliah E, Terry R (1983): The role of synaptic proteins in the pathogenesis of disorders of the central nervous system. Brain Pathol $\underline{3}, 77-85$

Masliah E, Terry RD, Mallory M, Alford M, Hansen LA (1990): Diffuse plaques do not accentuate synapse loss in Alzheimer's disease. Am J Pathol 137, 1293-1297

Masliah E, Terry RD, Alford M, DeTeresa RM, Hansen LA (1991): Cortical and subcortical patterns of synaptophysin-like immunoreactivity in Alzheimer disease. Am J Pathol 138, 235-246

Masliah E, Mallory M, Deerinck T, DeTeresa R, Lamont S, Miller A, Terry RD, Carragher B, Elliman M (1993): Re-evaluation of the structural organization of neuritic plaques in Alzheimer's disease. J Neuropathol Exp Neurol 52, 619-632

Masters CL, Simms G, Weinman NA, Multhaup G, McDonald BL, Beyreuther K (1985): Amyloid plaque core protein in Alzheimer disease and Down syndrome. Proc Natl Acad Sci USA $\underline{82}$, 4245-4249

Masuhr KF, Neumann M: Duale Reihe Neurologie. 6. Auflage; Georg Thieme Verlag 2007

McKee AC, Kosik KS, Kowall NW (1991): Neuritic pathology and dementia in Alzheimer's disease. Ann Neurol $\underline{30}, 156-165$

Mullan MJ, Crawford F, Axelman K, Houlden H, Lilius L, Winblad B, Lannfelt L (1992): A 
pathogenic mutation for probable Alzheimer's disease in the APP gene at the N-terminus of beta-amyloid. Nature Genet $\underline{1}, 345-347$

Mundel P, Heid HW, Mundel TM, Krüger M, Reiser J, Kriz W (1997): Synaptopodin: an actinassociated protein in telencephalic dendrites and renal podocytes. J Cell Biol 139, 193-204

Muñoz DG (1991): Chromogranin A-like immunoreactive neurites are major constituents of senile plaques. Lab Invest $\underline{64}, 826-832$

Murphy DD, Rueter SM, Trojanowski JQ, Lee VM (2000): Synucleins are developmentally expressed, and alpha-synuclein regulates the size of the presynaptic vesicular pool in primary hippocampal neurons. J Neurosci $\underline{20}$, 3214-3220

Murrell J, Farlow M, Ghetti B, Benson MD (1991): A mutation in the amyloid precursor protein associated with hereditary Alzheimer's disease. Science 254, 97-99

Perin MS, Fried VA, Stone DK, Xie XS, Südhof TC (1991): Structure of the 116-kDa polypeptide of the clathrin-coated vesicle/synaptic vesicle proton pump. J Biol Chem $\underline{266}, 3877-3881$

Perry G, Friedman R, Shaw G, Chau V (1987): Ubiquitin is detected in neurofibrillary tangles and senile plaque neurites of Alzheimer's brain. Proc Natl Acad Sci USA 또, 3033-3036

Petersen RC, Smith GE, Waring SC, Ivnik RJ, Tangalos EG, Kokmen E (1999): Mild cognitive impairment: clinical characterization and outcome.Arch Neurol $\underline{56}, 303-308$

Petersen RC, Doody R, Kurz A, Mohs RC, Morris JC, Rabins PV, Ritchie K, Rossor M, Thal L, Winblad B (2001): Current concepts in mild cognitive impairment. Arch Neurol $\underline{58}, 1985-$ 1992

Pettersson AF, Engardt M, Wahlund LO (2002): Activity level and balance in subjects with mild Alzheimer's disease. Dement Geriatr Cogn Disord 13, 213-216

Polymeropoulos MH (2000): Genetics of Parkinson's disease. Ann N Y Acad Sci 920, 28-32

Prekeris R, Klumperman J, Chen YA, Scheller RH (1998): Syntaxin 13 mediates cycling of plasma membrane proteins via tubulovesicular recycling endosomes. J Cell Biol $\underline{143}$, 957-971

Prekeris R, Yang B, Oorschot V, Klumperman J, Scheller RH (1999): Differential roles of syntaxin 7 and syntaxin 8 in endosomal trafficking. Mol Biol Cell $\underline{10}, 3891-3908$

Probst A, Götz J, Wiederhold KH, Tolnay M, Mistl C, Jaton AL, Hong M, Ishihara T, Lee VM, Trojanowski JQ (2000): Axonopathy and amyotrophy in mice transgenic for human fourrepeat tau protein. Acta Neuropathol $\underline{99}, 469-481$

Rogaev EI, Sherrington R, Rogaeva EA, Levesque G, Ikeda M, Liang Y, Chi H, Lin C, Holman K, Tsuda T et al. (1995): Familial Alzheimer's disease in kindreds with missense mutations in a gene on chromosome 1 related to the Alzheimer's disease type 3 gene. Nature $\underline{376}, 775-778$

Samuel W, Masliah E, Hill LR, Butters N, Terry R (1994): Hippocampal connectivity and 
Alzheimer's dementia: effects on synapse loss and tangle frequency in a two-component model. Neurology 44, 2081-2088

Saunders AM, Strittmatter WJ, Schmechel D, St George-Hyslop PH, Pericak-Vance MA, Joo SH, Rosi BL, Gusella JF, Crapper-MacLachlan DR, Alberts MJ et al. (1993): Association of apolipoprotein E allele $\varepsilon 4$ with late-onset familial and sporadic Alzheimer's disease. Neurology $\underline{43}, 1467-1472$

Scheff D, Price D (1996): Quantitative assessment of synaptic density in the outer molecular layer of the hippocampus dentate gyrus in Alzheimer disease. Dementia $7,226-232$

Schellenberg GD, Bird TD, Wijsman EM, Orr HAT, Anderson L, Nemens E, White JA, Bonnycastle L, Weber JL, Alonso ME et al. (1992): Genetic linkage evidence for a familial Alzheimer's disease locus on chromosome 14. Science $\underline{258}, 668-671$

Schiavo G, Rossetto O, Benfenati F, Poulain B, Montecucco C (1994): Tetanus and botulinum neurotoxins are zinc proteases specific for components of the neuroexocytosis apparatus. Ann N Y Acad Sci $\underline{710}, 65-75$

Schmitz C, Rutten BP, Pielen A, Schäfer S, Wirths O, Tremp G, Czech C, Blanchard V, Multhaup G, Rezaie P et al. (2004): Hippocampal neuron loss exceeds amyloid plaque load in a transgenic mouse model of Alzheimer's disease. Am J Pathol 164, 1495-1502

Selkoe DJ (2001): Alzheimer's Disease: Genes, Proteins, and Therapy. Physiol Rev $\underline{81}$, 741-766

Sherrington R, Rogaev EI, Liang Y, Rogaeva EA, Levesque G, Ikeda M, Chi H, Lin C, Li G, Holman $\mathrm{K}$ et al. (1995): Cloning of a gene bearing missense mutations in early-onset familial Alzheimer's disease. Nature $\underline{375}, 754-760$

Smith DH, Chen XH, Nonaka M, Trojanowski JQ, Lee VM, Saatman KE, Leono MJ, Xu BN, Wolf JA, Meaney DF (1999): Accumulation of amyloid beta and tau and the formation of neurofilament inclusions following diffuse brain injury in the pig. J Neuropathol Exp Neurol $\underline{58}, 982-992$

Söllner T, Whiteheart SW, Brunner M, Erdjument-Bromage H, Geromanos S, Tempst P, Rothman JE (1993): SNAP receptors implicated in vesicle targeting and fusion. Nature $\underline{362}, 318-324$

St George-Hyslop PH: Molecular Genetics of Alzheimer disease; in: Alzheimer Disease; hrsg. von Terry RD, Katzman R, Bick KL, Sisodia SS; 2. Auflage; Lippincott Williams \& Wilkins, Philadelphia 1999, 187-206

St George-Hyslop P, Haines J, Rogaev E, Mortilla M, Vaula G, Pericak-Vance M, Foncin JF, Montesi M, Bruni A, Sorbi S (1992): Genetic evidence for a novel familial Alzheimer's disease locus on chromosome 14. Nat Genet $\underline{2}, 330-334$

Stokin GB, Lillo C, Falzone TL, Brusch RG, Rockenstein E, Mount SL, Raman R, Davies P, 
Masliah E, Williams DS (2005): Axonopathy and transport deficits early in the pathogenesis of Alzheimer's disease. Science $\underline{307}, 1282-1288$

Stone JR, Okonkwo DO, Dialo AO, Rubin DG, Mutlu LK, Povlishock JT, Helm GA (2004): Impaired axonal transport and altered axolemmal permeability occur in distinct populations of damaged axons following traumatic brain injury. Exp Neurol 190, 59-69

Sturchler-Pierrat C, Abramowski D, Duke M, Wiederhold KH, Mistl C, Rothacher S, Ledermann B, Bürki K, Frey P, Paganetti PA et al. (1997): Two amyloid precursor protein transgenic mouse models with Alzheimer disease-like pathology. Proc Natl Acad Sci USA 94, 13287-13292

Susuki N, Cheung TT, Cai XD, Odaka A, Otvos L Jr, Eckman C, Golde TE, Younkin SG (1994): An increased percentage of long amyloid beta protein secreted by familial amyloid beta protein precursor (beta APP717) mutants. Science 264, 1336-1340

Sutton RB, Fasshauer D, Jahn R, Brunger AT (1998): Crystal structure of a SNARE complex involved in synaptic exocytosis at 2.4 A resolution. Nature $\underline{395}, 347-353$

Takahashi RH, Milner TA, Li F, Nam EE, Edgar MA, Yamaguchi H, Beal MF, Xu H, Greengard P, Gouras GK (2002): Intraneuronal Alzheimer abeta42 accumulates in multivesicular bodies and is associated with synaptic pathology. Am J Pathol 161, 1869-1879

Tanzi RE, Moir RD, Wagner SL (2004): Clearance of Alzheimer's Abeta peptide: the many roads to perdition. Neuron $\underline{43}, 605-608$

Terry AV Jr, Buccafusco JJ (2003): The cholinergic hypothesis of age and Alzheimer's diseaserelated cognitive deficits: recent challenges and their implications for novel drug development. J Pharmacol Exp Ther $\underline{306}$, 821-827

Terry RD, Gonatas NK, Weiss M (1964): Ultrastructural studies in Alzheimer's presenile dementia. Am J Pathol 4ㅗ, 269-297

Terry RD, Masliah E, Salmon DP, Butters N, DeTeresa R, Hill R, Hansen LA, Katzman R (1991): Physical basis of cognitive alterations in Alzheimer's disease: synapse loss is the major correlate of cognitive impairment. Ann Neurol $\underline{30}, 572-580$

Terry RD, Masliah E, Hansen LA: The Neuropathology of Alzheimer Disease and the Structural Basis of Its Cognitive Alterations; in: Alzheimer Disease; hrsg. von Terry RD, Katzman R, Bick KL, Sisodia SS; 2. Auflage; Lippincott Williams \& Wilkins, Philadelphia 1999, 187206

Tesseur I, Van Dorpe J, Bruynseels K, Bronfman F, Sciot R, Van Lommel A, Van Leuven F (2000): Prominent axonopathy and disruption of axonal transport in transgenic mice expressing human apolipoprotein E4 in neurons of brain and spinal cord. Am J Pathol 157, 1495-1510

Tokuda T, Ikeda S, Sekijima Y, Shoji S, Yanagisawa N, Tomaka A (1997): Plasma levels of amyloid 
beta proteins $A \beta 1-40$ and $A \beta 1-42(43)$ are elevated in Down's syndrome. Ann Neurol $\underline{41}$, $271-273$

Tsai J, Grutzendler J, Duff K, Gan WB (2004): Fibrillar amyloid deposition leads to local synaptic abnormalities and breakage of neuronal branches. Nat Neurosci $\underline{7}, 1181-1183$

Uéda K, Fukushima H, Masliah E, Xia Y, Iwai A, Yoshimoto M, Otero DA, Kondo J, Ihara Y, Saitoh T (1993): Molecular cloning of cDNA encoding an unrecognized component of amyloid in Alzheimer disease. Proc Natl Acad Sci USA 무, 11282-11286

Ungar D, Hughson FM (2003): SNARE protein structure and function. Annu Rev Cell Dev Biol $\underline{19}$, 493-517

Van Broeckhoven C, Backhovens H, Cruts M, De Winter G, Bruyland M, Cras P, Martin JJ (1992):

Mapping of a gene predisposing to early-onset Alzheimer's disease to chromosome 14q24.3. Nat Genet 2 , 335-339

Vassar R, Bennett BD, Babu-Khan S, Kahn S, Mendiaz EA, Denis P, Teplow DB, Ross S, Amarante P, Leoloff R et al. (1999): Beta-secretase cleavage of Alzheimer's amyloid precursor protein by the transmembrane aspartic protease BACE. Science $\underline{286}, 735-741$

Wilcock GK (2003): Memantine for the treatment of dementia. Lancet Neurol 2, 503-505

Wirths O, Weickert S, Majtenyi K, Havas L, Kahle PJ, Okochi M, Haass C, Multhaup G, Beyreuther K, Bayer TA (2000): Lewy body variant of Alzheimer's disease: alpha-synuclein in dystrophic neurites of A beta plaques. Neuroreport 11, 3737-3741

Wirths O, Multhaup G, Czech C, Blanchard V, Moussaoui S, Tremp G, Pradier L, Beyreuther K, Bayer TA (2001): Intraneuronal A $\beta$ accumulation precedes plaque formation in $\beta$-amyloid precursor protein and presenilin-1 double-transgenic mice. Neurosci $\quad$ Lett $\underline{306}, 116-120$

Wirths O, Multhaup G, Czech C, Feldmann N, Blanchard V, Tremp G, Beyreuther K, Pradier L, Bayer TA (2002): Intraneuronal APP/Abeta trafficking and plaque formation in beta-amyloid precursor protein and presenilin-1 transgenic mice. Brain Pathol 12 27 275-286

Wirths O, Multhaup G, Bayer TA (2004): A modified $\beta$-amyloid hypothesis: intraneuronal accumulation of the $\beta$-amyloid peptide - the first step of a fatal cascade. J Neurochem $\underline{91}$, $513-520$

Wirths O, Weis J, Kayed R, Saido TC, Bayer TA (2007): Age-dependent axonal degeneration in an Alzheimer mouse model. Neurobiol Aging 28, 1689-1699

Wirths O, Breyhan H, Schäfer S, Roth C, Bayer TA (2008): Deficits in working memory and motor performance in the APP/PS1ki mouse model for Alzheimer's disease. Neurobiol Aging 29, $891-901$

Wirths O, Breyhan H, Marcello A, Cotel MC, Brück W, Bayer TA (2010): Inflammatory changes 
are tightly associated with neurodegeneration in the brain and spinal cord of the APP/PS1KI mouse model of Alzheimer's disease. Neurobiol Aging 31, 747-757

Wolfe MS (2008a): Gamma-secretase: structure, function, and modulation for Alzheimer's disease. Curr Top Med Chem $\underline{8}, 2-8$

Wolfe MS (2008b): Inhibition and modulation of gamma-secretase for Alzheimer's disease. Neurotherapeutics $\underline{5}, 391-398$ 


\section{Danksagung}

Ich danke Herrn Dr. Oliver Wirths für die freundliche Betreuung und Unterstützung meiner Promotionsarbeit.

Herrn Prof. Dr. Thomas A. Bayer möchte ich für das Promotionsangebot in seiner Arbeitsgruppe und die Vergabe der interessanten Fragestellung danken.

Der gesamten Arbeitsgruppe danke ich für die fachliche Hilfe und die freundschaftliche Arbeitsatmosphäre, die meine Laborarbeit so angenehm gemacht hat. 


\section{LEBENSLAUF}

Am 1. März 1985 wurde ich als erstes Kind meiner Eltern Heinrich und Christa Wente, geb. Strunk, in Stadthagen (Niedersachsen) geboren. Von 1991 bis 1997 besuchte ich die Julius-RodenbergGrundschule und die Orientierungsstufe in Rodenberg und wechselte 1997 zum Wilhelm-BuschGymnasium Stadthagen. Dort schloss ich meine schulische Laufbahn 2004 mit meinem Abitur (Note 1,2) ab.

Im Oktober 2004 begann ich mein Medizinstudium an der Georg-August-Universität Göttingen. Im Januar 2008 begann ich mit der experimentellen Arbeit zu der vorliegenden Dissertation in der Arbeitsgruppe für Molekulare Psychiatrie der Abteilung Psychiatrie und Psychotherapie unter der Leitung von Herrn Prof. Dr. rer. nat. T. A. Bayer. Meine wissenschaftliche Tätigkeit zum Thema „Untersuchungen zu synaptischen Proteinen in einem Tiermodell für die Alzheimer-Krankheit“ wurde von Herrn Dr. Oliver Wirths betreut.

Nach meinem Praktischen Jahr, das ich an der Universität Bordeaux II (Frankreich) und an der Universitätsmedizin Göttingen absolvierte, schloss ich mein Studium im Dezember 2010 mit dem Zweiten Abschnitt der Ärztlichen Prüfung (Gesamtnote „sehr gut“) ab. 